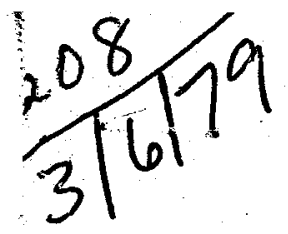

\title{
ANALYSIS OF BERYLLIUM PARTS FOR COSMOS 954
}

\author{
J. E. Hanafee
}

October 25,1978

Work performed under the auspices of the U.S. Department of Energy by the UCLLL under contract number W-7405-ENG-48.

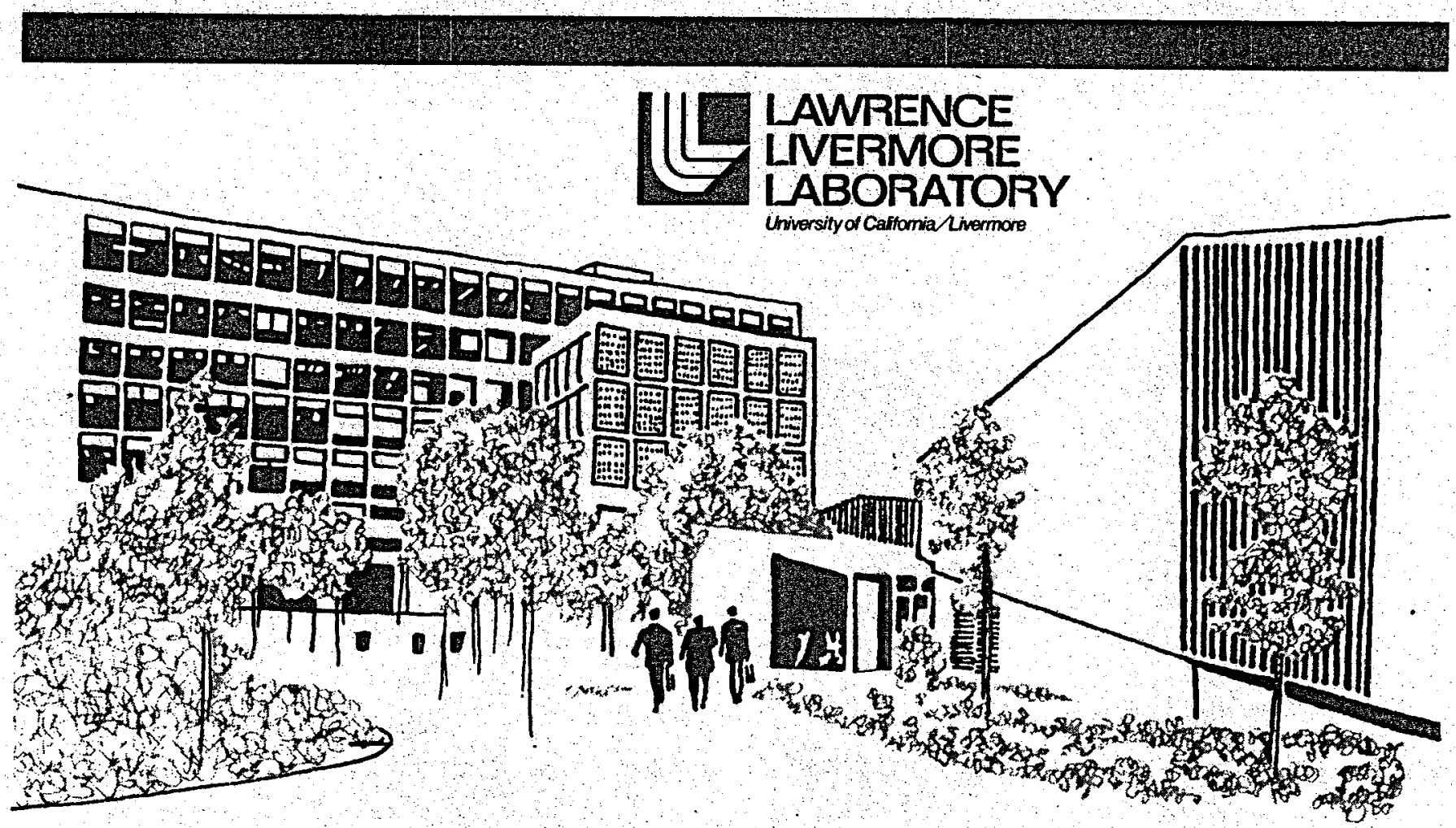




\section{DISCLAIMER}

This report was prepared as an account of work sponsored by an agency of the United States Government. Neither the United States Government nor any agency Thereof, nor any of their employees, makes any warranty, express or implied, or assumes any legal liability or responsibility for the accuracy, completeness, or usefulness of any information, apparatus, product, or process disclosed, or represents that its use would not infringe privately owned rights. Reference herein to any specific commercial product, process, or service by trade name, trademark, manufacturer, or otherwise does not necessarily constitute or imply its endorsement, recommendation, or favoring by the United States Government or any agency thereof. The views and opinions of authors expressed herein do not necessarily state or reflect those of the United States Government or any agency thereof. 


\section{DISCLAIMER}

Portions of this document may be illegible in electronic image products. Images are produced from the best available original document. 


\title{
ANALYSIS OF BERYLLIUM PARTS FOR COSMOS 954
}

\begin{abstract}
Operation Morning Light was conducted to search for the reactor core of Cosmos 954, the nuclear-powered Soviet satellite that crashed in the northwest territories of Canada in late January 1978. Many of the satellite parts found were beryllium. This study discusses the geometry, condition, microstructure, and possible fabrication history of these beryllium parts.
\end{abstract}

\section{INTRODUCTION}

The Soviet satellite Cosmos 954, launched on September 18, 1977, crashed in the northwest territories of Canada on January 24, 1978. A nuclear reactor with many kilograms of enriched uranium 235 was on board. The amount and disposition of the highly dangerous fuel was not known, and it was imperative that it be located. Canadian Prime Minister Trudeau asked President Carter for assistance in the search for the reactor fuel, and the Lawrence Livermore Laboratory provided the major portion of the scientific team for the American Task Force.

In the massive search, called Operation Morning Light, only about $15 \mathrm{~kg}$ of debris were found, although the satellite weighed several thousand kilograms. Most of the debris consisted of beryllium.

A total of 49 pieces of beryllium from the Cosmos 954 Russian satellite have been found to date. These pieces fall into three general categories:

- Thirty-three rods approximately $2 \mathrm{~cm}$ diam by $10 \mathrm{~cm}$ long were found in a pattern approximately 100 nautical miles long and 5 nautical miles wide in sectors 1 and 2 (Fig. 1) during the initial search from January through April, 1978. An additional rod about $2 \mathrm{~cm}$ diam by $2 \mathrm{~cm}$ long was found, which may be a portion of a beryllium rod. Most of the rods (from 20 to 25 ) were found in a pattern 15 . nautical miles by 5 nautical miles in sectors 1 and 2. During the summer of 1978; eight more rods were found. Analysis of all the rods indicates that they are solid beryllium rods with a niobium sheath. There is a localized scale on the outside of the sheath consisting of uranium (with fission products) and an iron base alloy (either stainless steel or a low alloy steel).

- Six beryllium cylinders $10 \mathrm{~cm}$ diam by $40 \mathrm{~cm}$ long were found in sectors 2 and 3 . They were in remarkably good condition and appear to be solid with no mechanical or electrical connections. The six cylinders all weigh within about $10 \mathrm{~g}$ of $3600 \mathrm{~g}$.

- An irregularly shaped piece known as the "Moose Hoof " was found in sector 2. It was $10 \mathrm{~cm}$ diam by $5 \mathrm{~cm}$ long with a 45-deg bevel. There was a U-shaped groove about one third of the way through on the diameter and extending the length of the axis.

Beryllium is not a common structural material, but it is a good neutron reflector and useful in nuclear reactors. It is known that the "-design provided for destruction of reflector at entryfollowed by total destruction of reactive zone.", and that "... the beryllium reflector included six moving elements ... and several tens of rods of cylindrical form." Therefore, it is logical to assume that both the beryllium rods and cylinders are part of a reflector and/or control mechanisms for the nuclear reactor on board Cosmos 954. It would be quite useful to study the beryllium parts in detail.

Under difficult conditions, a short laboratory study was only conducted on two rods, one cylinder, and one niobium sheath. The beryllium parts were all radioactive, necessitating examination mainly in hot cells. Coupled with changing 


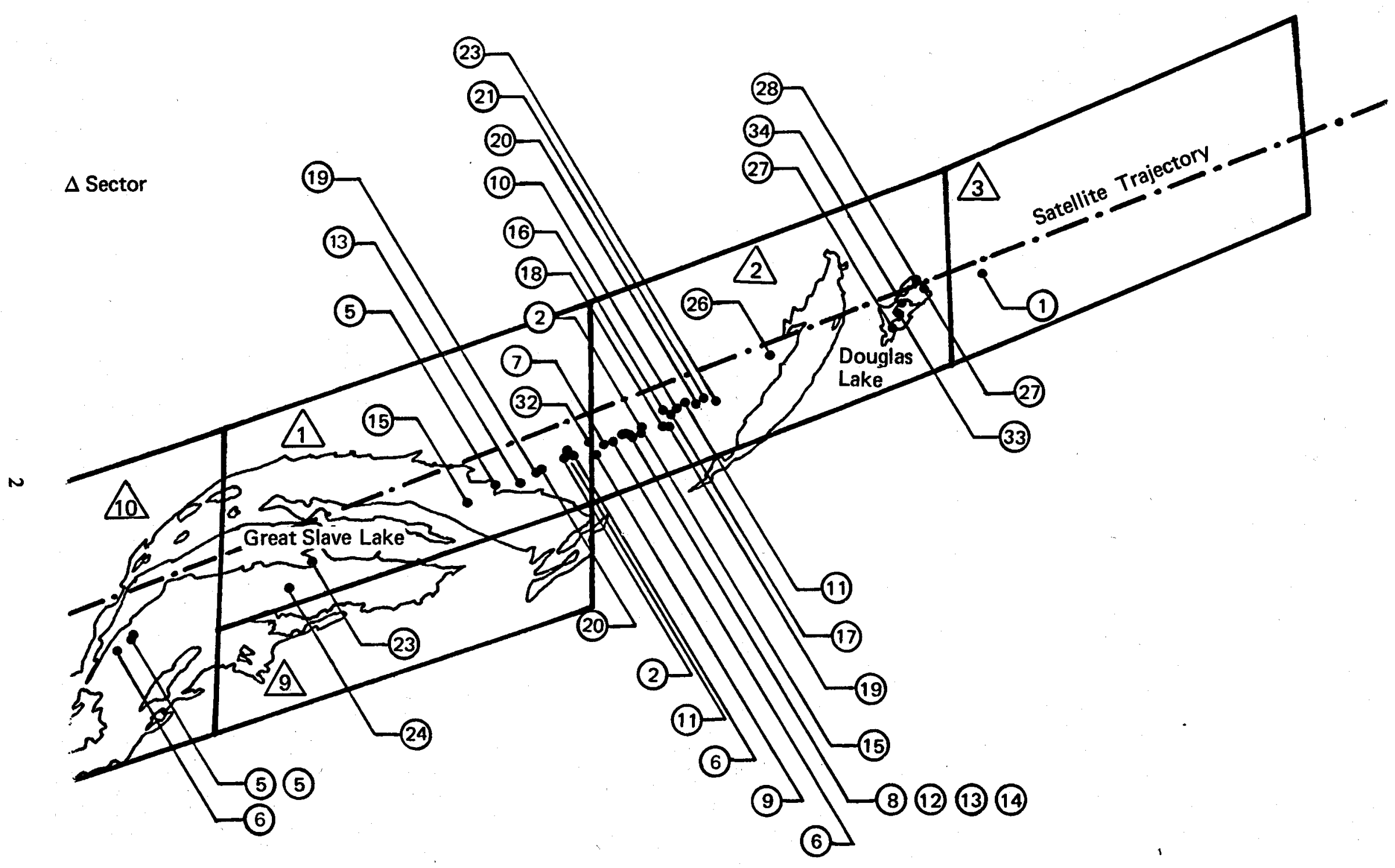

FIG. 1. Location of beryllium parts. 


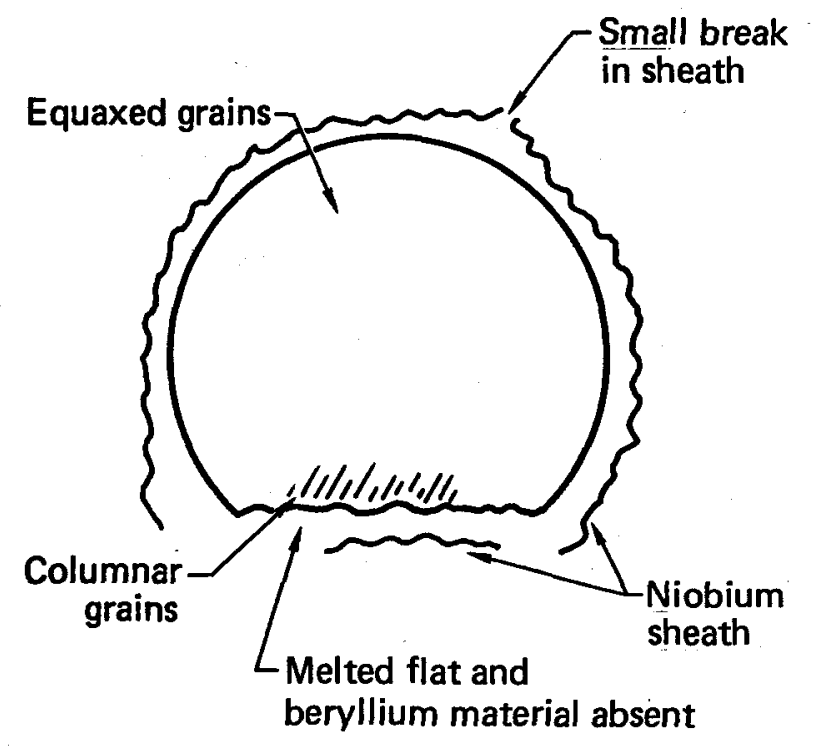

FIG. 2. Schematic of WNRE photomicrograph of $\operatorname{rod}$ ML-11 (1).

priorities during the course of the search, this severely limited the extent of the beryllium parts study. There is considerably more which could be done. Following is an analysis of the beryllium parts. It is based on (1) color and black and white photographs of rods, (2) a partial metallurgical analysis of two rods and a niobium sheath at
Whiteshell (WNRE) Laboratories (see Fig. 2), (3) limited direct observations by J. Robbins, LLL metallurgist, on an early visit to Whiteshell Laboratory, (4) critique of (1) and (2) by J. Hanafee, LLL metallurgist, and (5) discussion and laboratory work by J. Hanafee while at WNRE.

\section{RODS}

\section{GENERAL APPEARANCE}

The rods are shown in Figs. 3 through 76 and are listed in Table 1. Note that the observations presented here are based on photographs rather than direct examinations of the parts, which would undoubtedly yield more information. None of the rods are in pristine condition; all have melted somewhat, particularly on both ends, and they have some oxidation products on the outer surface. The melting and oxidation products occur on only one side of the rods; the other side is generally in fairly good condition. The niobium sheaths are in relatively good condition on most of the rods, i.e., at least one-half of the sheath is usually intact. It does not appear that any rod is totally devoid of a niobium sheath, although a large portion of a sheath was found by itself [see rod ML-12 (1) in Table 2].

The extent of melting varied considerably. In some cases, beryllium melted and was lost along the entire length of the rod [e.g., ML-16 (2)]. In other cases, there was little melting and loss of material, and the ends of the rods were fairly flat [e.g., ML-2 (2)].

The rods usually appeared straight, but rod ML-17 (2) was bent along the axis at both ends making it slightly bow shaped. The bend appeared to be fairly symmetrical about the center, and, considering the diameter of the rod, the force to bend the rod would not be small. 
Table 1. Thirty four Cosmos 954 beryllium rods recovered.

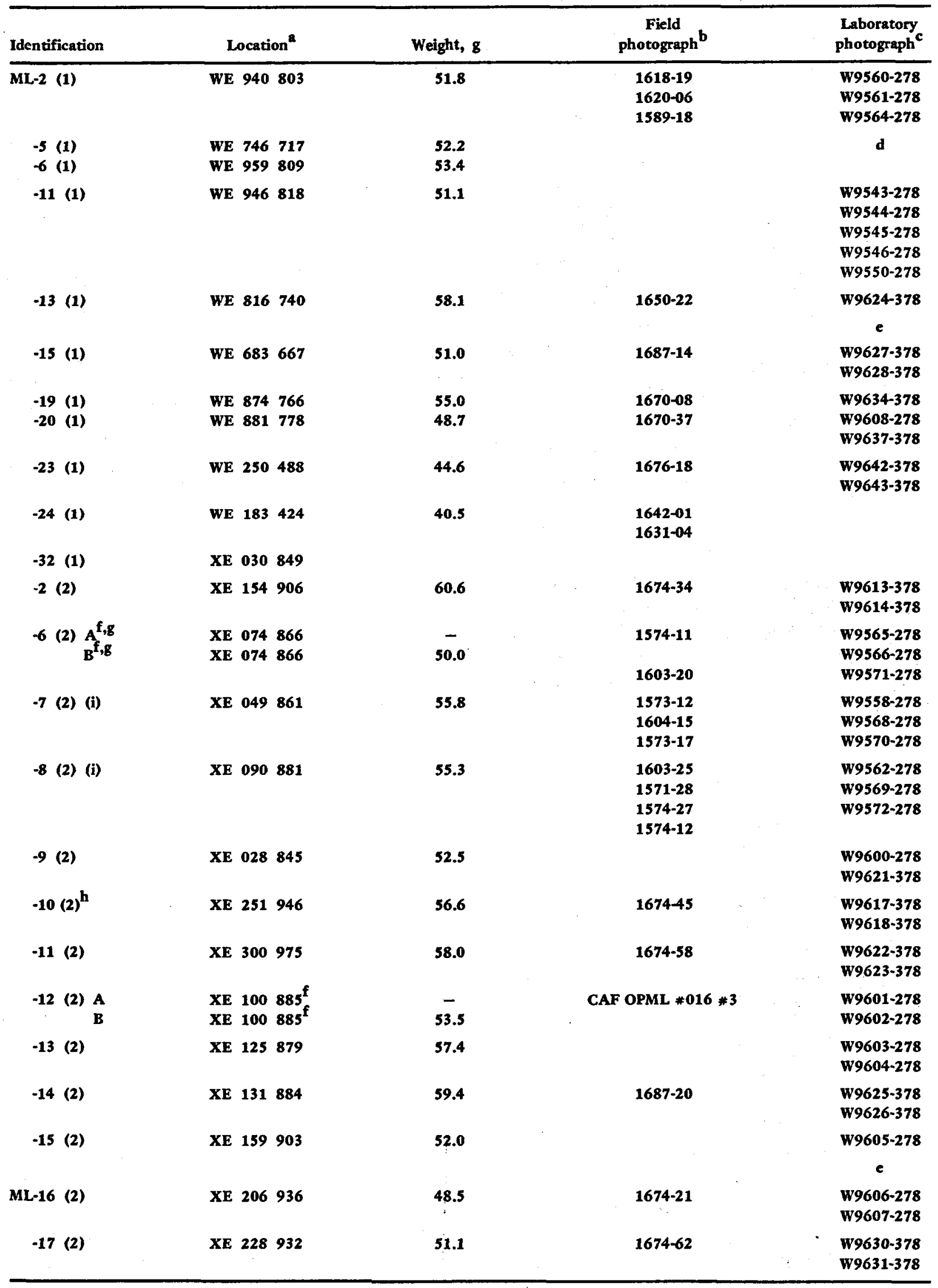


Table 1. (continued)

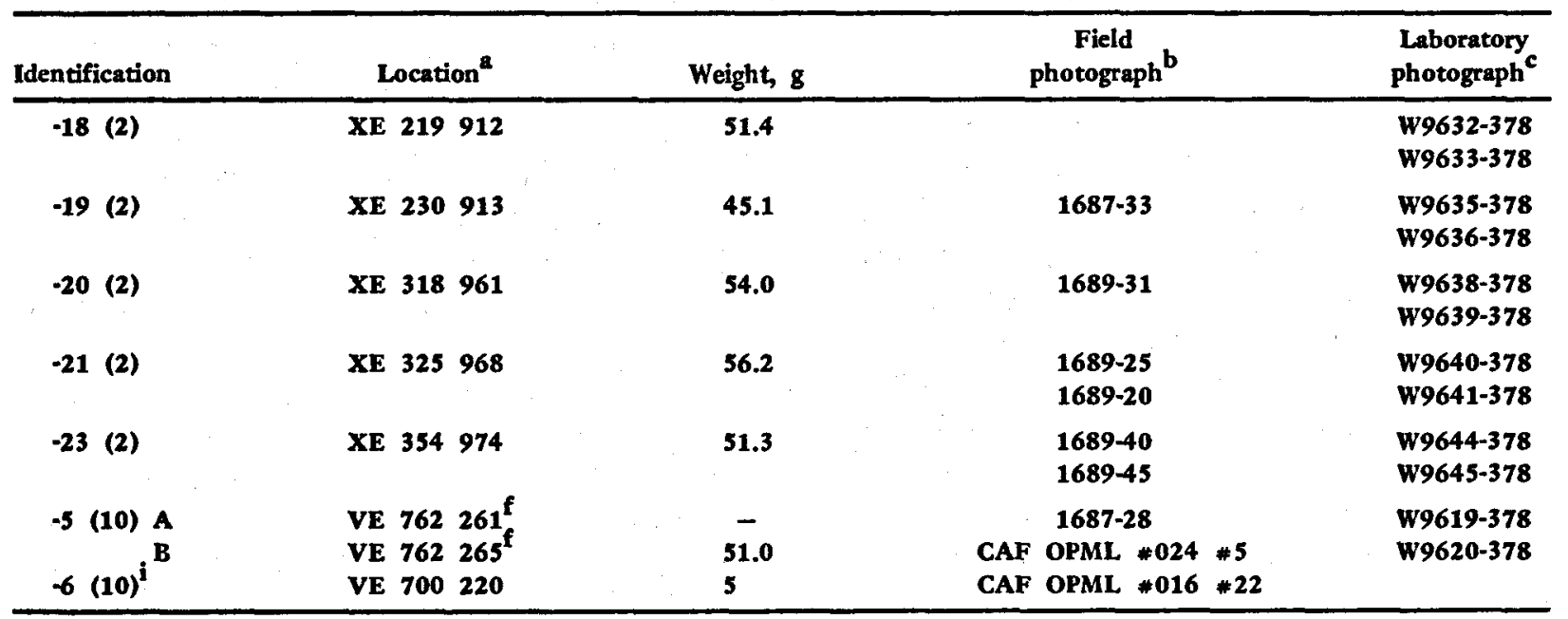

${ }^{2}$ Coordinates refer to the universal transverse mercatron grid system.

bield photograph by EG\&G unless noted otherwise.

claboratory photographs by WNRE.

dee Appendix A.

CPhotograph number not known.

Two rods found at these locations. Identification of Hit No. (A or B) and photographs is uncertain.

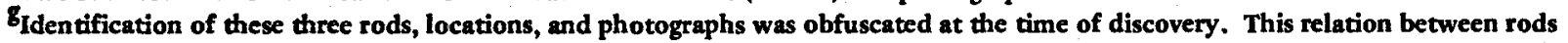
and photographs represents the correction made in Edmonton in February 1978.

hame as X0113.

$i_{20} \mathrm{~mm}$ diam by $20 \mathrm{~mm}$ long. Not confirmed as beryllium material.

Table 2. Cosmos 954 beryllium cylinders, moose hoof, and niobium sheath recovered.

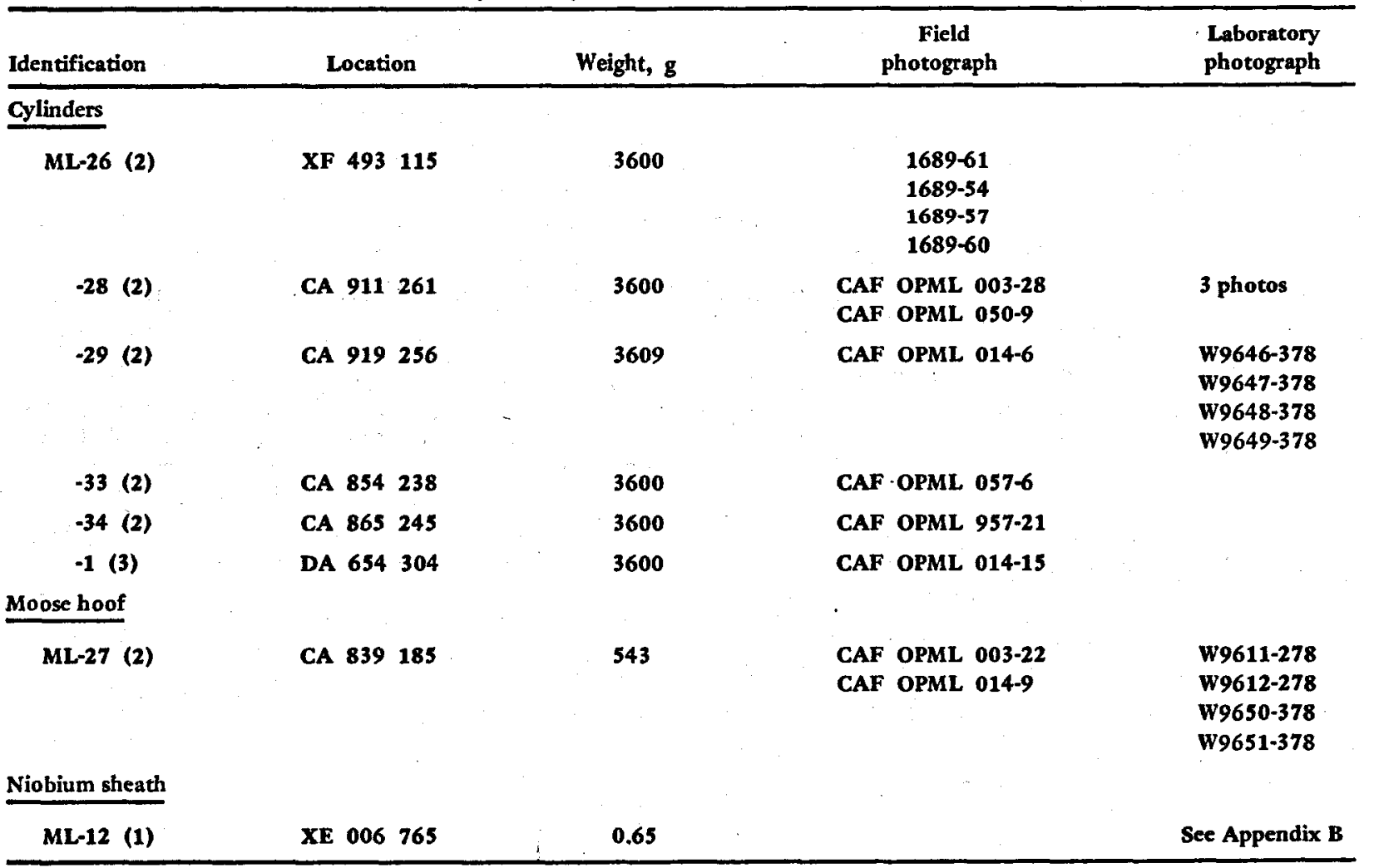




\section{IDENTIFICATION OF ROD MATERIAL}

To my knowledge, a chemical analysis for beryllium, per se, was not conducted. The identification of the rod material was based on density and activation products. The reported density $(1.83 \mathrm{~g} / \mathrm{cc})$ was slightly below the theoretical density. Emission spectroscopy for impurities was done and boron was not detected in the beryllium.

It was reported that beryllium oxide was observed, but a chemical analysis was not reported, and I do not believe one was conducted. This is not a difficult analysis and could be useful for three reasons:

- There are two general categories of beryllium, each with very different mechanical properties and applications. Generalizing somewhat, the category with much higher mechanical strength contains from about 0.5 to $2 \%$ beryllium oxide. Confirming the existence of and determining the exact quantity of beryllium oxide would contribute substantially to characterizing the rods. The Soviets have reported on research to improve (attain higher mechanical properties) the other type of beryllium not containing beryllium oxide.

- Beryllium oxide has a higher density than beryllium. Hence, if the rods are basically beryllium with 0.5 to $2 \%$ beryllium oxide (typical of powder origin beryllium), the density should be slightly higher than the theoretical density. This is contrary to the density of the rods reported to be slightly below theoretical density. Note that beryllium exposure to radiation may lower its density.

- There are second-phase particles in the microstructure of the rods. Positive quantitative knowledge of the presence of beryllium oxide would indicate that these second-phase particles are probably beryllium oxide.

\section{BERYLLIUM BORIDES}

The possibility that the rods were beryllium borides of various sorts was discussed early in time. Boron is essentially not soluble in beryllium at or near room temperature, and it would form one or more of six compounds. With the information then available, two observations could be made. First, the compounds with the lower amounts of boron
(Table 3) are fairly red in color and should not be mistaken for beryllium. The density measurements could conceivably be inaccurate enough not to conflict with the measured rod densities of about 1.83 , although I believe this is unlikely. The compounds in the high boron range do resemble beryllium in color, but the densities are substantially higher. 1 do not believe such a large consistent error in densities is possible.

It is possible to make the microstructure of beryllium borides appear similar to that of beryllium: However, after comparing the microstructures of rod ML-5 (1) with the beryllium boride photomicrographs at LLL, I believe that the rod microstructure resembled beryllium rather than the beryllium borides. The latter generally have a more acicular grain structure and polarize much more readily. The absence of boron was later confirmed by emission spectroscopy analysis.

\section{MICROSTRUCTURE}

WNRE only conducted metallographic studies on rods ML-5 (1) and ML-11 (1); Appendix A contains a report issued on ML-5. A metallurgical analysis on ML-1 (1) was not issued, but the results were discussed briefly at the April, 1978 meeting at WNRE.

Grain size is a major factor in determining the mechanical properties of beryllium. WNRE measured grain size on a cross section of rod ML$5(1)$ and they reported a size of $50 \mu$. From WNRE photomicrographs on a cross section of the rod, I used the line intercept method to determine a

Table 3. Beryllium borides and densities (Ref. 2).

\begin{tabular}{lc}
\hline Compound & $\begin{array}{c}\text { Theoretical density } \\
\rho 0\end{array}$ \\
\hline $\mathrm{Be} / \mathrm{cm}^{3}$
\end{tabular}


grain size of $48.1 \mu$ across one diameter and 51.3 across a line $90 \mathrm{deg}$ from the first determination. The average, $49.7 \mu$, is fortuitously close to the WNRE value, particularly considering the problems associated with grain size determinations in beryllium. The grain size is quite uniform with no evidence of a duplex structure. The $50-\mu$ grain size is on the high side for powder origin beryllium, with "middle-of-the-line" beryllium in the United States ranging from 25 to $35 \mu$.

The metallographic preparation of these specimens was not quite perfect, resulting in two artifacts. First, some of the grain structure is obscure and hence the grain size determinations may be high. From careful study of the available photomicrographs, I do not believe an error of more than 10 to $15 \%$ is possible. This would not significantly affect the strength estimate. Second, some twins can be seen in the microstructure (see Appendix A). Twins in beryllium are caused by specific mechanical forces, and they can usually be removed by temperatures above about 700 to $850^{\circ} \mathrm{C}$. Thus, the presence of twins can sometimes be used to ascertain the thermal and mechanical history of a part. In this case, however, I am sure the twins were formed during the metallographic preparation and should be ignored.

Because of the inherent anisotropy of beryllium, grain morphology is an important factor in obtaining isotropic properties. The grains appear to be equiaxed, i.e., they are not elongated or pancake shaped as a result of, for example, some possible earlier extrusion or rolling process. This has not been confirmed by examination of the microstructure parallel to the rod axis.

In rod ML-5 (1) a layer of columnar grains on the outer surface extends along approximately $7 \mathrm{~mm}$ of the $63-\mathrm{mm}$ circumference (Appendix A). The extent of the columnar grains in the axial direction is not known. The grains extend inward 0.2 to $0.5 \mathrm{~mm}$, the length of the columnar grain. There is some indication of epitaxial grain growth, and there is no grain growth in the matrix adjacent to the columnar grains. Grain growth may take place in powder origin beryllium from 700 to $1000^{\circ} \mathrm{C}$ over a period of several minutes to a few hours. (The exact times and temperatures could easily be determined using samples from the rods.) The columnar grains were caused by melting and resolidification (beryllium melts at $1284^{\circ} \mathrm{C}$ ). Beryllium is a good heat conductor and if the surface were at the melting temperature for a long period, some grain growth would be expected farther in from the surface. This sort of structure (columnar grains and original equiaxed grains) is often seen in the fusion zone/parent metal area of welded beryllium. It is concluded that this microstructure was caused by a high heat input for a short period of time (seconds or less). It would be interesting to know if this feature occurred in any or all of the other rods and, if so; if there is a pattern.

Another layer of material occurred intermittently on the outside of the columnar and equiaxed grains (see Appendix A). Its appearance differs somewhat from beryllium, and it is porous. It probably consists of a substance other than beryllium, such as part of the niobium sheath; or perhaps it is the product of a reaction between the molten beryllium and other materials. This could be easily determined by current analytical methods, but from the photomicrograph alone it is not possible to be more definitive on the nature of the outermost layer.

Fissionable products were found on the outside surface. Using mass spectrometry, WNRE detected Uranium $^{235}$ on the surface of rod ML-5 (1), and autoradiography showed that it extended over only about $6 \mathrm{~mm}$ of the 63-mm circumference (Appen$\operatorname{dix}$ A).

Four photomicrographs of ML-11 (1) were shown at the April, 1978 meeting at WNRE. Labeled $233 \mathrm{E} 1$, they showed that beryllium had melted and been removed underneath the niobium sheath (Fig. 2). Columnar grain growth along a melted edge of rod ML-11 (1) was observed which was similar to that found in rod ML-5 (1).

\section{MECHANICAL PROPERTIES}

Three of several major factors controlling the mechanical properties of beryllium are unknown, vis., $\mathrm{BeO}, \mathrm{Fe}$ and $\mathrm{Al}$ levels. A fourth factor, method of manufacture, is not positively known. However, if the grain morphology is fairly isotropic and $\mathrm{BeO}$ is present, then the beryllium is of powder origin. The most common method of consolidating beryllium powder is vacuum hot pressing.

A simple relationship has long been established between grain size and strength for many metal alloy systems. This relationship, Hall-Petch, has been found to apply to powder-origin beryllium. 
Using this information and assuming that there is nothing exceptional about the $\mathrm{BeO}, \mathrm{Fe}$, and $\mathrm{Al}$ contents, and that the rods are powder-origin hot pressed material, then the $50-\mu$ grain size would indicate an ultimate strength from 30 to $35 \mathrm{ksi}$ and yield strength from 15 to $20 \mathrm{ksi}$, which is fairly low.

WNRE measured the hardness on the transverse sections of two rods as follows:

- ML-5 (1): center (in fine equiaxed grain structure)-140 VPN;

inner edge of the columnar grains-121 VPN;

outer edge of the columnar grains-148 VPN.

- ML-11 (1): center (in fine equiaxed grain structure)-153 VPN.

The hardness of beryllium reported by several investigators ranges from about 100 to $300 \mathrm{VPHN}$. For this span of values, the beryllium ranged from fully annealed to highly cold-worked ingot beryllium to powder-origin beryllium; impurity content varied considerably. Because of the lack of information on the chemistry and texture of the rods, it is impossible to draw quantitative conclusions from the hardness data; but qualitatively, the rods are in the lower one-third of the reported hardness range for beryllium. This would indicate a fairly low strength, but as for the grain size and strength relationship, it would be somewhat speculative to quantitatively relate hardness to strength without additional laboratory study.

Thus, from the available evidence, viz., grain size and hardness, it appears that the beryllium rods are medium to low strength. It is pertinent to note that the rods are large enough to make tensile specimens, and it would not be difficult to conduct the mechanical tests.

\section{ROD DIMENSIONS}

Field observations consistently reported the rods to be $3 / 4$ to 1 in. in diameter by 4 in. long, but these were estimates. Some of the rods are actually slightly elliptical in cross section. In view of ample evidence of melting and loss of material upon reentry, I believe the original cross section to be circular. The single Whiteshell report quotes a diameter of $20 \mathrm{~mm}$. For measurements of the photograph, I find a diameter of $20 \pm 1 \mathrm{~mm}$. Thus, I concluded that the original cross section was circular with a diameter of $20 \mathrm{~mm}$.

The original length is a more difficult problem. To my knowledge, length has not been measured, although some photographs of rods have included a centimeter rule. The melting and distortion introduces uncertainties, but the present length appears to be from 9 to $11 \mathrm{~cm}$. Knowing the correct original length would be quite helpful; for example, was the original length many times $10 \mathrm{~cm}$ designed to break at $10-\mathrm{cm}$ intervals upon disassembly? Optical and scanning microscopy could be used to help ascertain the original length of the rods.

\section{NIOBIUM SHEATH}

A portion of one niobium sheath was found separately on sample ML-12 (1) (see Table 2), and WNRE conducted SEM and EDX analyses on the piece. A formal report was not issued to my knowledge, but the experimental data are shown in Appendix B. Figure B-1 clearly shows the corrugated shape in the cross section view.

The sheath is $0.05 \mathrm{~mm}$ thick and there appears to be two kinds of deposit on the outside surface. The first is an iron-uranium scale (Figs. B-1 through B-3). It appears that the iron alloy (probably stainless steel) and uranium reacted with each other in a molten state and were deposited in that state on the niobium sheath. In one place (Fig. B-2), the iron alloy forms a less-porous thin layer next to the sheath, with the iron alloy mixture on the outside. No significant reaction occurred between the ironuranium alloy and the niobium sheath.

A deposit of calcium or calcium compound appears on the outside surface (Figs. B-4 and B-5); it was deposited in a molten state. The calcium is deposited in bands both along and across the corrugations. Considering the high reactivity of calcium with moisture and air, the deposit is probably a calcium compound. From this evidence, I would conclude that a molten calcium compound was sprayed across the niobium sheath during the satellite disintegration. Other tests could further elucidate the nature of the calcium deposit. 


\section{CYLINDERS}

Six beryllium cylinders were found for $30 \mathrm{~km}$ along the flight path in sectors 2 and 3 (Figs. 77 through 90 , and Table 2 ). The cylinders were about $10 \mathrm{~cm}$ diam by $40 \mathrm{~cm}$ long, with six notches in each end and a step at one end. WNRE used emission spectrography on a single chip from cylinder ML-28 (2), and it was found to be "high-purity beryllium." This would be unusual-high-purity beryllium is weak mechanically and expensive to make. Although emission spectrography can pick up the common impurity elements in beryllium, special techniques have to be used, particularly for oxygen. Thus, it is clearly established that the cylinders are beryllium, but which of three general categories is not known, viz., powder origin, ingot beryllium, or some special high-purity grade.

The cylinders had several remarkable features. First, all cylinders were in excellent condition. There was some discoloration from oxidation and a very small amount of melting at the ends only, but otherwise they were not damaged; no electrical or mechanical connections were observed; all the cylinders weighed within about $10 \mathrm{~g}$ of $3600 \mathrm{~g}$; and finally, they were solid. Three cuts were made in cylinder ML-28 (2), as shown in Figs. 91 through 94. The 1-cm-thick slice was macro-etched $(20 \%$ $\mathrm{HNO}_{3}, 2 \% \mathrm{HF}$, remainder $\mathrm{H}_{2} \mathrm{O}$ ) halfway across the diameter. The macro-etching did not reveal any inhomogeneities, indicating that the cylinder was solid. After cutting for some time along the axis of one-half of the cylinder, it was deliberately fractured the remainder of the way (Figs. 91, 92, and 92). The fracture surface did not show any discontinuities along the axis, again indicating that the cylinder was solid.

Although no metallography was conducted on the cylinders, several observations were made. Earlier reports indicated a row of spot welds on at least one cylinder. I examined ML-1 (3) up to magnifications of 30 in the hot cell at WNRE and the reported row of spots did resemble spot welds; but upon closer examination, I found many more such spots. In some cases, the pattern appeared to be random. The straight row was lined up with one of the machined notches that contained a moderate amount of melted metal. I concluded that the spots were caused by a spray of molten metal during satellite disintegration, and that some of the spots tended to line up as some molten metal sprayed from the notches.

The surface finish of the cylinders was very coarse. Such machining procedures, I am sure, would introduce considerable machining damage, lower the ultimate strength perhaps as much as $25 \%$, and reduce the total elongation to fracture to less than $1 \%$. It is possible to heat treat or etch the beryllium to remove the machining damage and restore mechanical properties. These cylinders were not etched, and it would require a simple metallographic study (one specimen) to determine if the cylinders had been heat-treated to remove the damage. If the machining damage was not removed, then the cylinders were used in a situation requiring very little mechanical strength.

Examination of ML-1 (3) in the WNRE hot cell revealed numerous cracks around the step and notches at each end. In one case, the cracks extended along the axis of the cylinder for about $7 \mathrm{~cm}$. From the oxidation and melting pattern, five of the cylinders appeared to have traveled "step end first"; the sixth traveled with the other end first. The cylinders were radioactively contaminated. ML-28 (2) measured 1.5 to $2 \mathrm{R}$ at about $1 \mathrm{~cm}$. This was uniform across the diameter of the 1-cm-thick slice, including the etched portion. Collimation may not have been sufficient, and the $2-R$ reading may have been caused by contamination on the outside diameter or impurities in the beryllium.

\section{MOOSE HOOF}

This part is unique in that only one was found (Figs. 95 through 99). It is about $10 \mathrm{~cm}$ in diam by $5 \mathrm{~cm}$ long, with a $45-\mathrm{deg}$ bevel and an extensive groove. I believe it was determined to be beryllium by density, although I have not seen a chemical analysis. A considerable amount of scale appears on the part. No laboratory studies were conducted. 


\section{SUMMARY}

Forty-one beryllium rods $2 \mathrm{~cm}$ diam by $10 \mathrm{~cm}$ long were found. They were enclosed in a niobium sheath and had both activation and fission products. Most rods and sheaths had undergone substantial melting and loss of material at one or both ends, or in some cases along the entire length. The beryllium was most likely of powder-origin manufacture and appears to be of medium or low strength.

A rod about $2 \mathrm{~cm}$ diam by $2 \mathrm{~cm}$ long was found that might be a portion of a beryllium rod. Six beryllium cylinders were found. They were in pristine condition. They had six notches on each end and a step on one end, but otherwise they were solid with no electrical or mechanical connections. The six cylinders all weighed within about $10 \mathrm{~g}$ of
$3600 \mathrm{~g}$. A single piece of beryllium with a unique geometry was found. It is $10 \mathrm{~cm}$ diam by $5 \mathrm{~cm}$ long with a substantial bevel and groove.

The beryllium parts were not extensively characterized, because of the high priority given to fuel-particle analysis. For a laboratory and personnel familiar with beryllium (and with the handling of radioactive material), established methods could be used to determine many elementary properties, e.g., strength, unique physical and chemical properties, original geometry, and method of manufacture. In addition, I am confident that a metallurgical study of the microstructures of these beryllium parts would reveal more information about the thermalmechanical history of the satellite upon disintegration, should this be desired.

\section{ACKNOWLEDGMENTS}

I would like to thank the WNRE scientific staff for their excellent cooperation and for providing the beryllium characterization described in this report. Considering the increased difficulty in handling resulting from the use of a hot cell facility, the program priorities that emphasized fuel particulate analyses, and the limited time and resources available for satellite debris analysis, Whiteshell Nuclear Research Establishment did an outstanding job. In addition, I appreciate guidance and review of the manuscript by J. L. Robbins and F.W. Jessen, Jr.

\section{REFERENCES}

1. Official Communications from USSR to Canadian government.

2. A. E. Abey, J. Appl. Phys. 41, 5254-5259 (1970). 


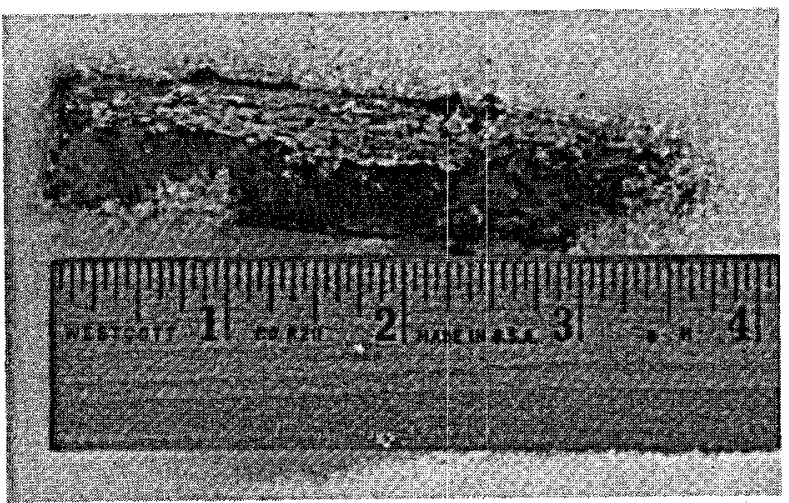

FIG. 3. ML-2(1).

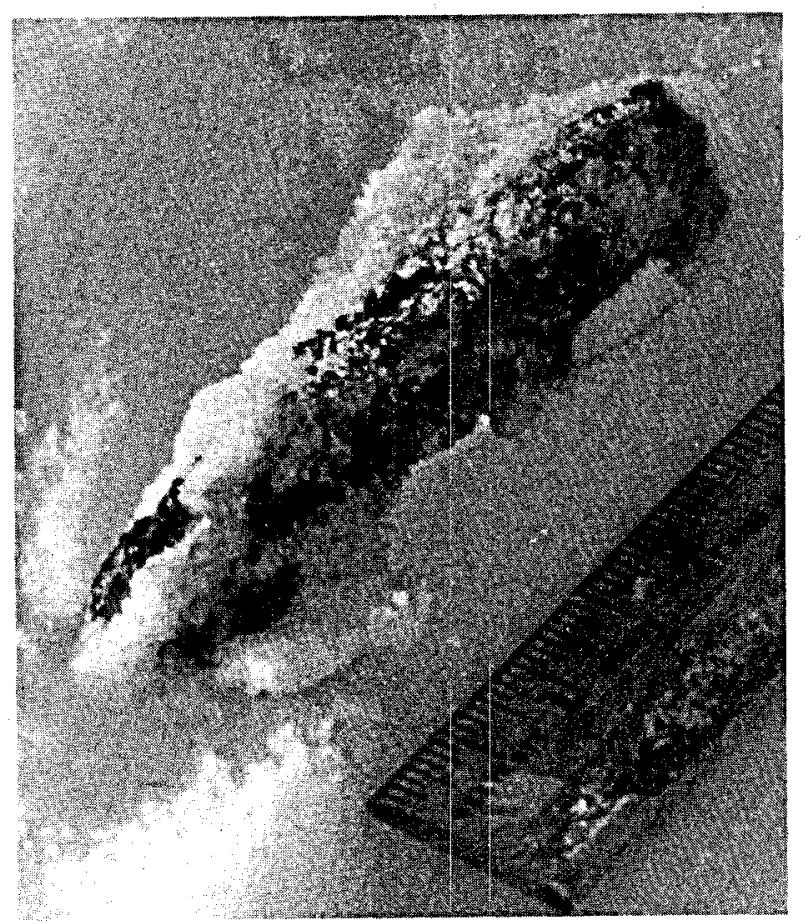

FIG. 4. ML-2(1).

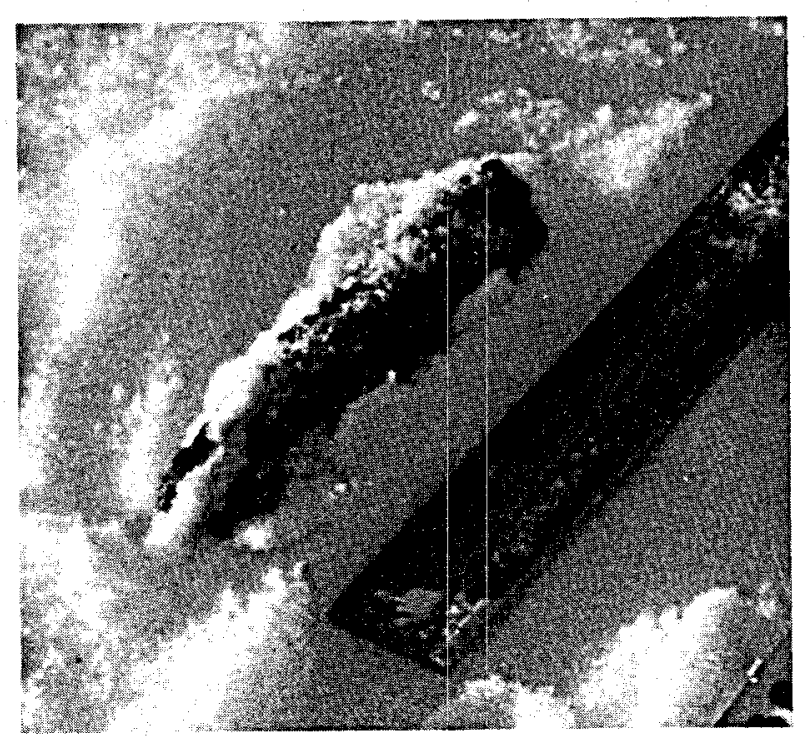

FIG. 5. ML-2(1).

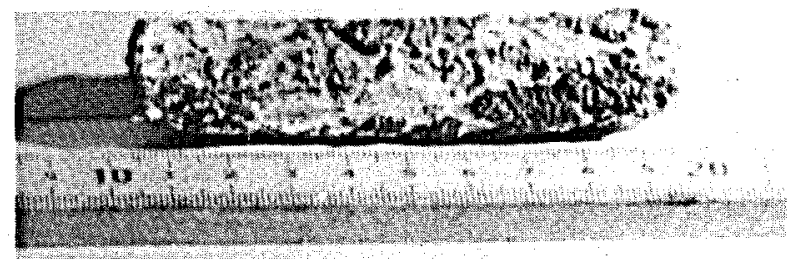

FIG. 6. ML-2(1).

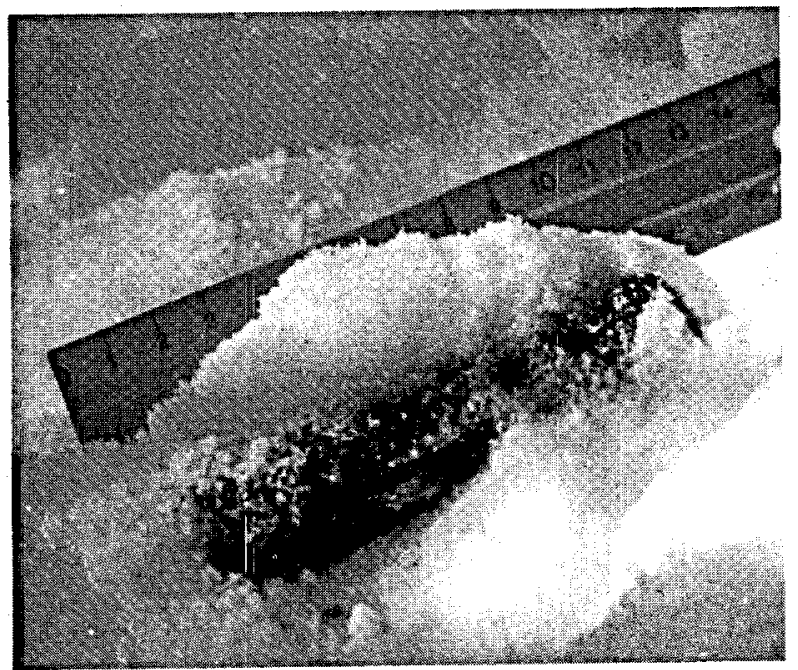

FIG. 7. ML-13(1).

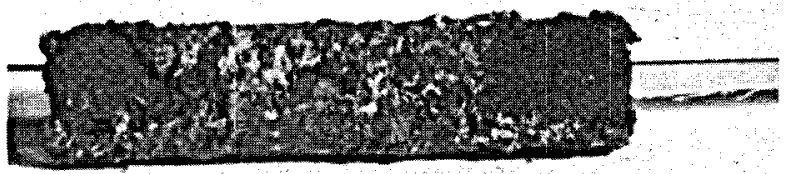

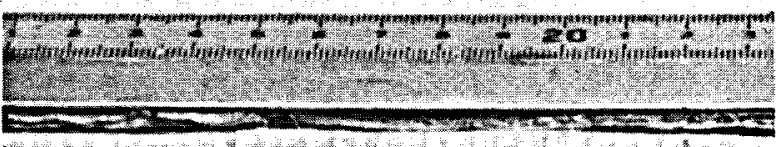

FIG. 8. ML-13(1).

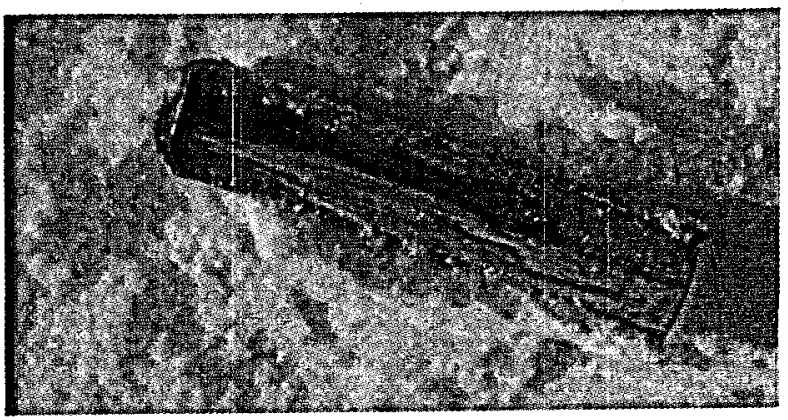

FIG. 9. ML-15(1). 


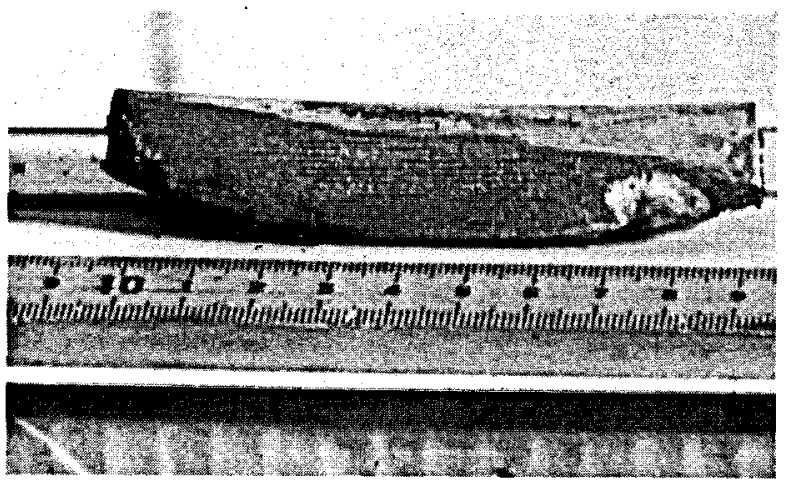

FIG. 10. ML-15(1).

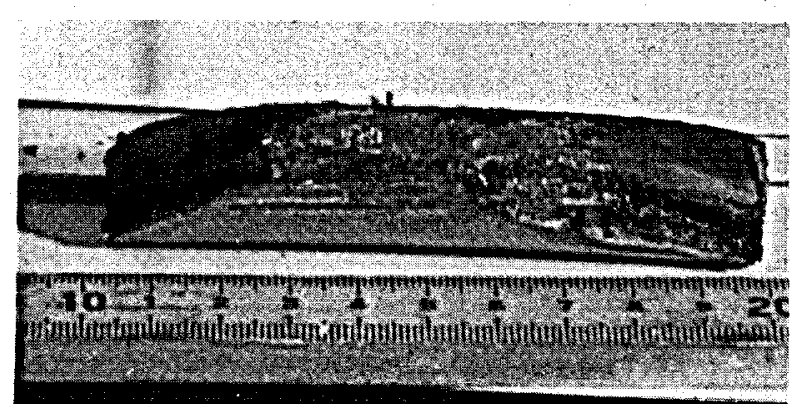

FIG. 11. ML-15(1).

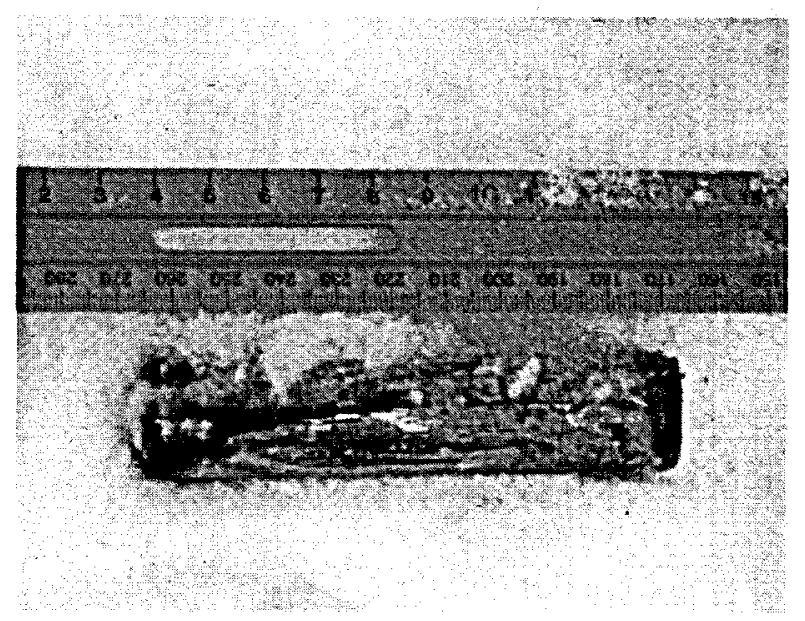

FIG. 12. ML-19(1).

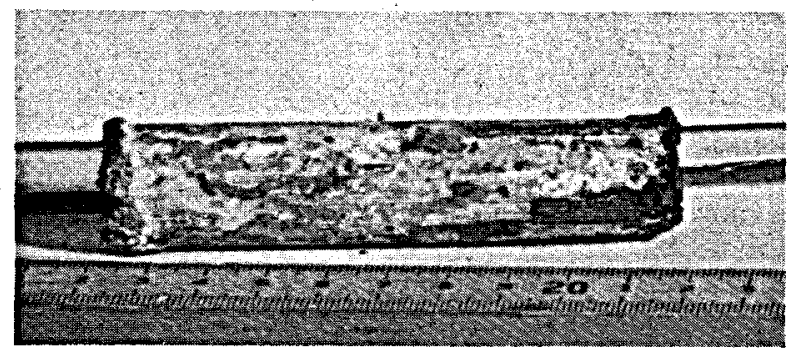

FIG. 13. ML-19(1).

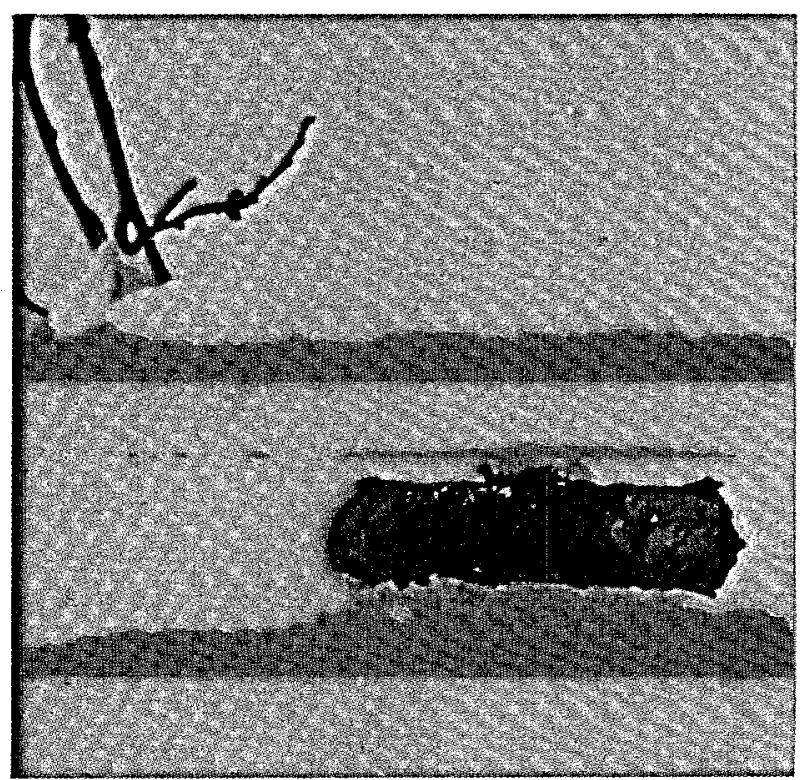

FIG. 14. ML-20(1).

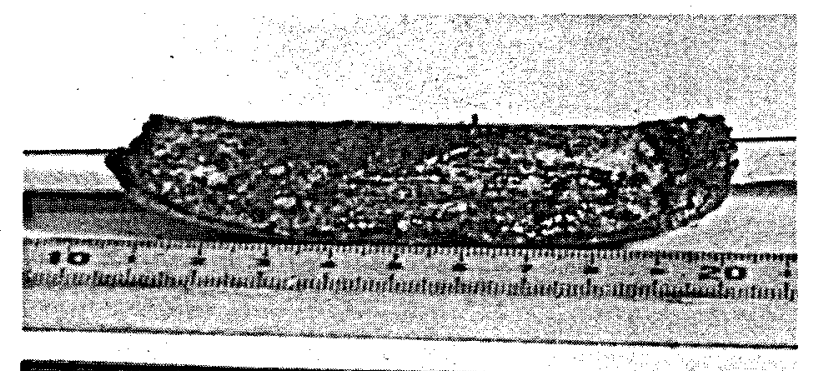

FIG. 15. ML-20(1).

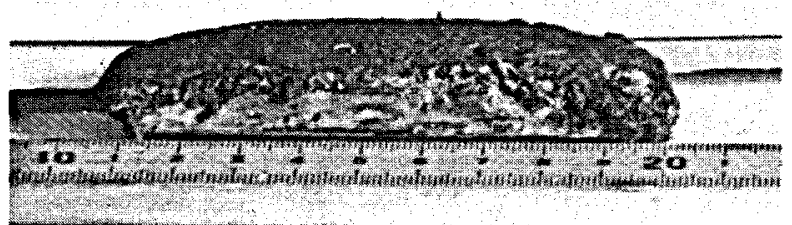

FIG. 16. $M L-20(1)$.

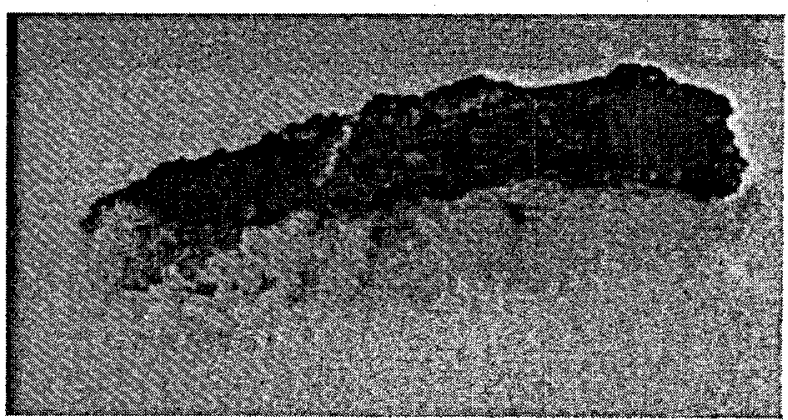

FIG. 17. ML-23(1). 


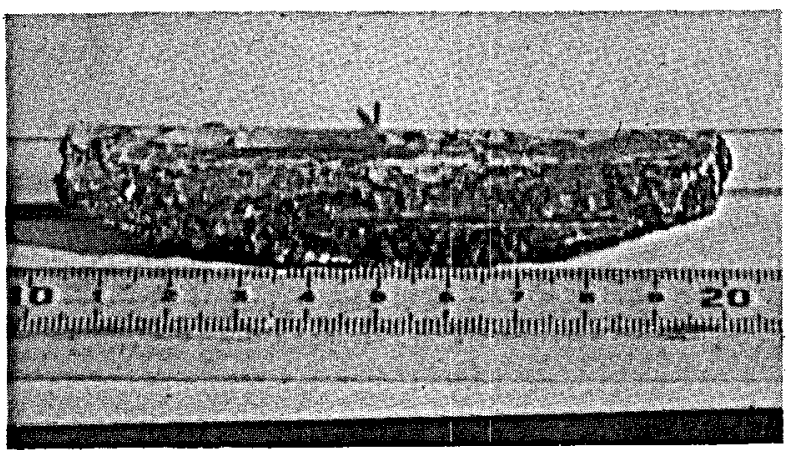

FIG. 18. ML-23(1).

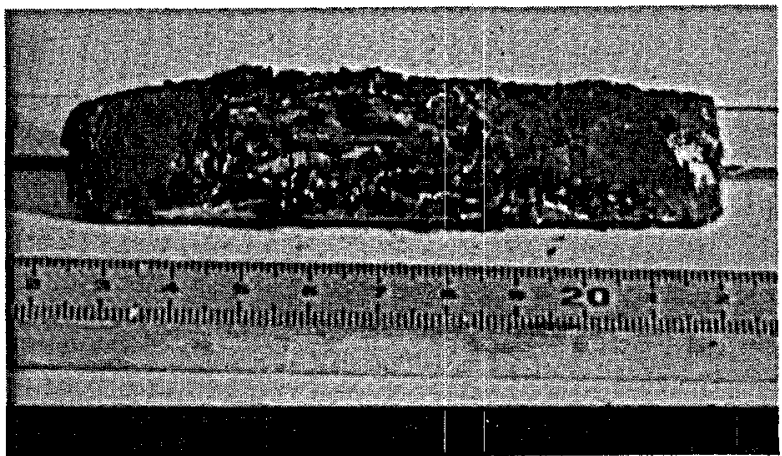

FIG. 19. ML-23(1).

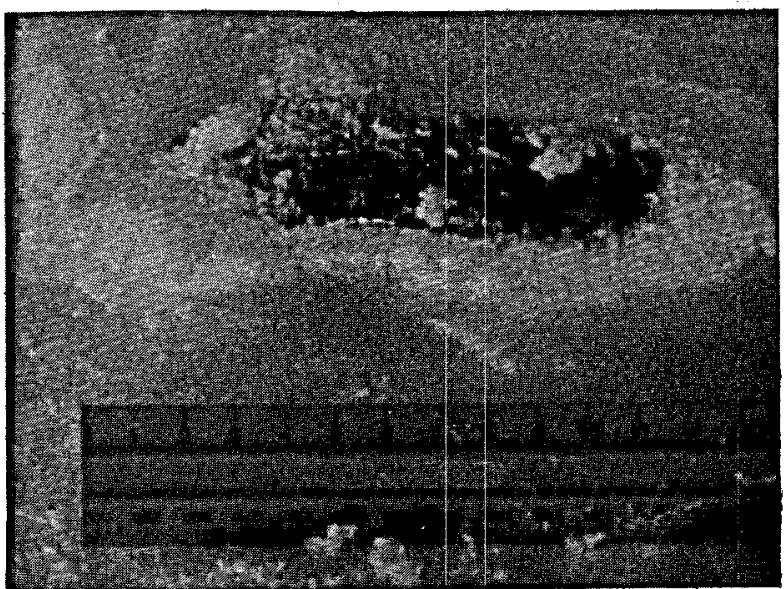

FIG. 20. ML-24(1).

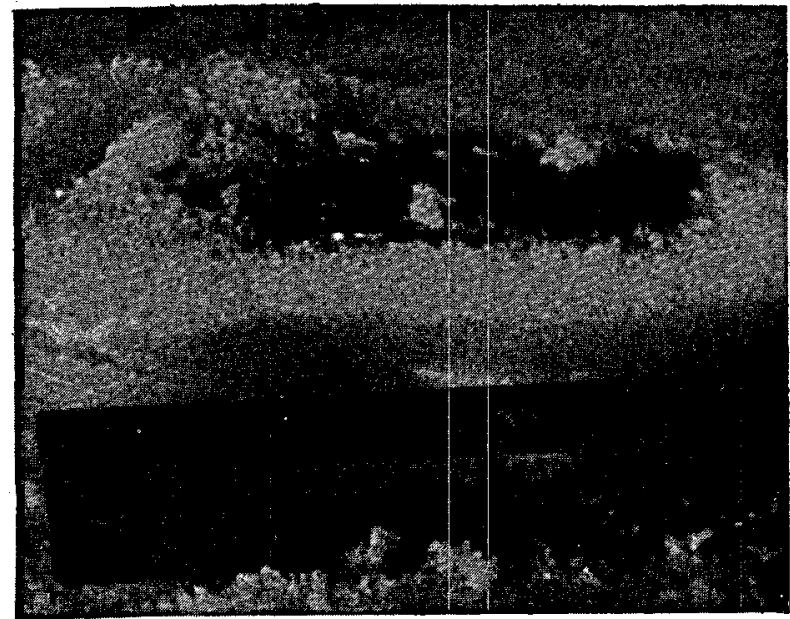

FIG. 21. ML-24(1)

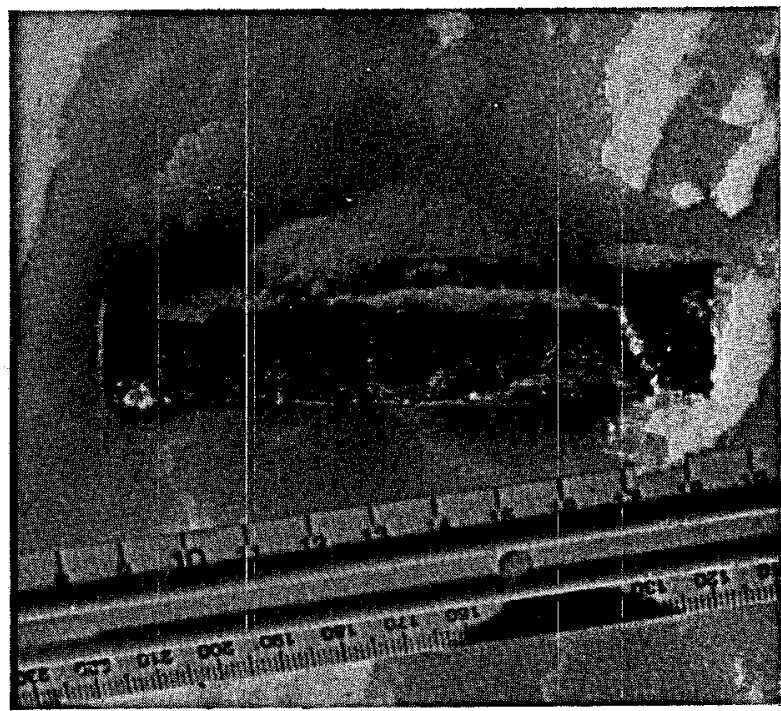

FIG. 22. ML-2(2).

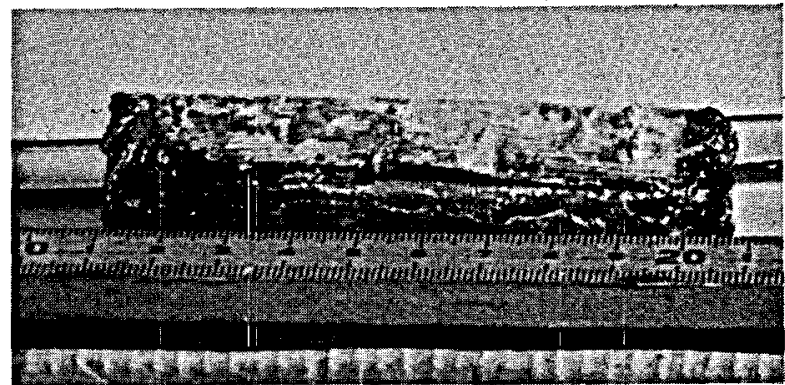

FIG. 23. ML-2(2).

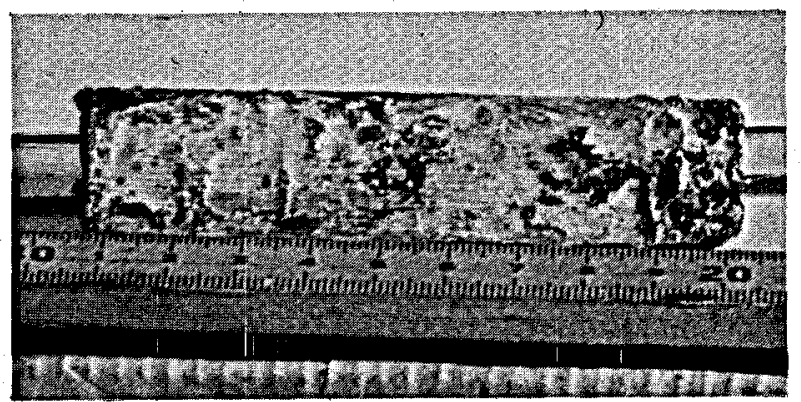

FIG. 24. ML-2(2).

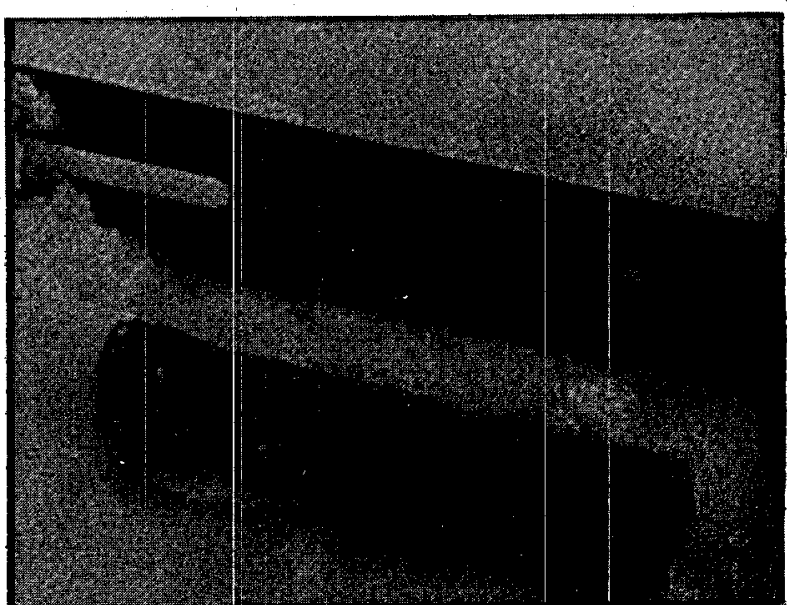

FIG. 25. ML-6(2). 


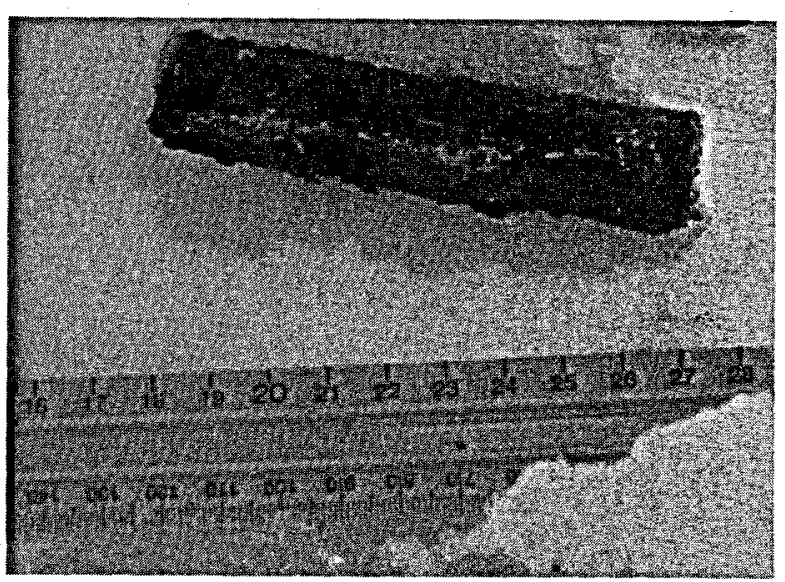

FIG. 26. $M L-7(2)$.

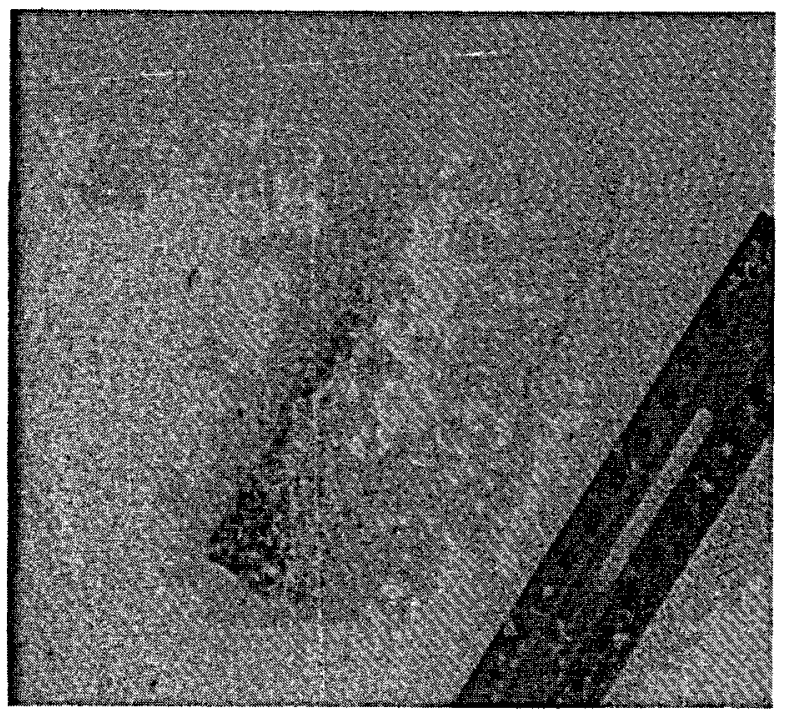

FIG. 27. ML-7(2).

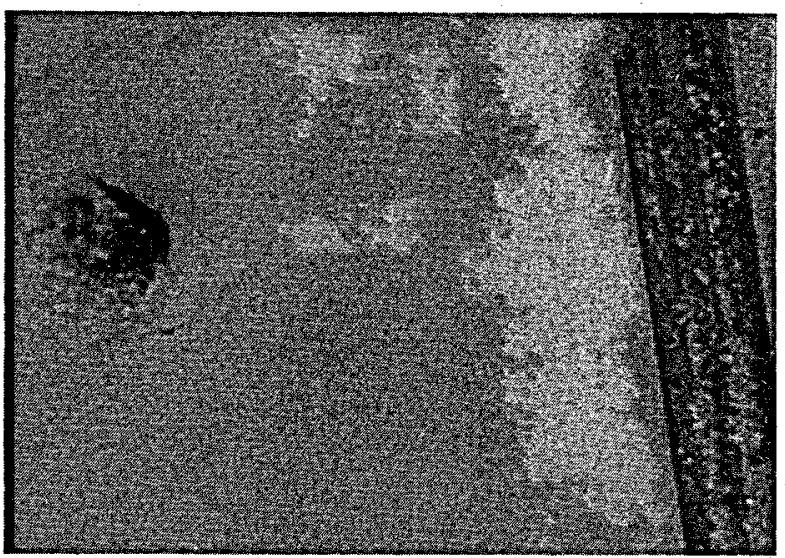

FIG. 28. ML-7(2).

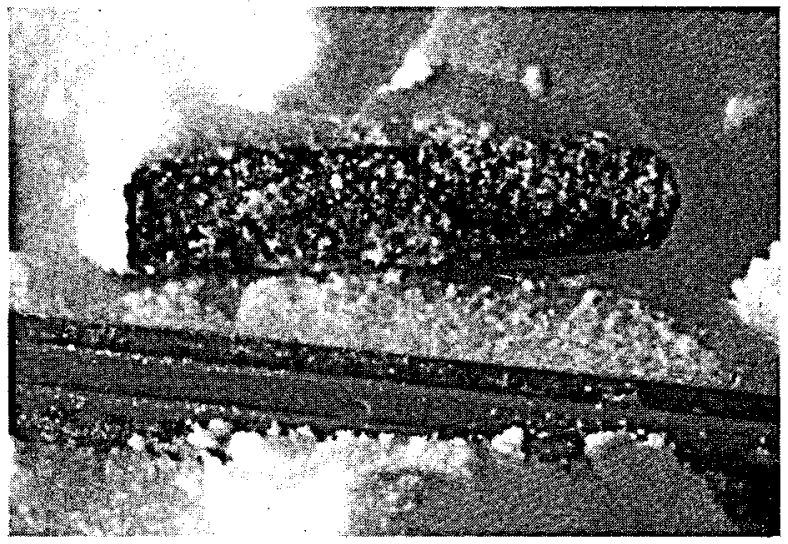

FIG. 29. ML-8(2).

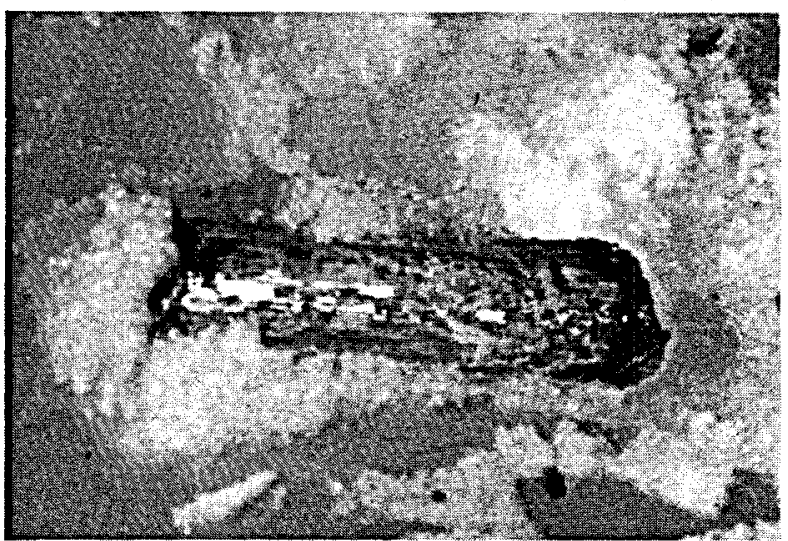

FIG. 30. ML-8(2).

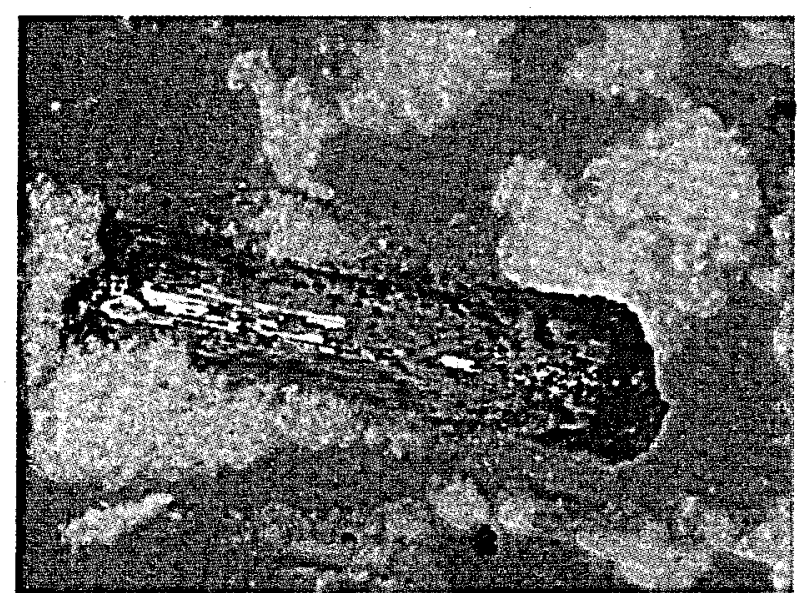

FIG. 31. ML-8(2). 


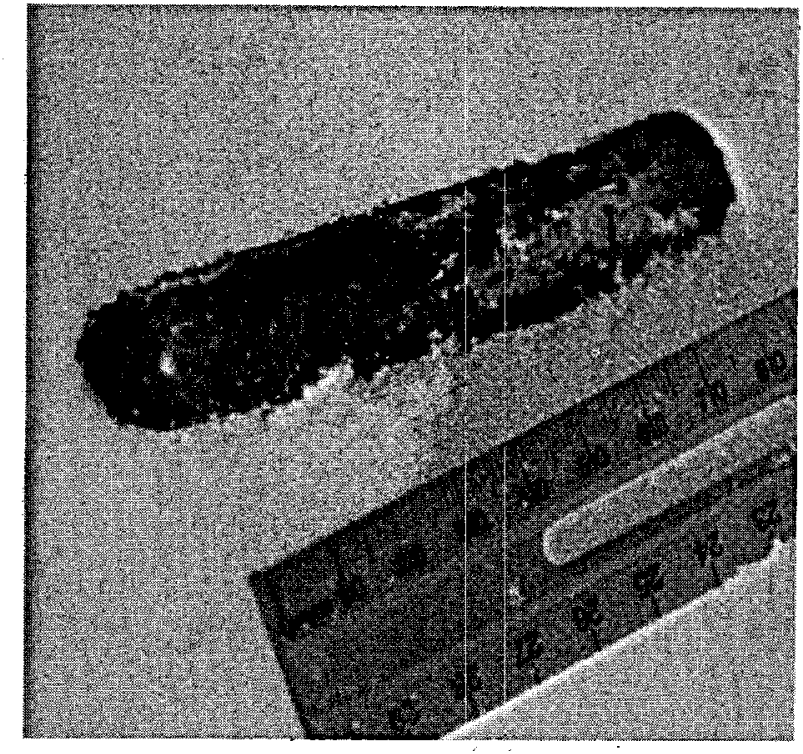

FIG. 32. ML-8(2).

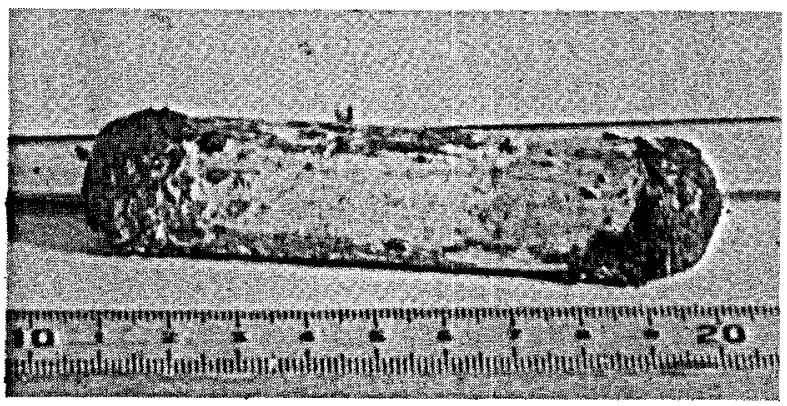

FIG. 33. ML-9(2).

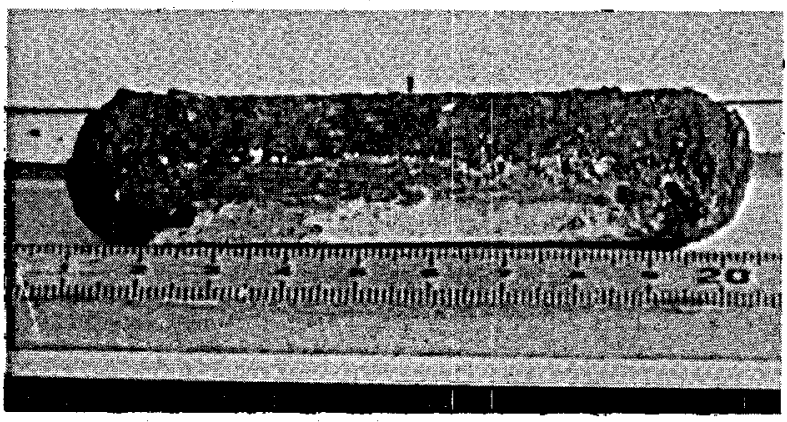

FIG. 34. ML-9(2).

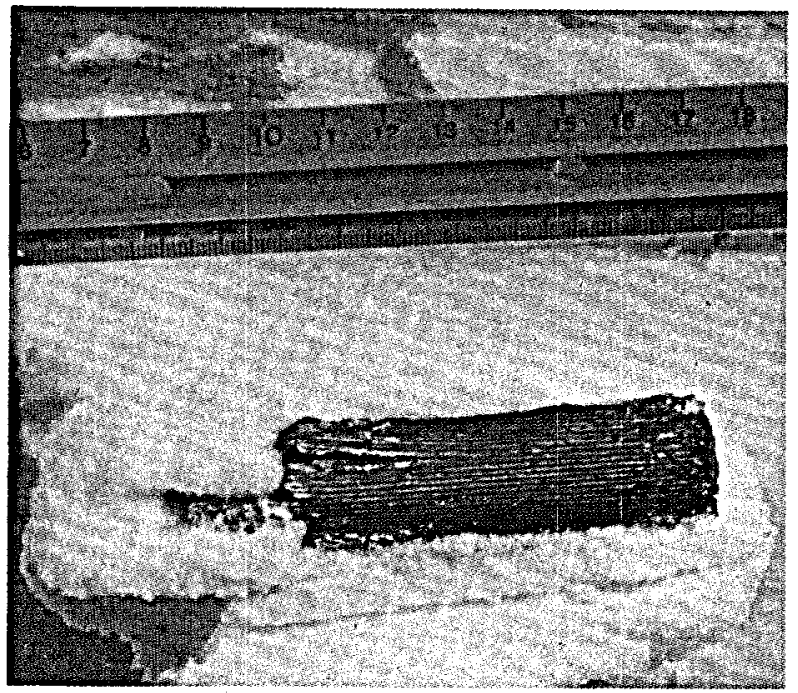

FIG. 35. ML-10(2).

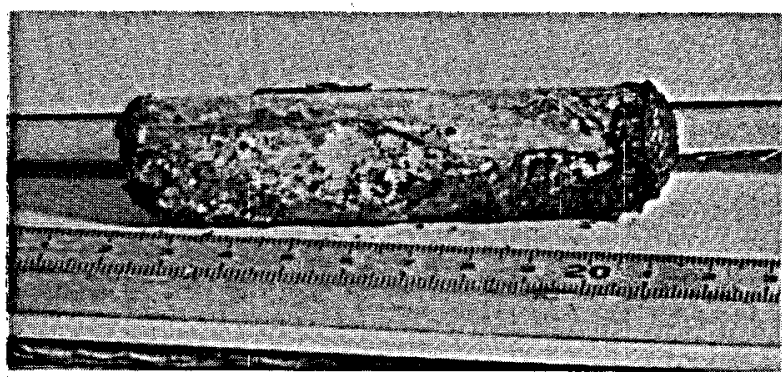

FIG. 36. ML-10(2).

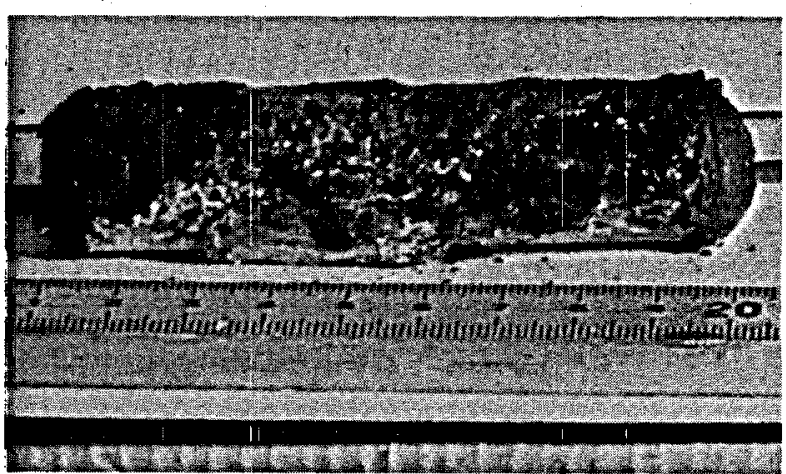

FIG. 37. ML-10(2).

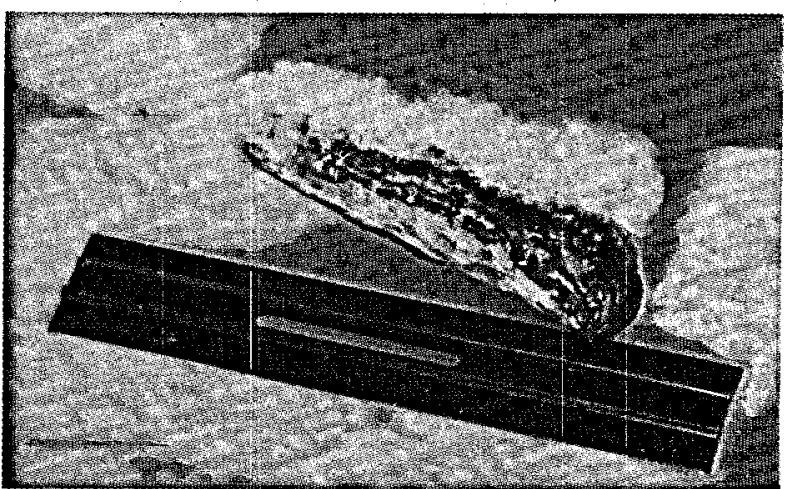

FIG. 38. ML-11(2). 


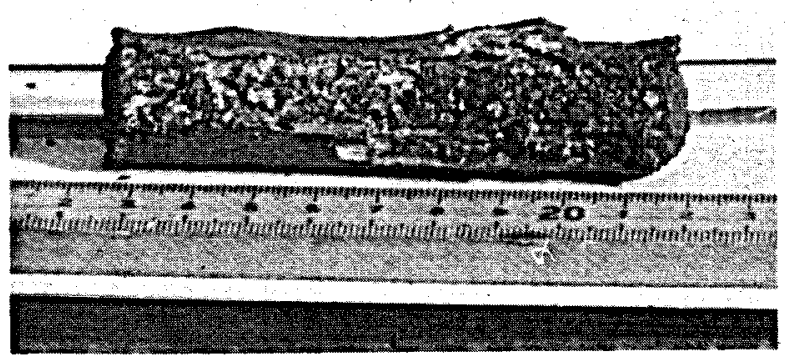

FIG. 39. ML-11(2).

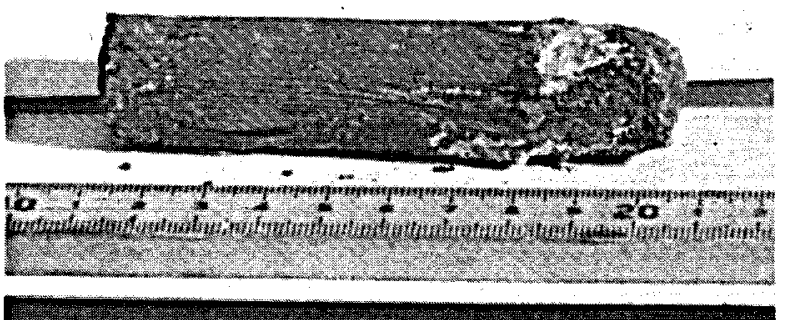

FIG. 40. ML-11(2).

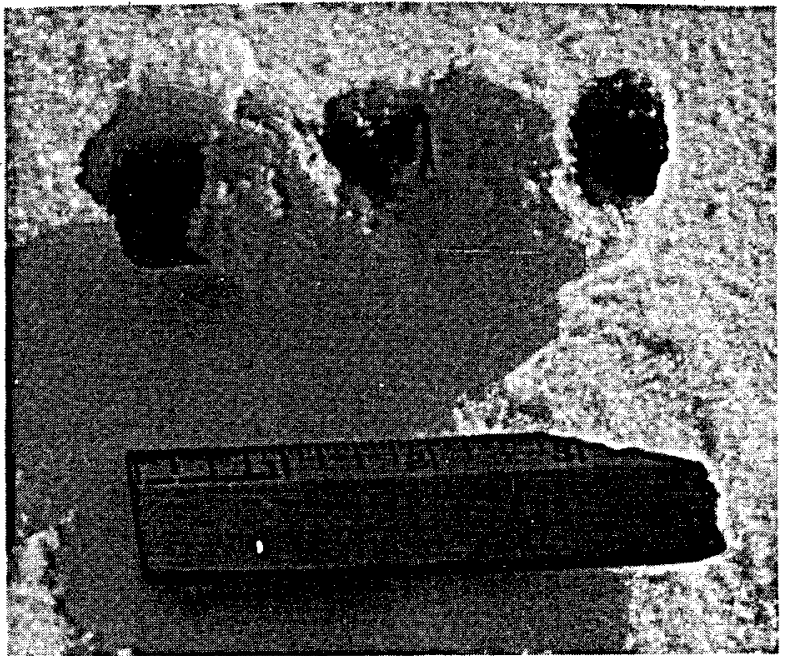

FIG. 41. ML-12(2).

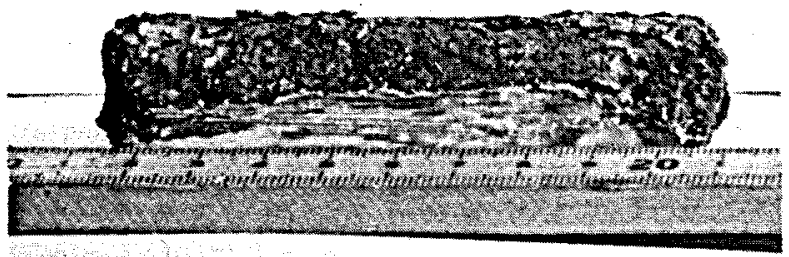

FIG. 42. ML-12(2).

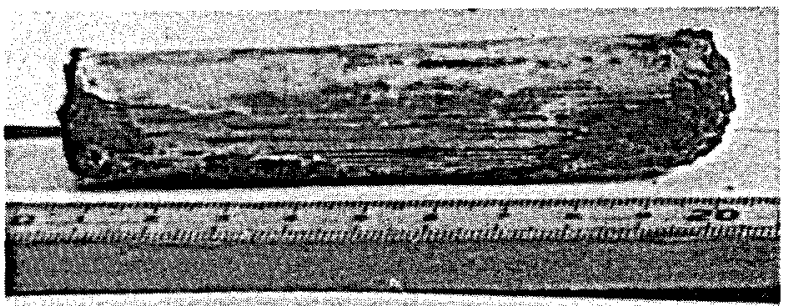

FIG. 43. ML-12(2).

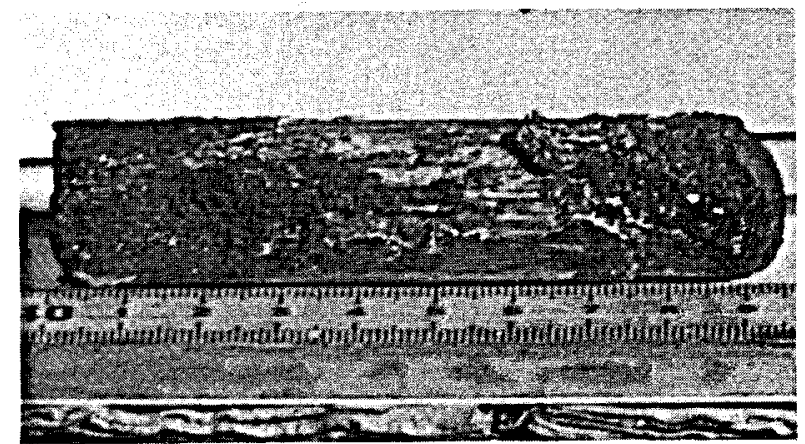

FIG. 44. ML-13(2).

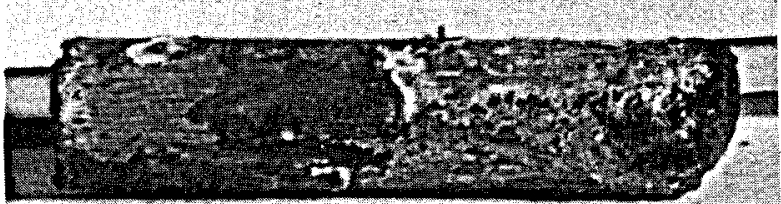

6.802, 4.

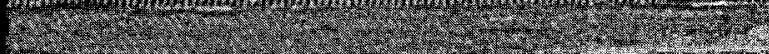

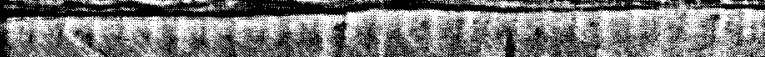

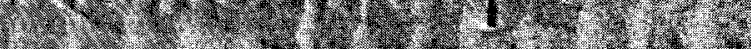

FIG. 45. ML-13(2).

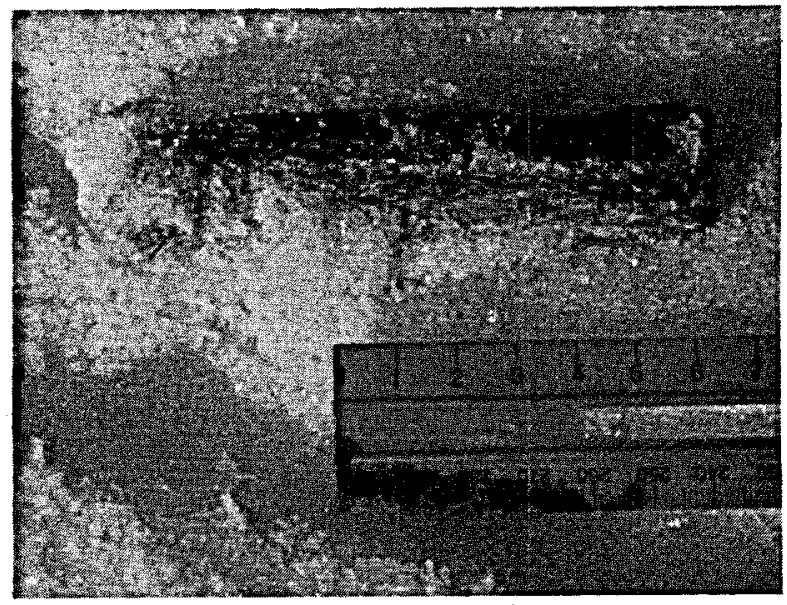

FIG. 46. ML-14(2). 


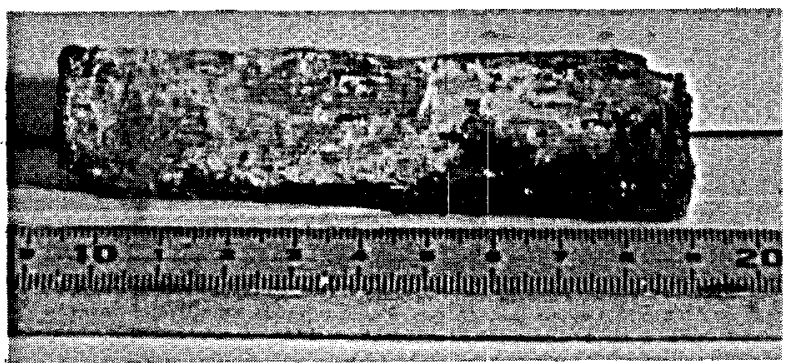

FIG. 47. ML-14(2).

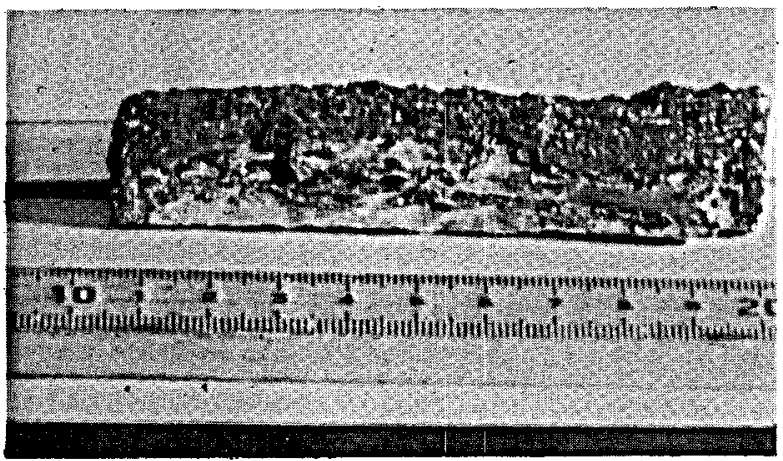

FIG. 48. ML-14(2).

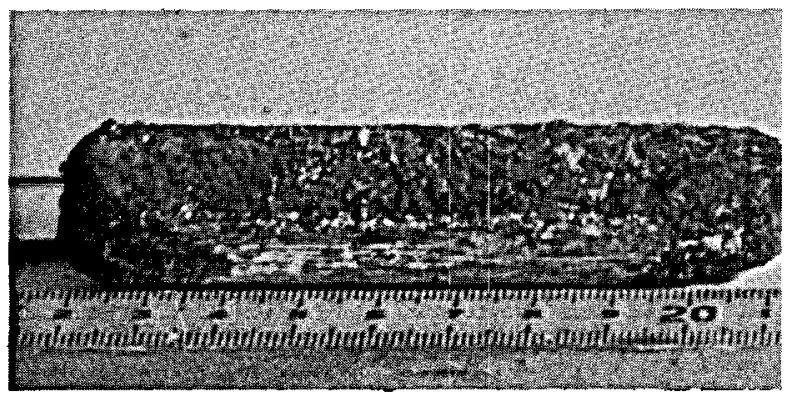

FIG. 49. ML-15(2).

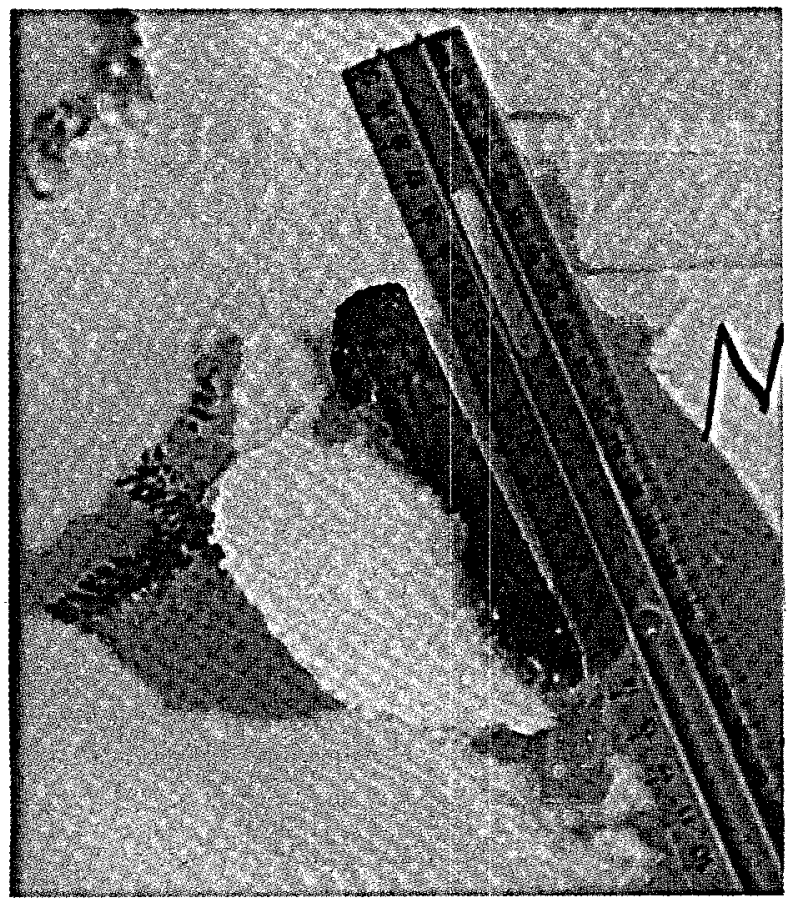

FIG. 50. ML-16(2).

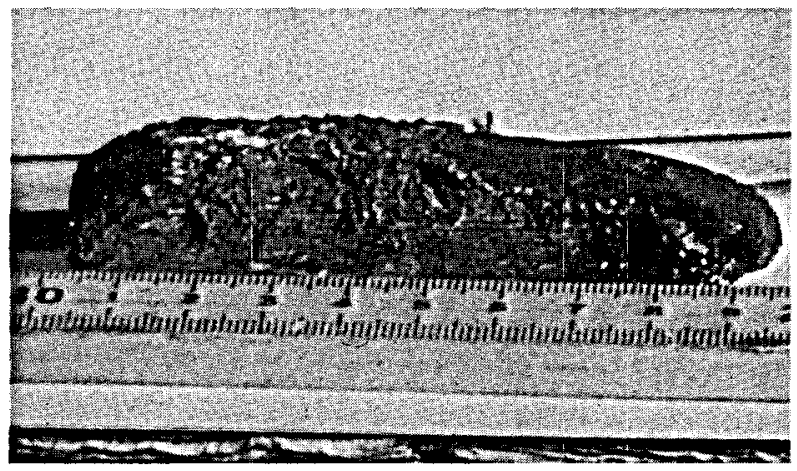

FIG. 51. ML-16(2).

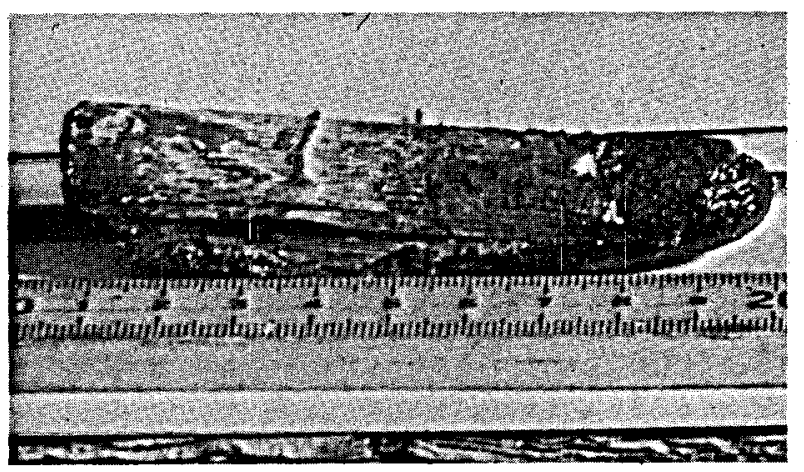

FIG. 52. ML-16(2).

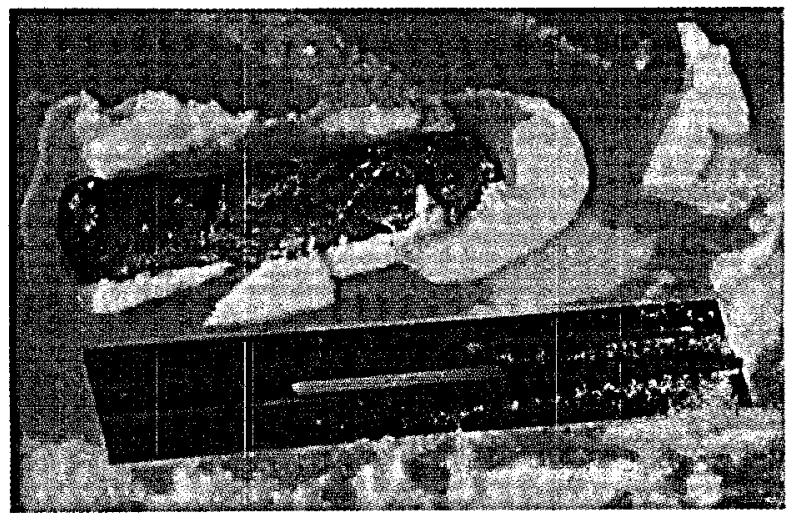

FIG. 53. ML-17(2)

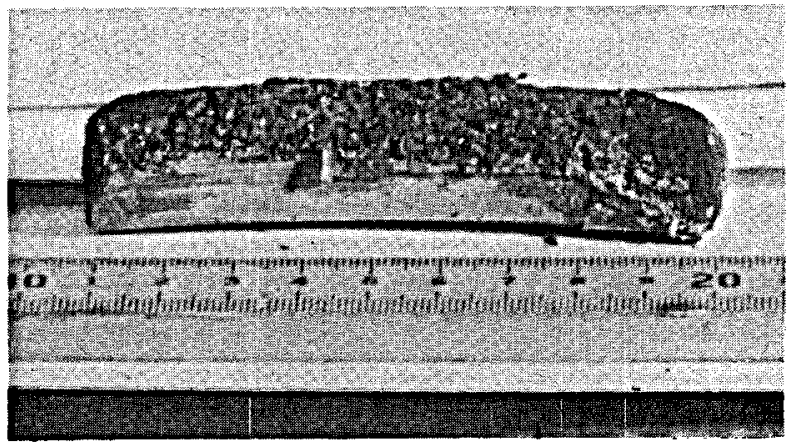

FIG. 54. ML-17(2). 


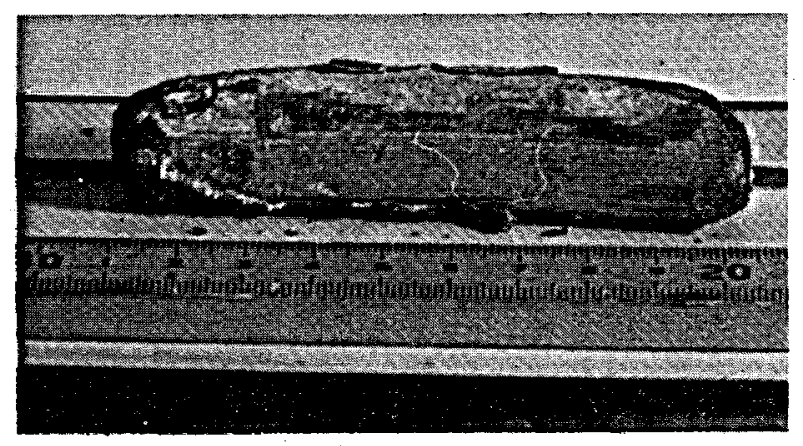

FIG. 55. $M L-17(2)$.

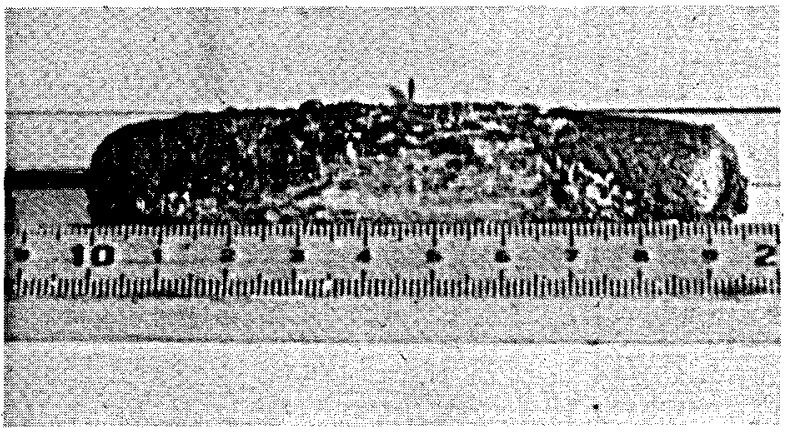

FIG. 56. ML-18(2).

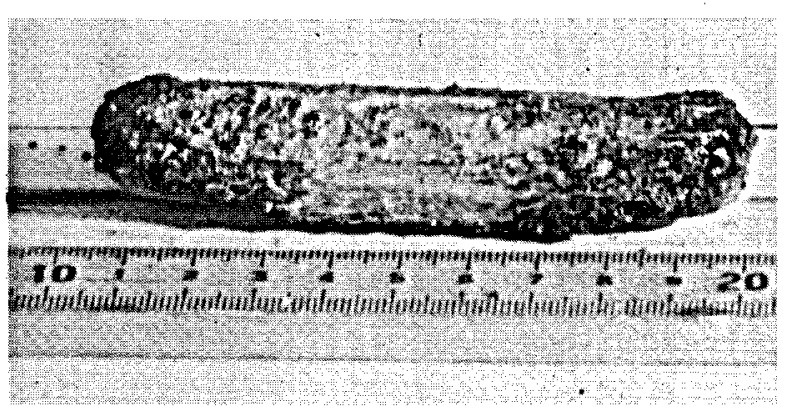

FIG. 57. ML-18(2).

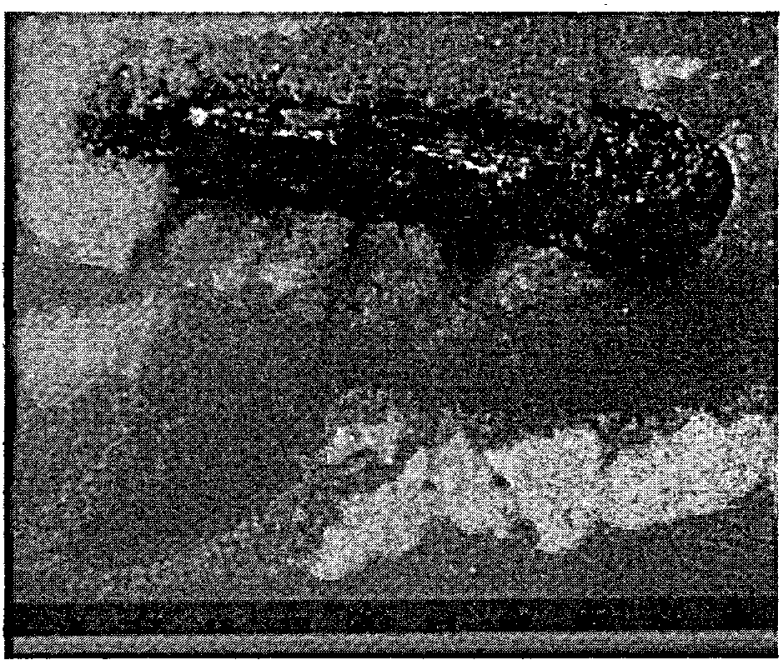

FIG. 58. ML-19(2).

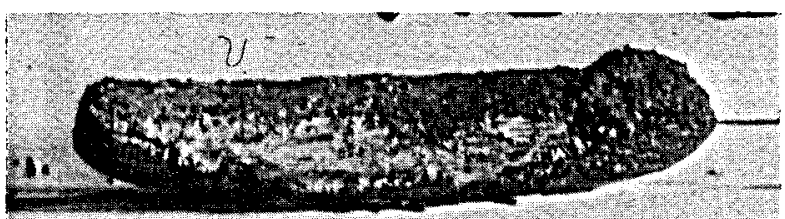

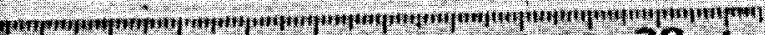

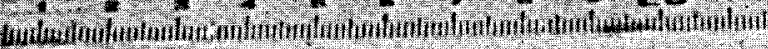

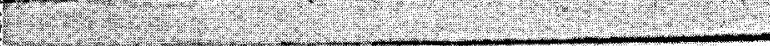

FIG. 59. ML-19(2).

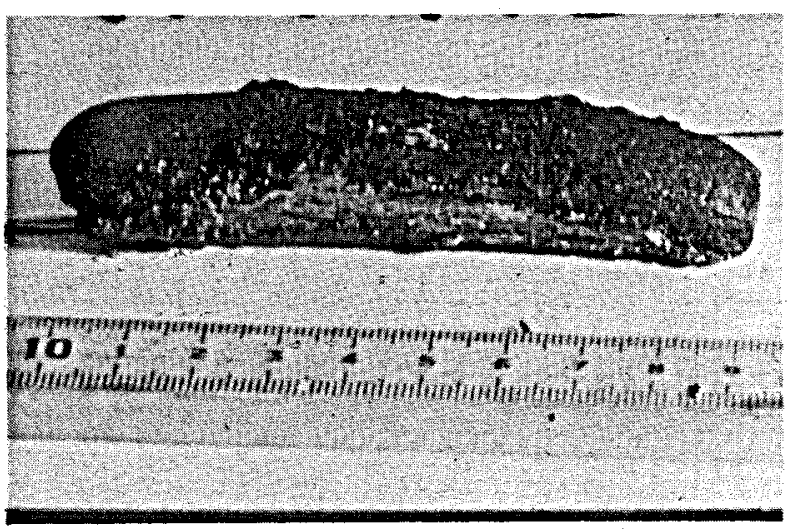

FIG. 60. ML-19(2).

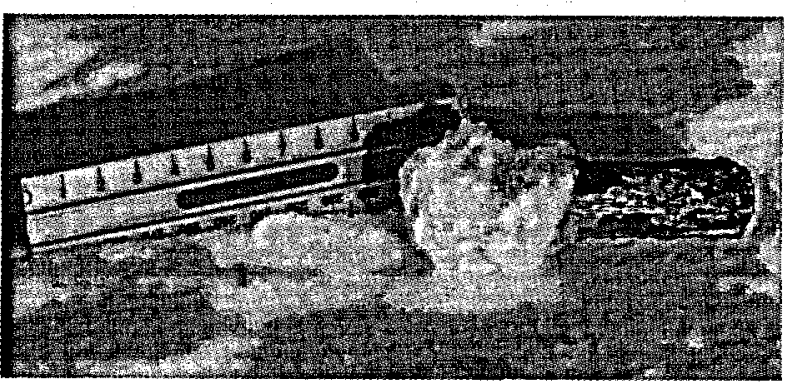

FIG. 61. ML-20(2).

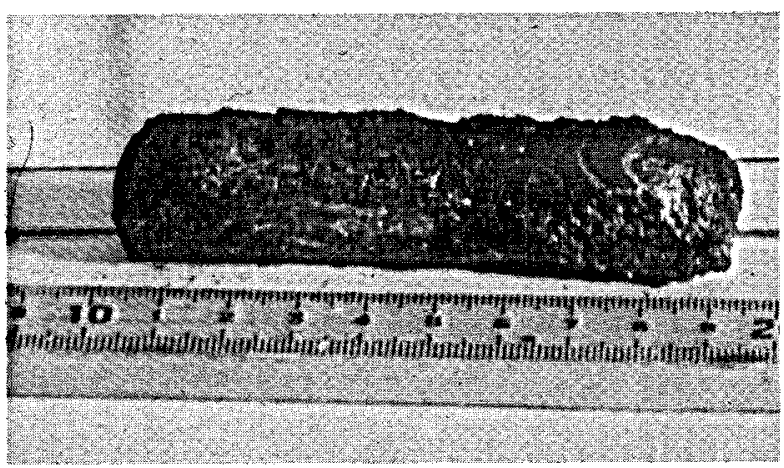

FIG. 62. ML-20(2). 


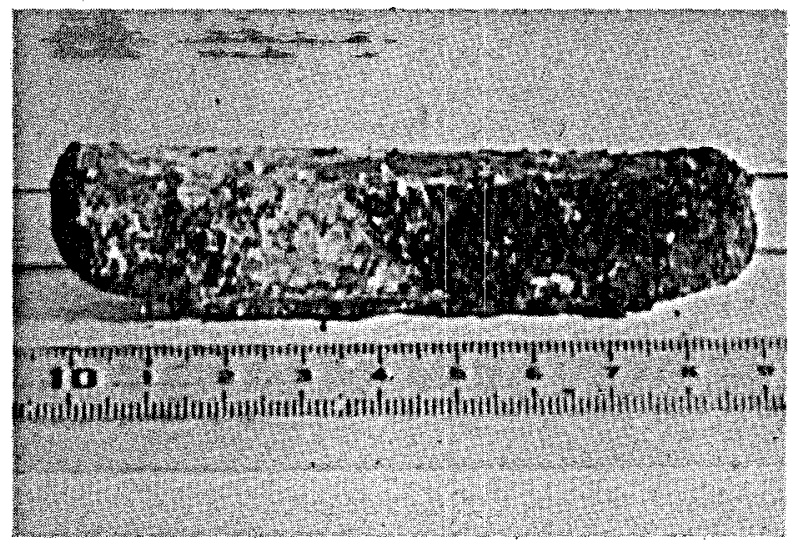

FIG. 63. ML-20(2).

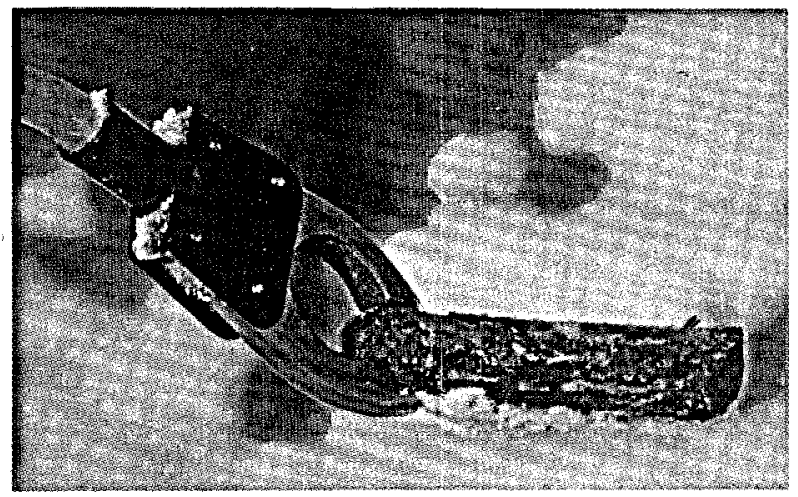

FIG. 64. ML-21(2).

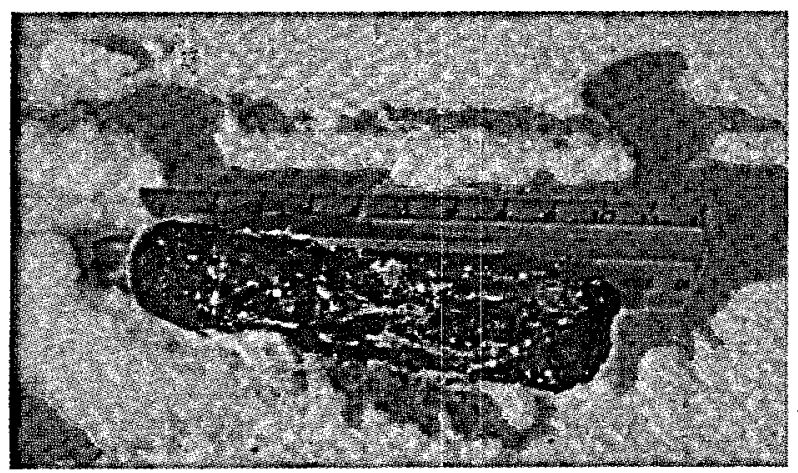

FIG. 65. ML-21(2).

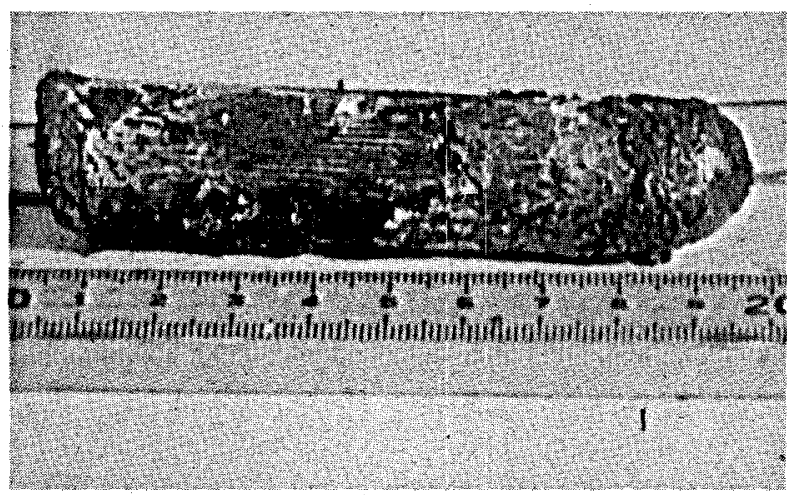

FIG. 66. ML-21(2).

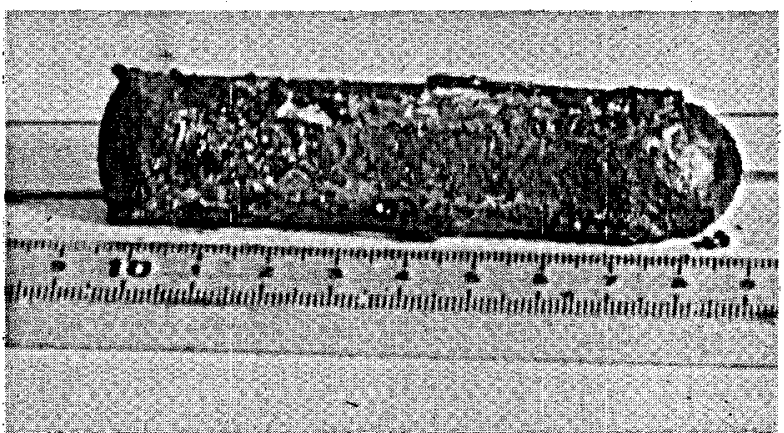

FIG. 67. ML-21(2).

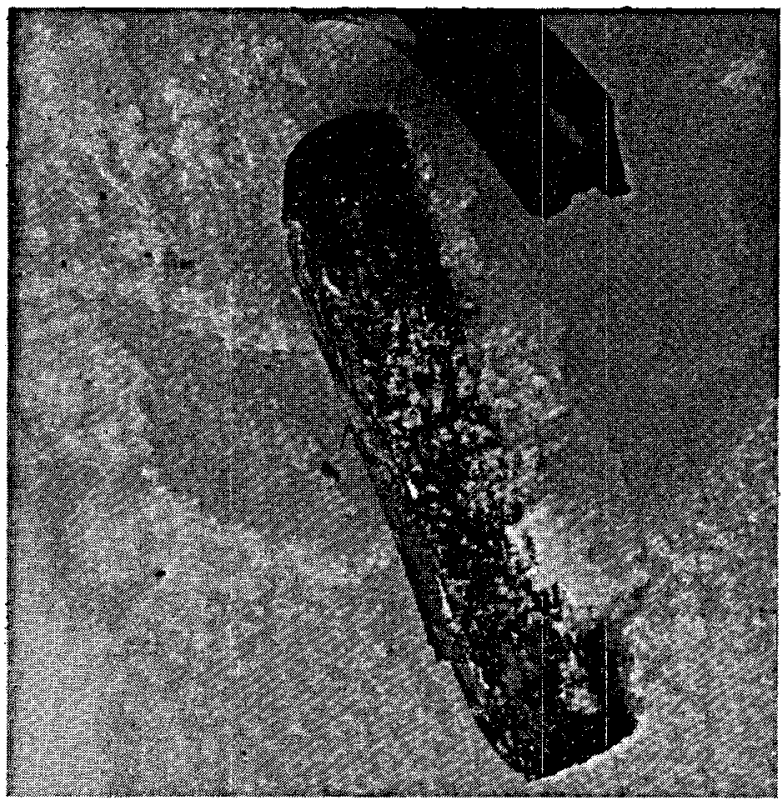

FIG. 68. ML-23(2).

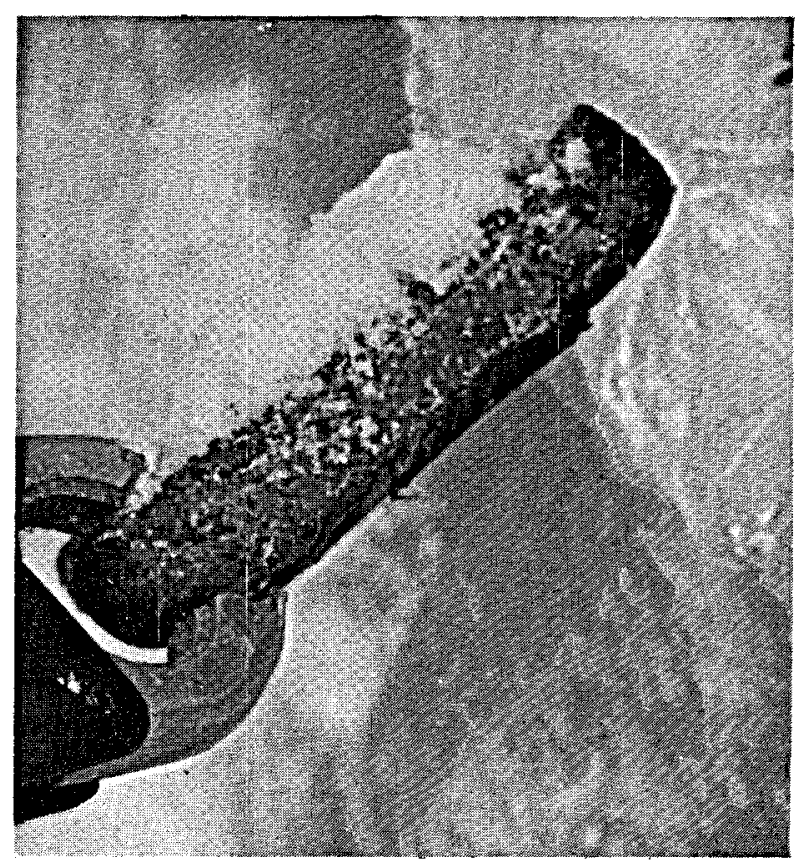

FIG. 69. ML-23(2). 


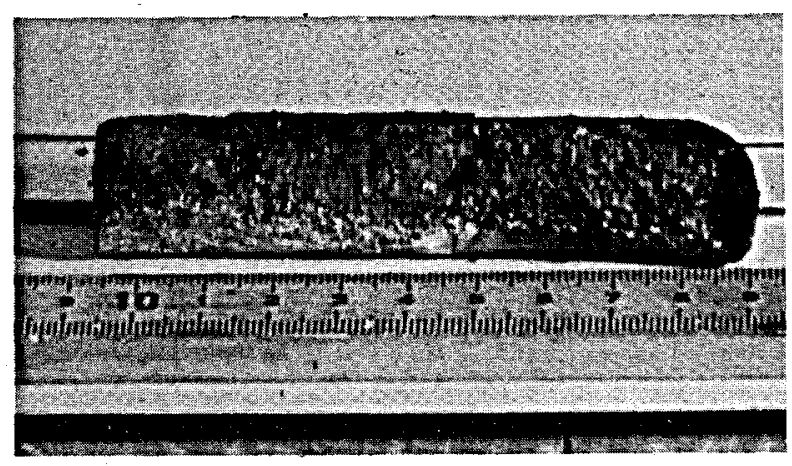

FIG. 70. ML-23(2).

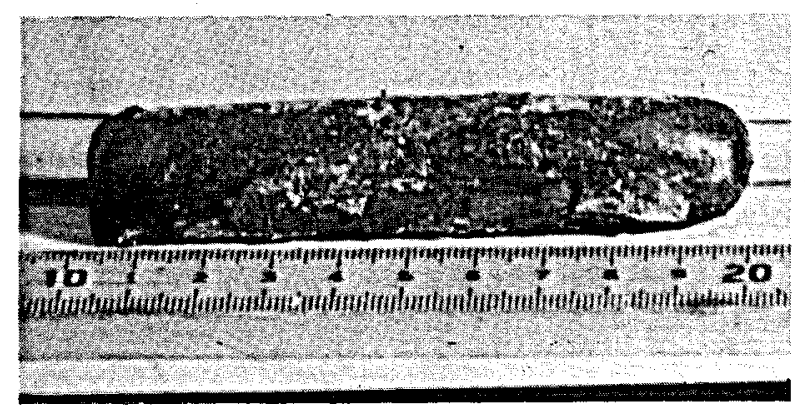

FIG. 71. ML-23(2).

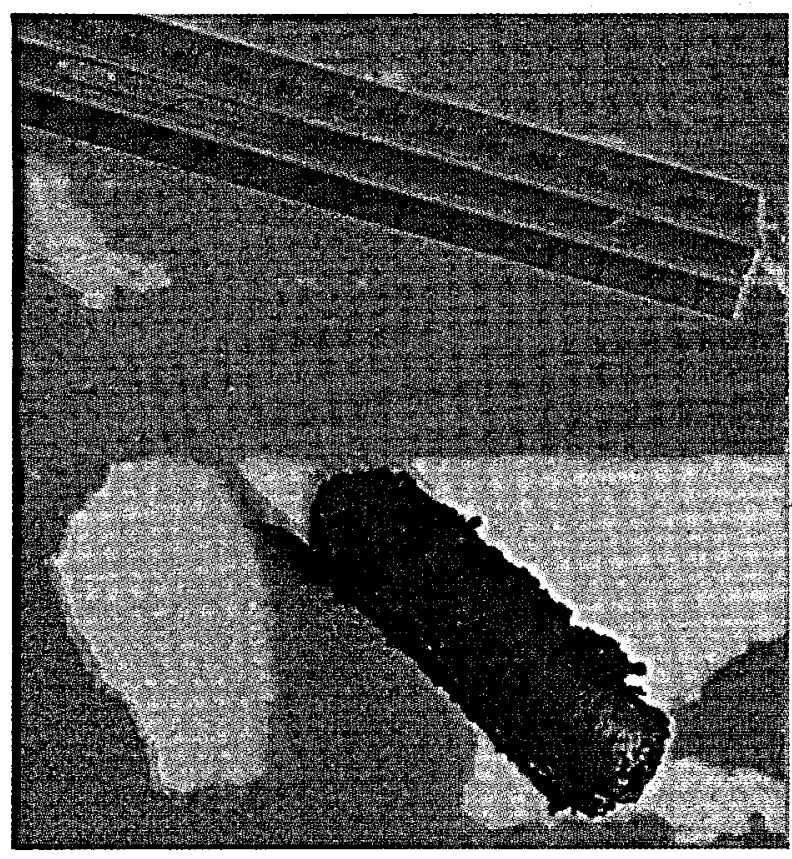

FIG. 72. ML-5(10).

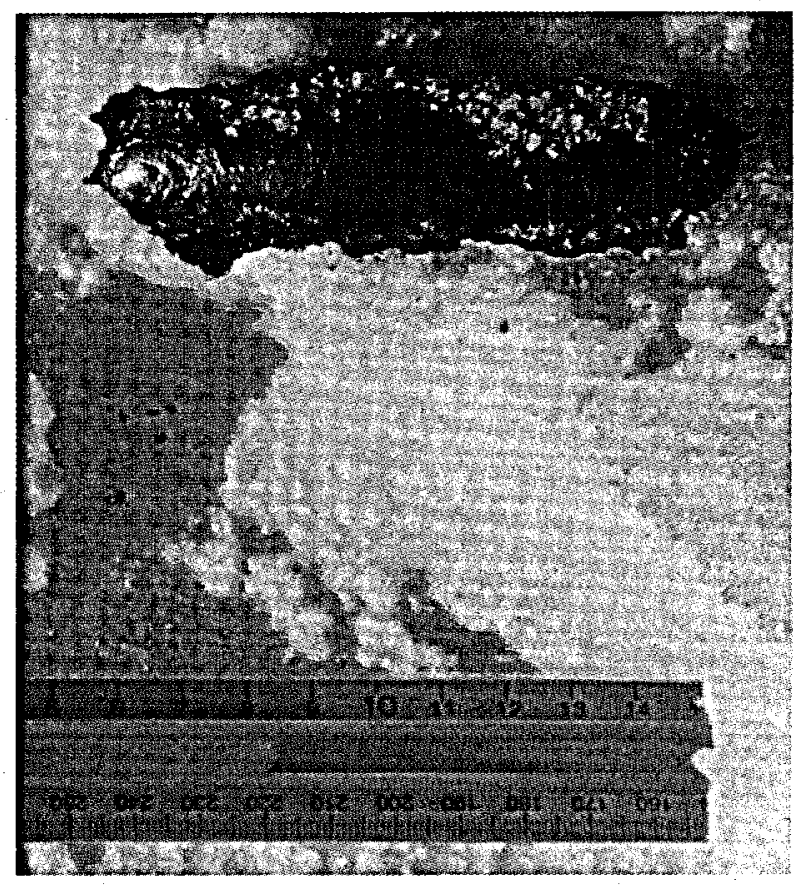

FIG. 73. ML-5(10).

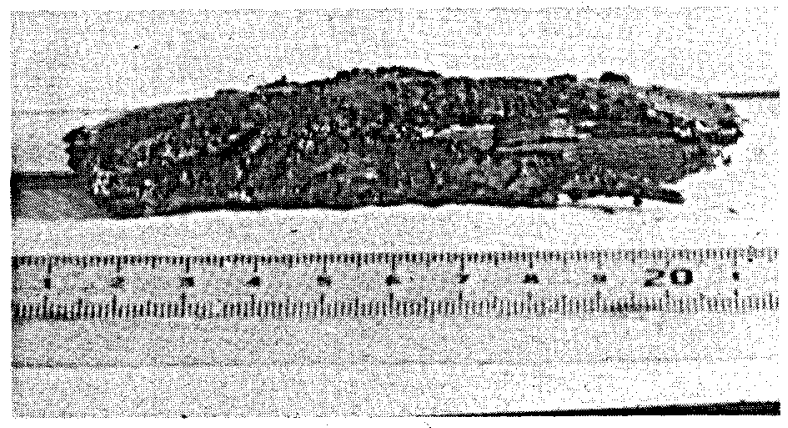

FIG. 74. ML-5(10).

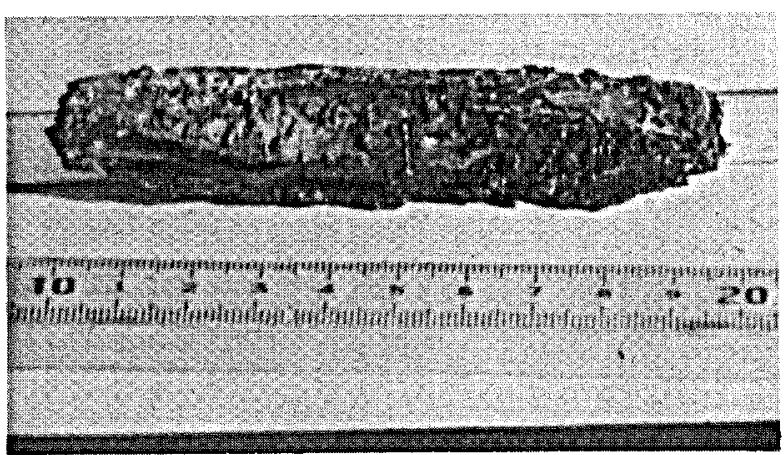

FIG. 75. ML-5(10). 


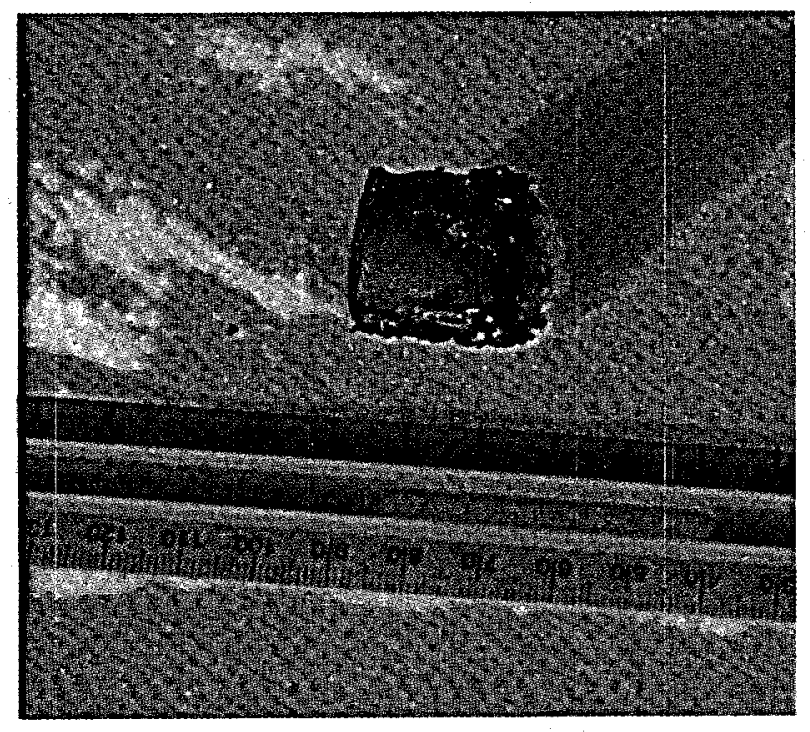

FIG. 76. ML-6(10).

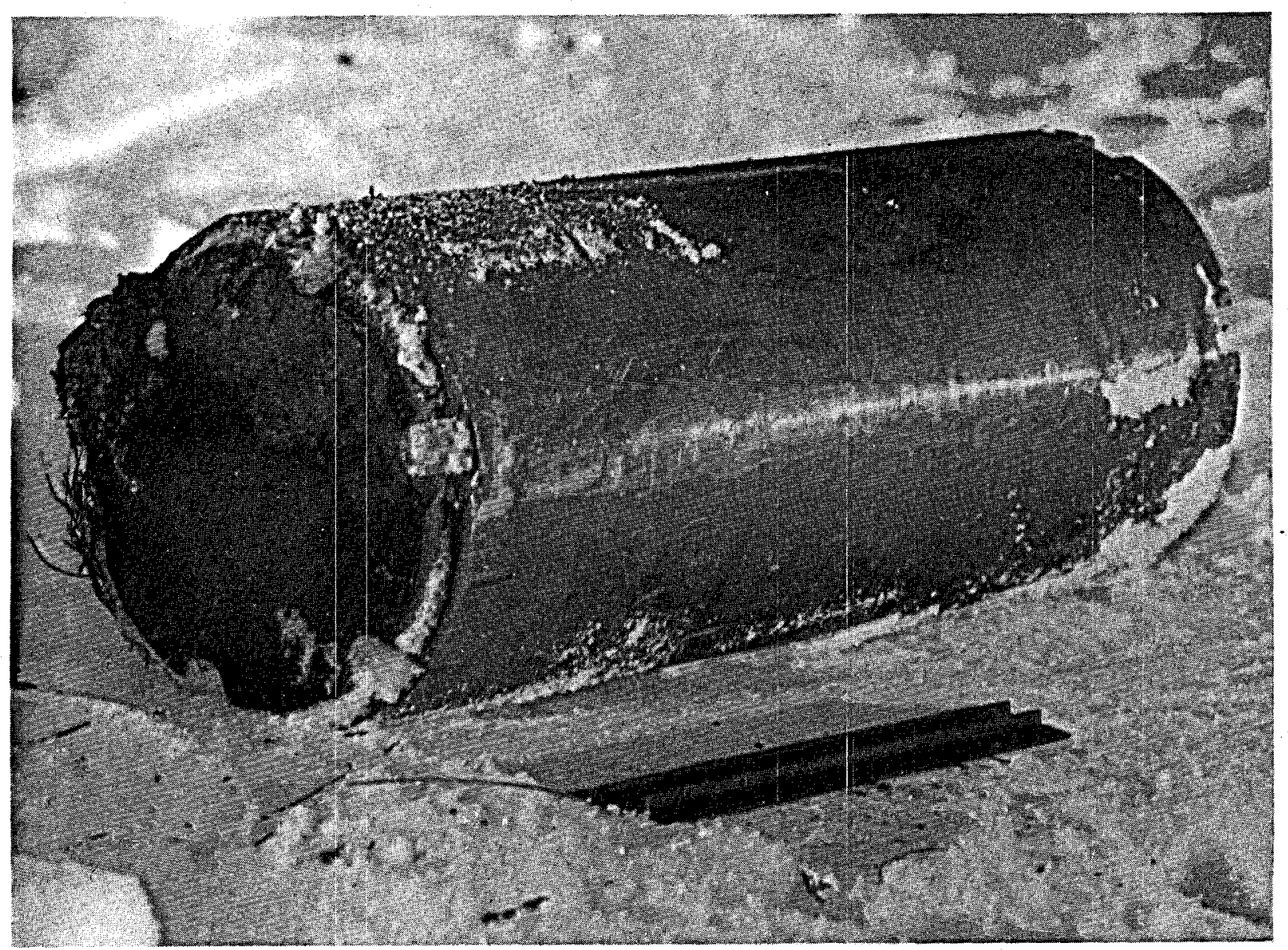

FIG. 77. ML-26(2). 


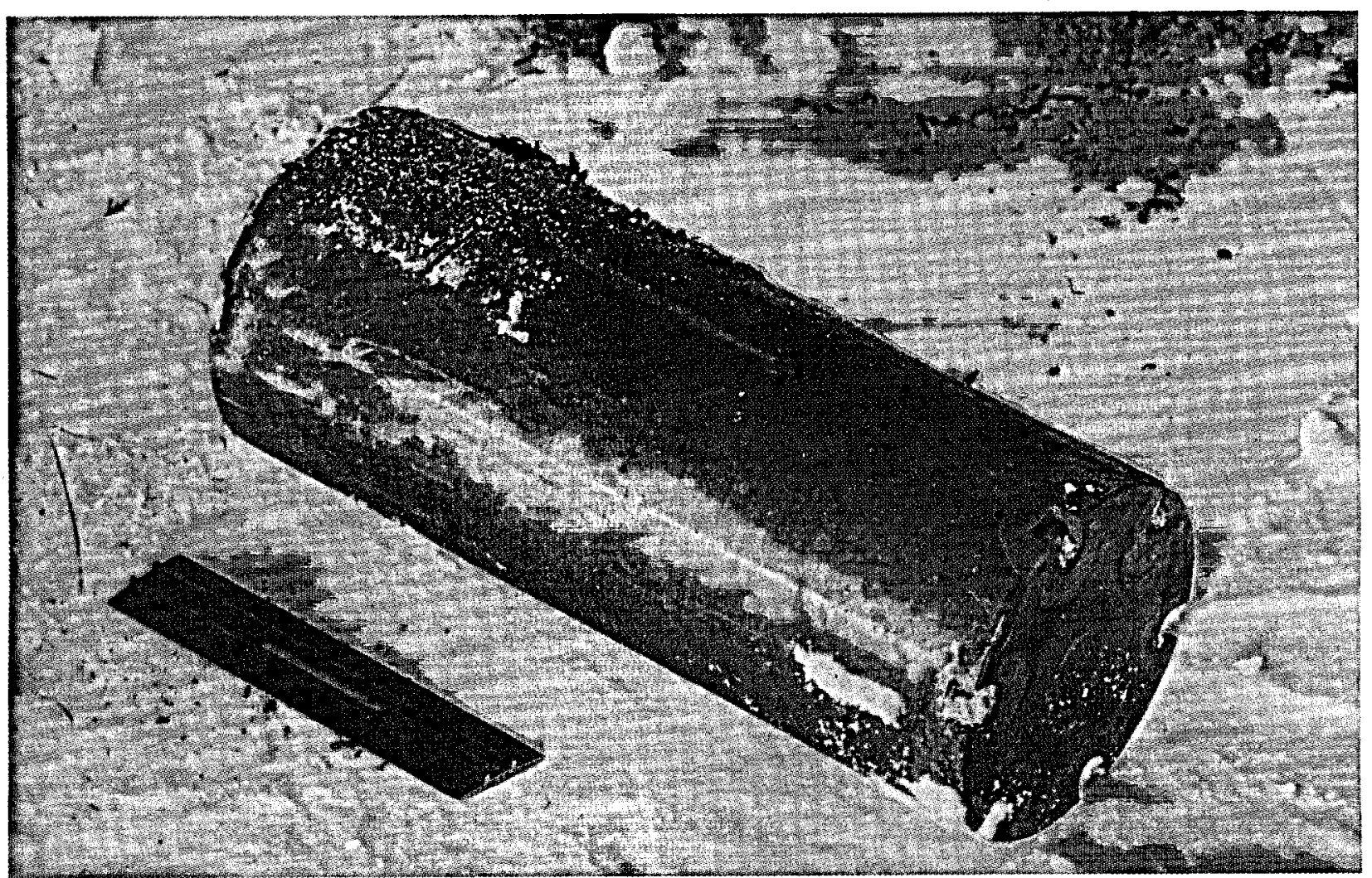

FIG. 78. ML-26(2).

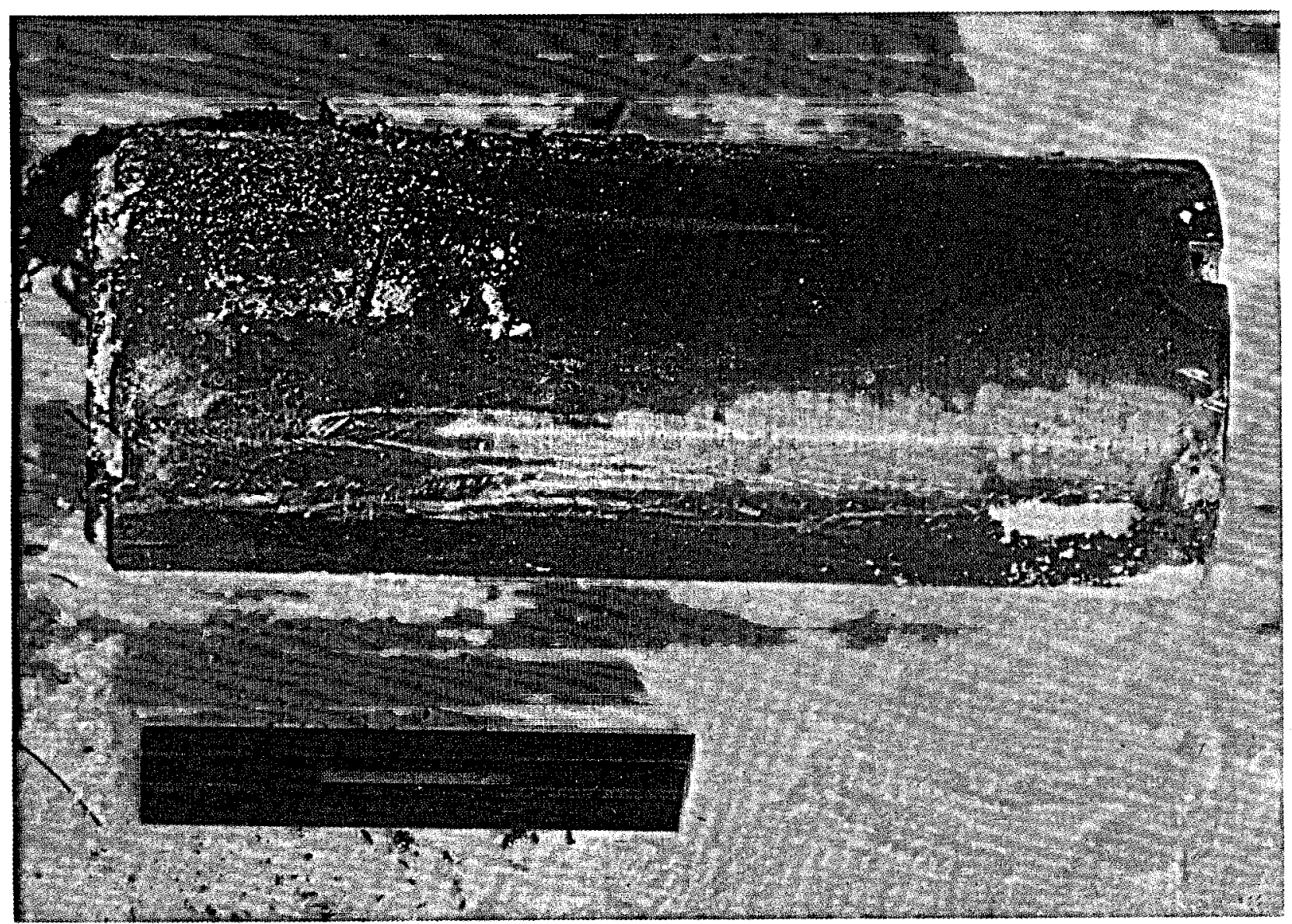

FIG. 79. ML-26(2). 


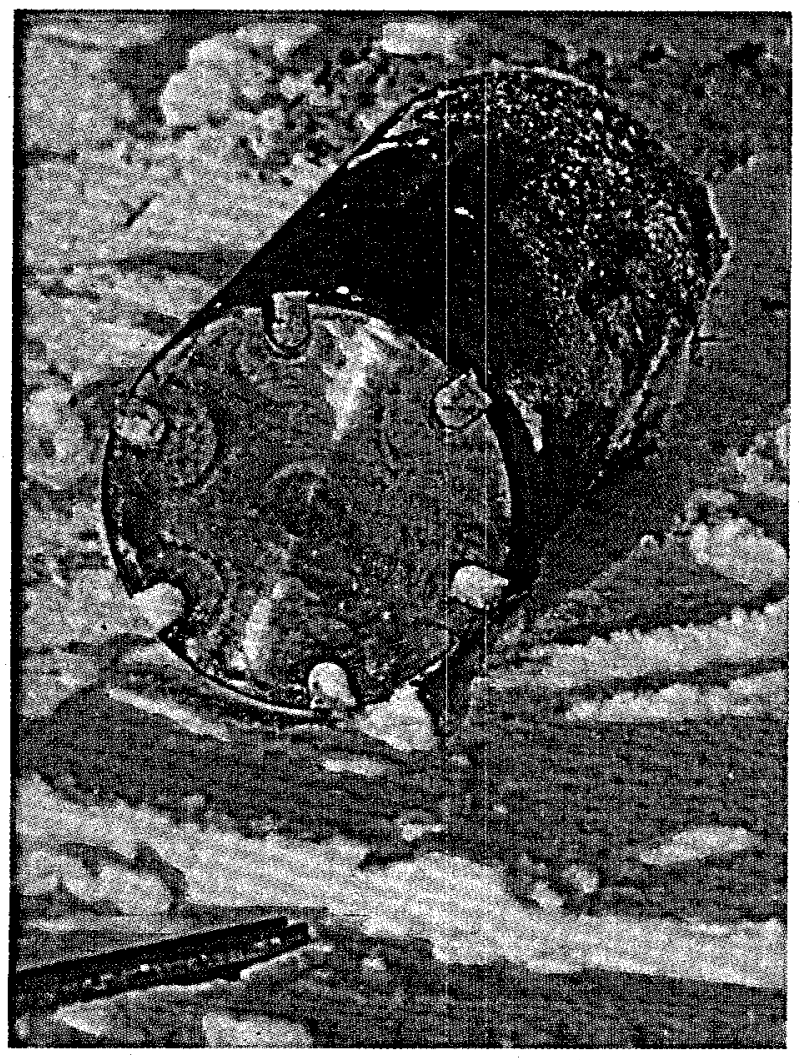

FIG. 80. ML-26(2).

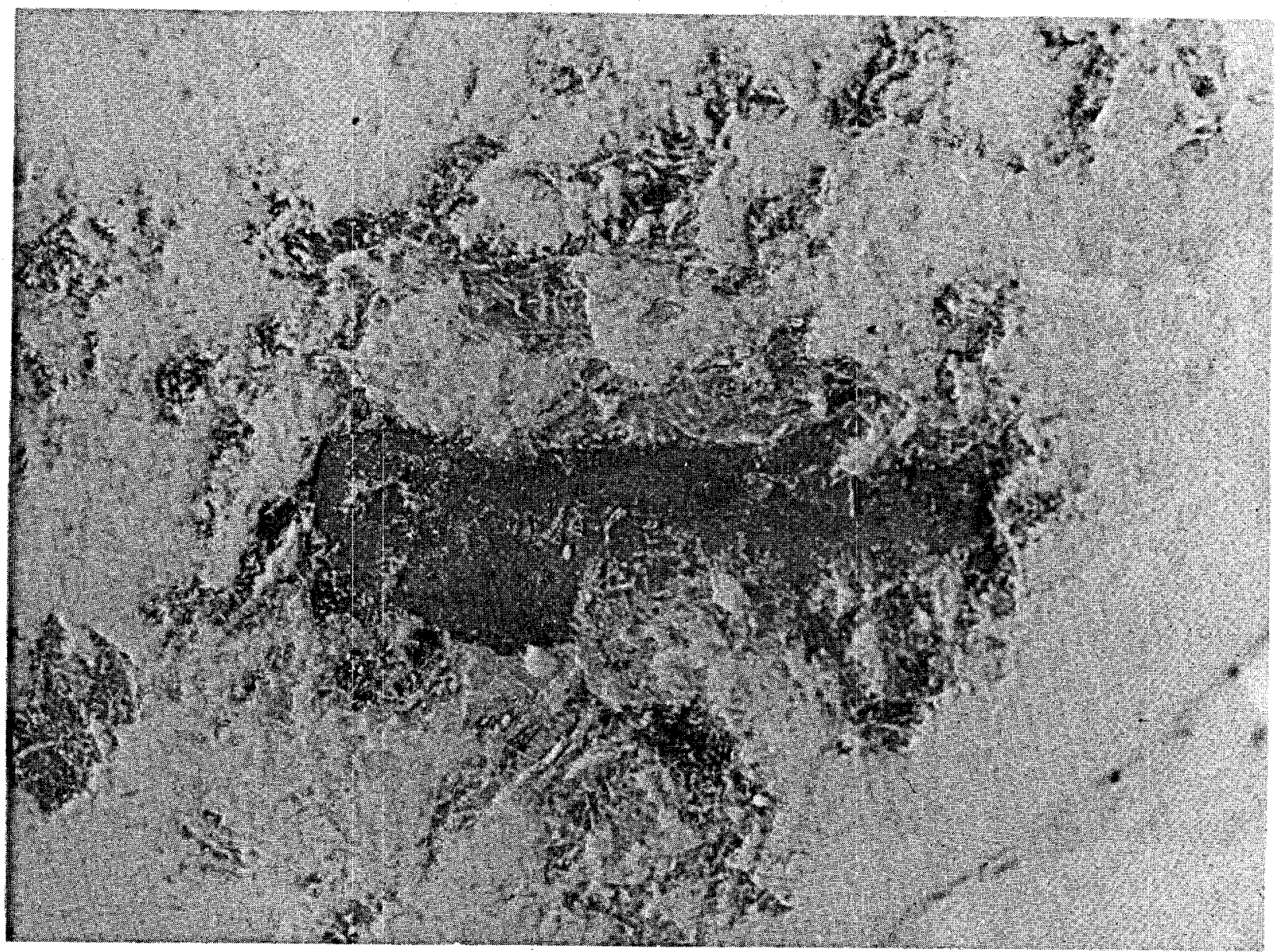

FIG. 81, ML-28(2). 


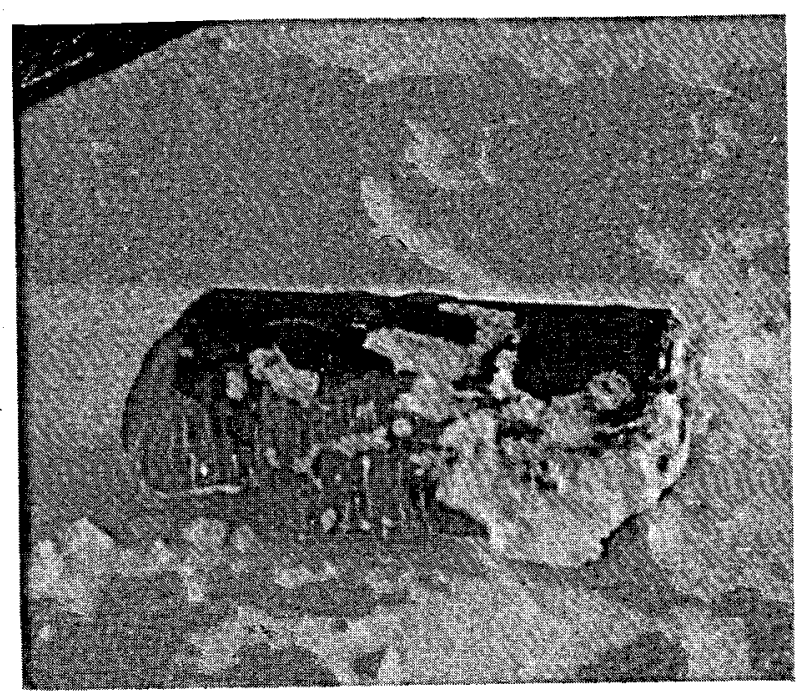

FIG. 82. $\operatorname{ML-28(2).~}$

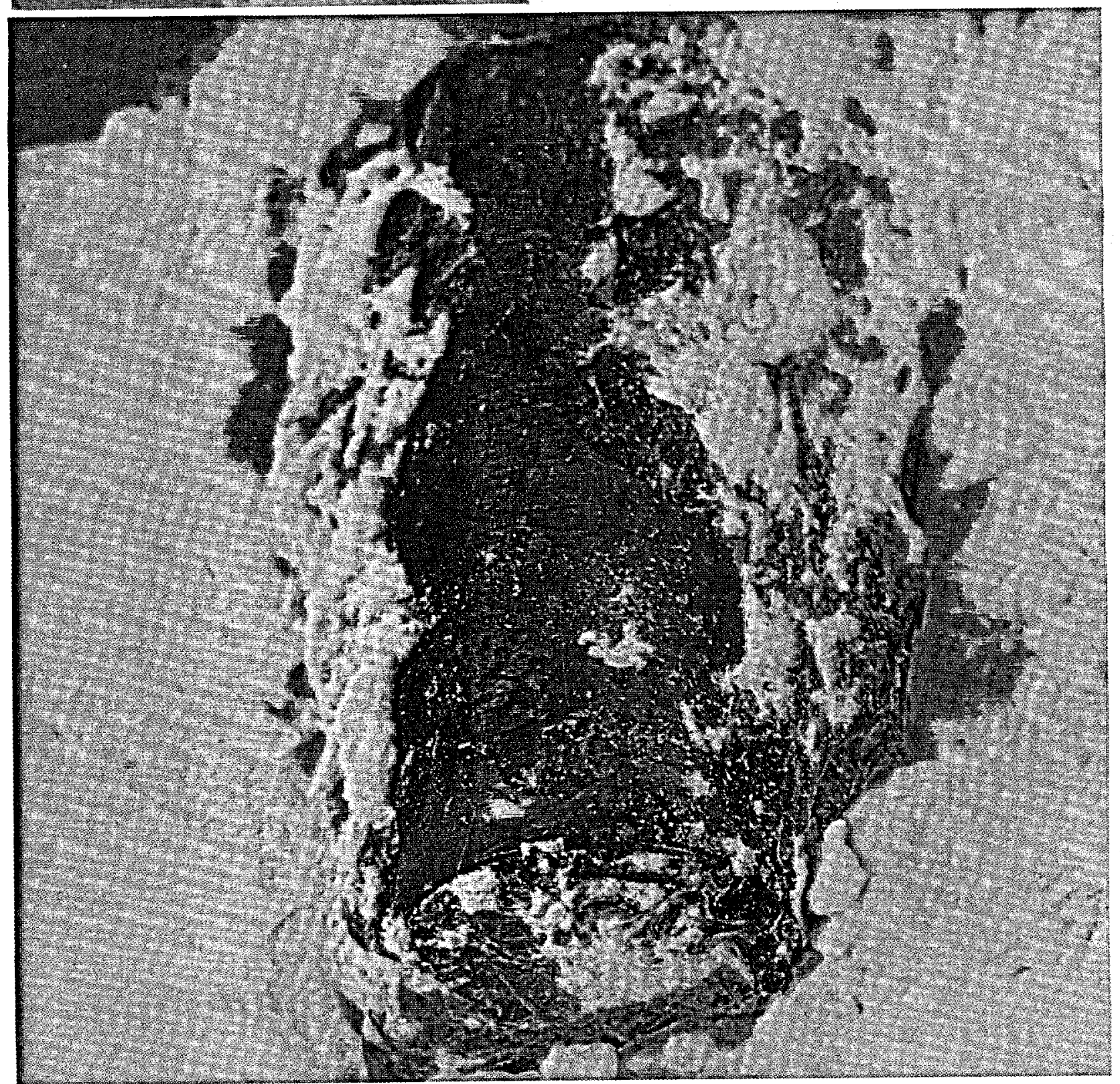

FIG. 83. ML-29(2). 


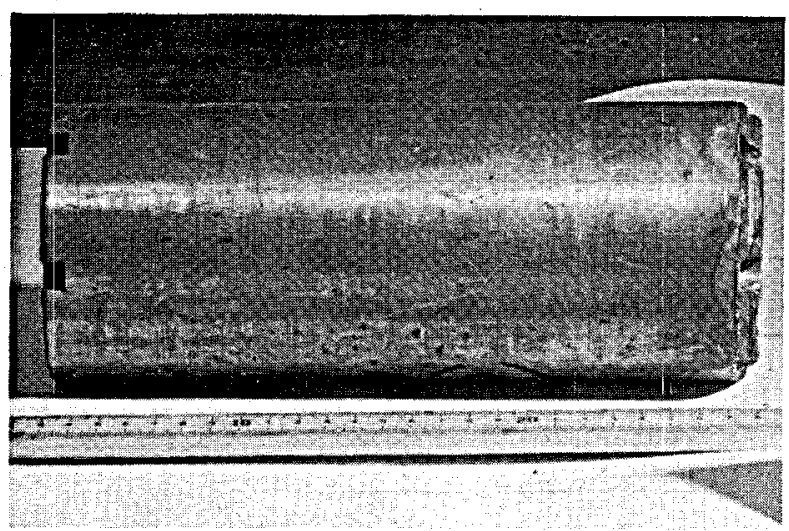

FIG. 84. ML-29(2).

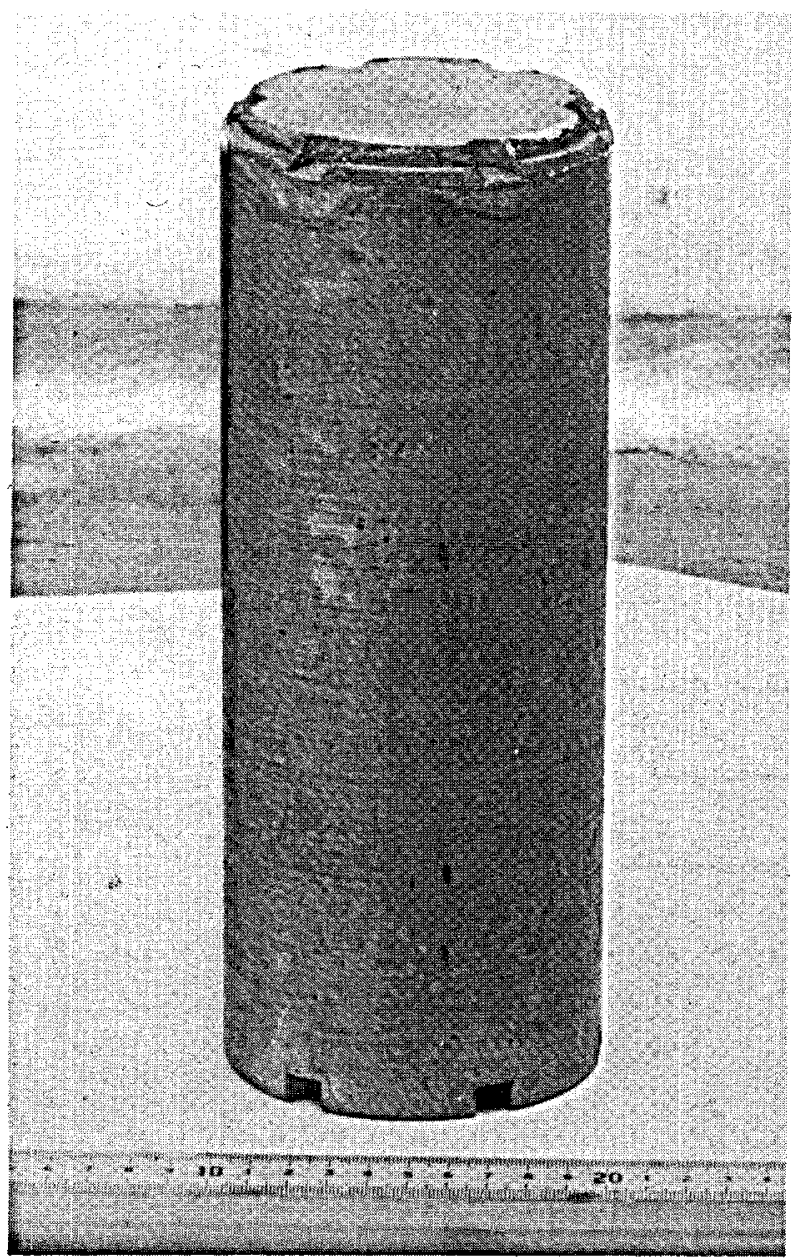

FIG. 85. ML-29(2). 


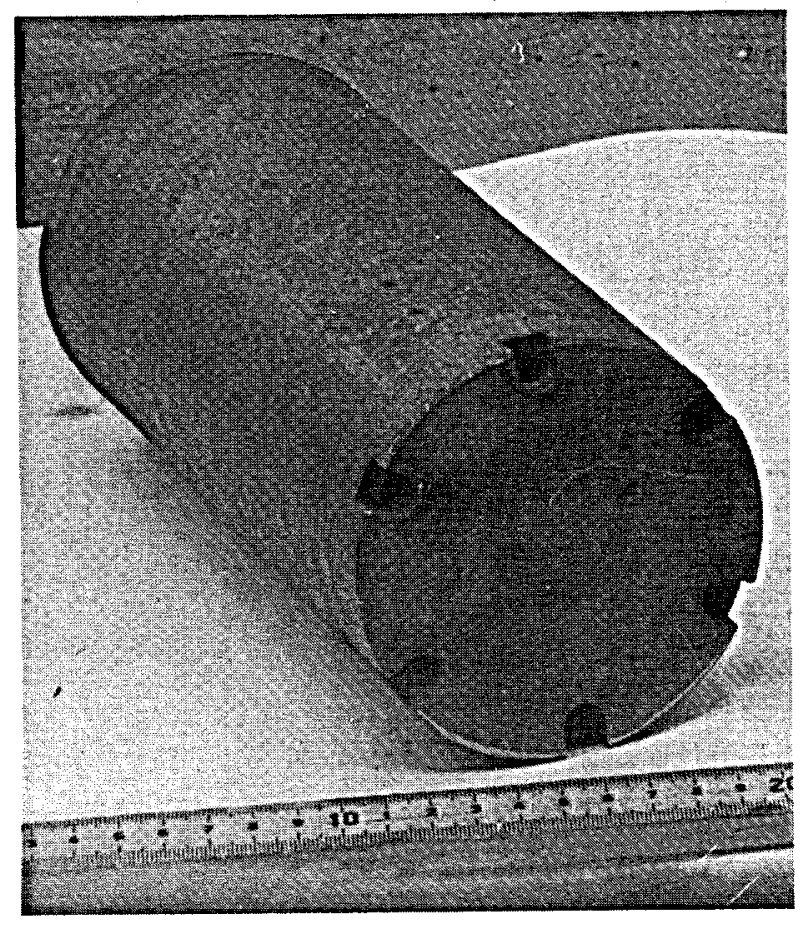

FIG. 86. ML-29(2).

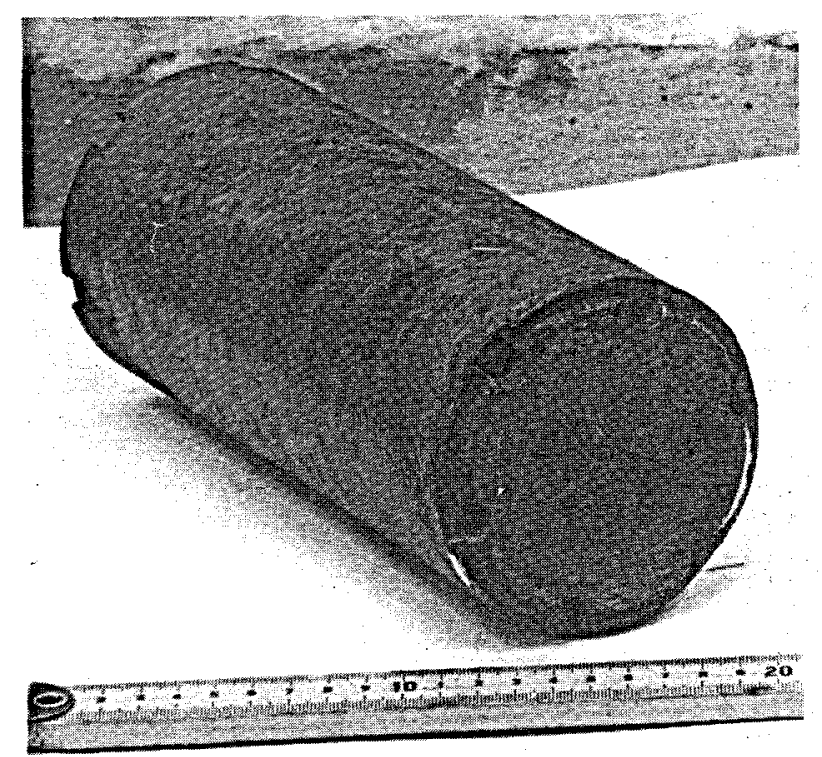

FIG. 87. ML-29(2).

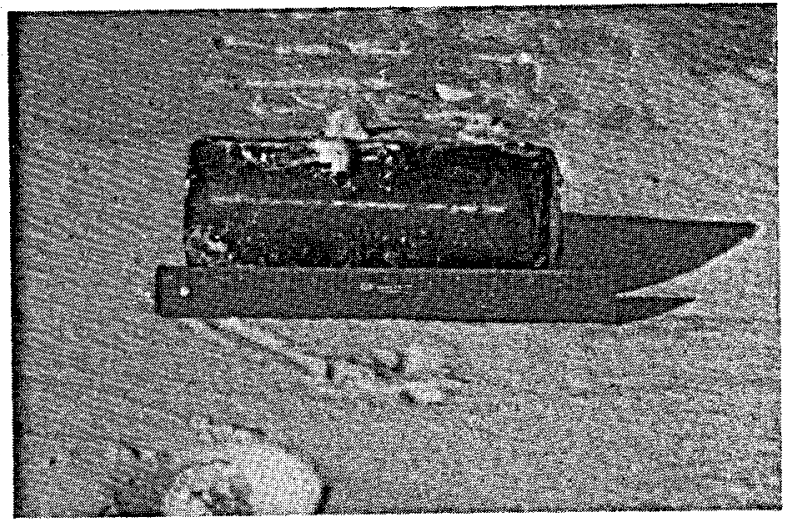

FIG. 88. ML-33(2).

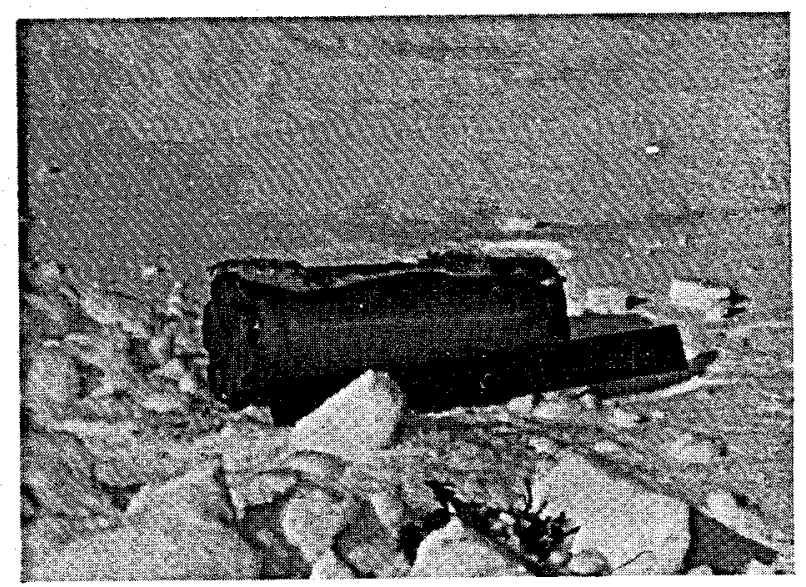

FIG. 89. ML-34(2). 


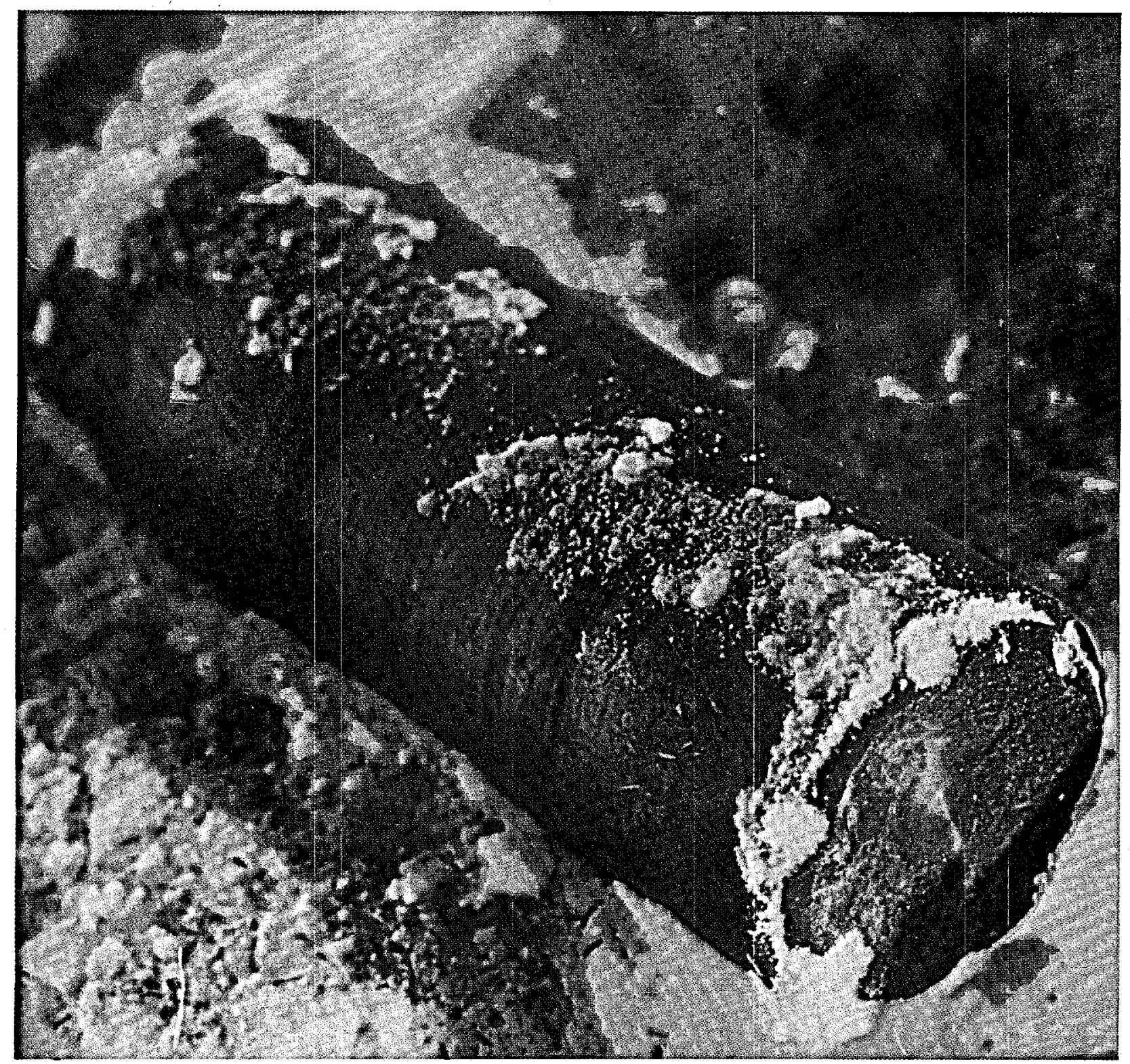

FIG. 90. ML-1(3).

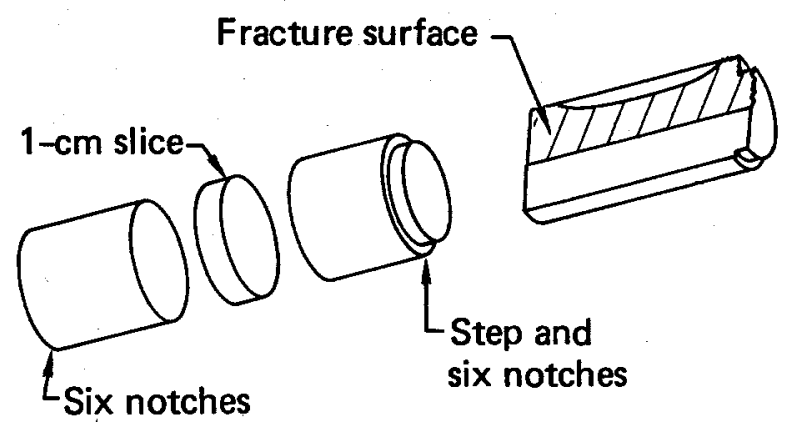

FIG. 91. Schematic showing cutting of cylinder ML-28(2). 


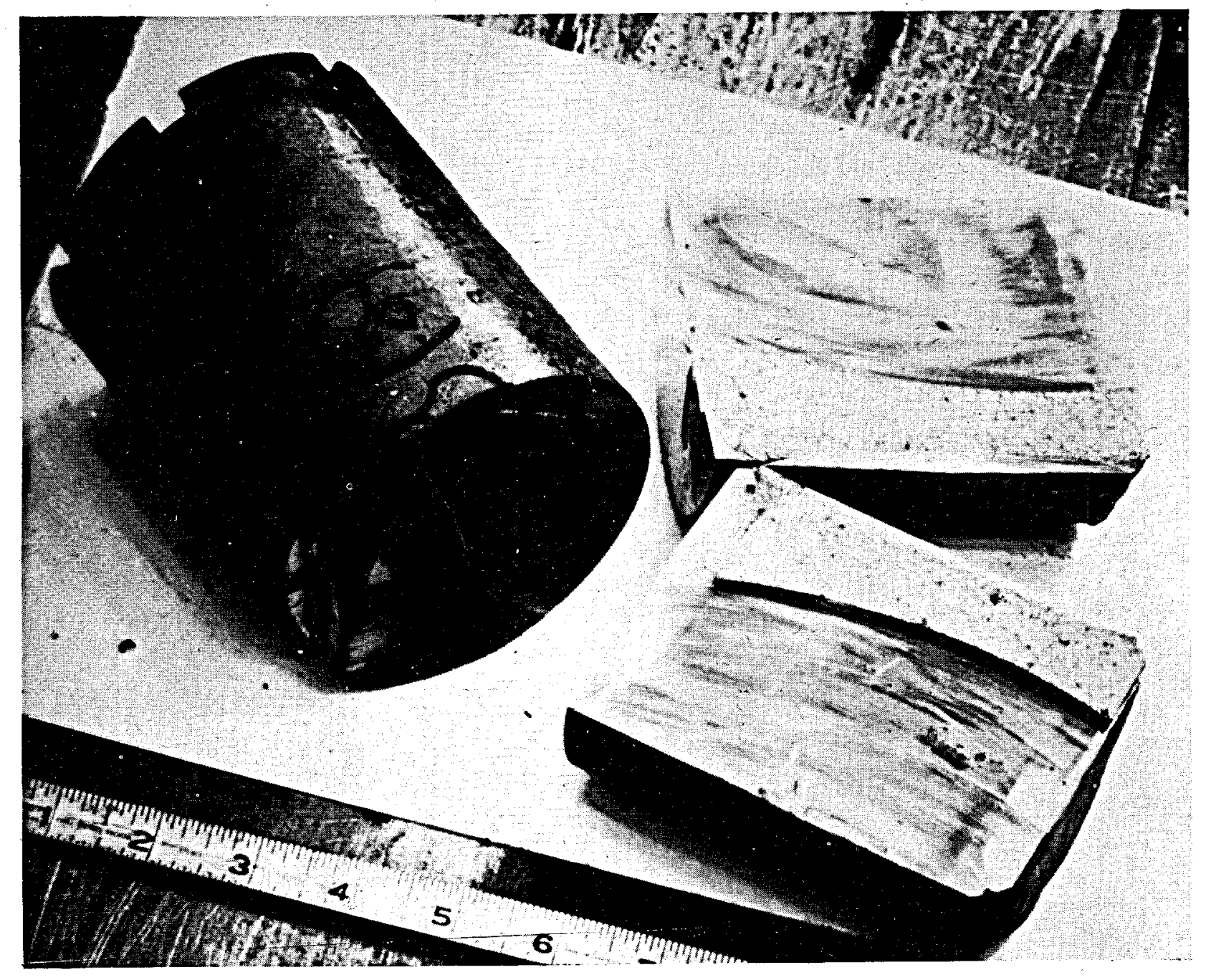

FIG. 92. Sections of cylinder ML-28(2). 


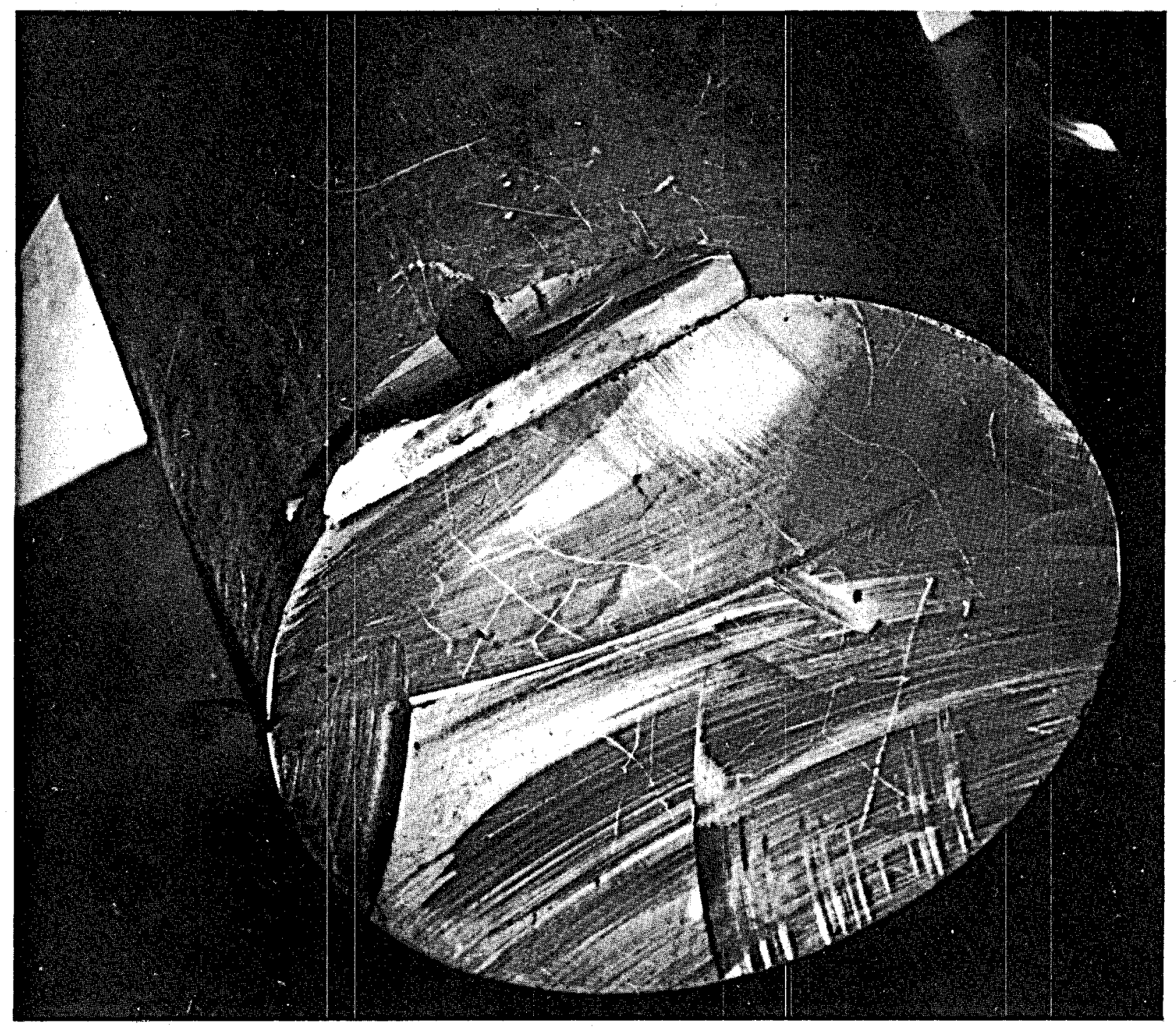

FIG. 93. Cross section of cylinder ML-28(2). 


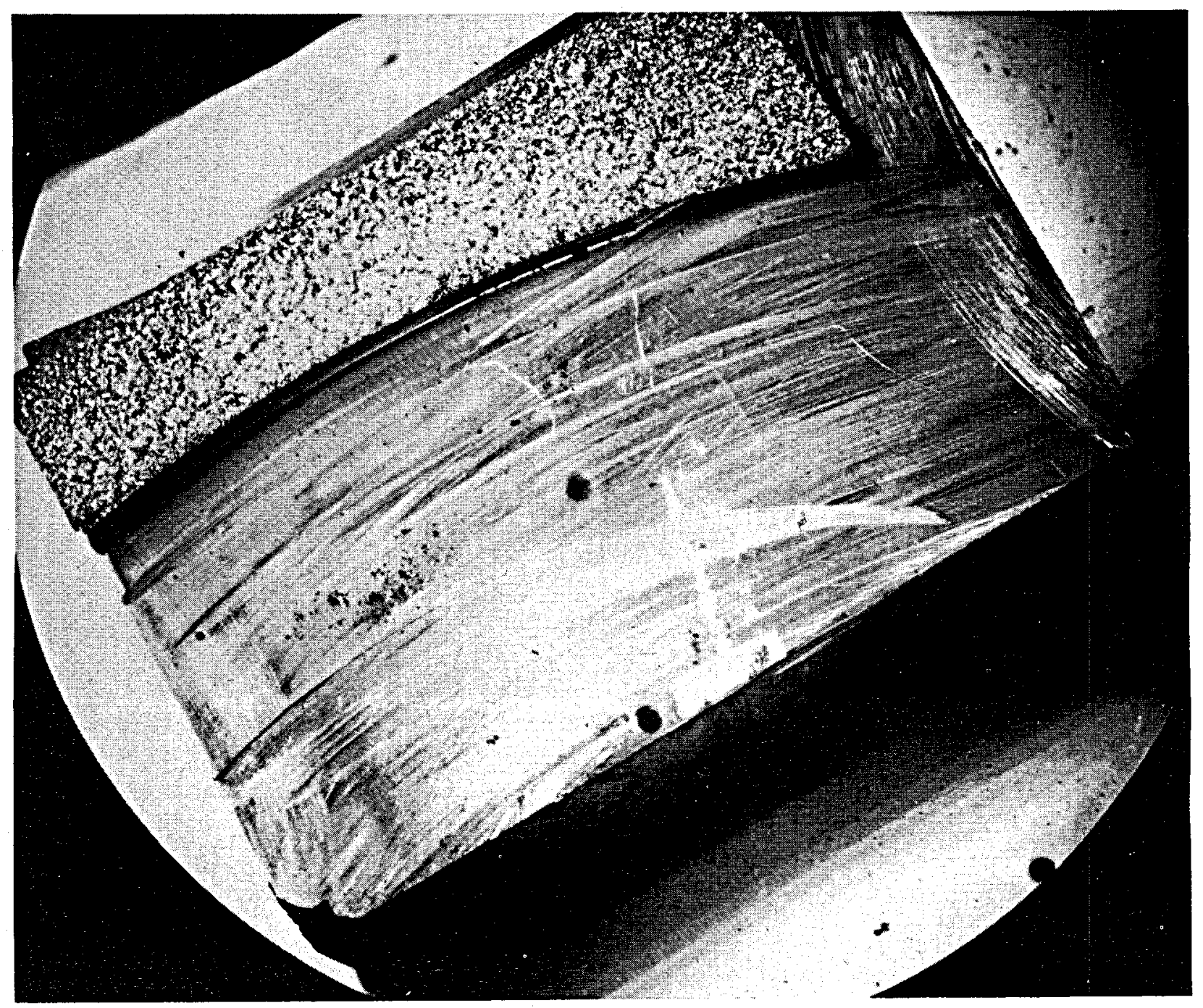

FIG. 94. Close-up of longitudinal saw cut and fracture of cylinder ML-28(2). 


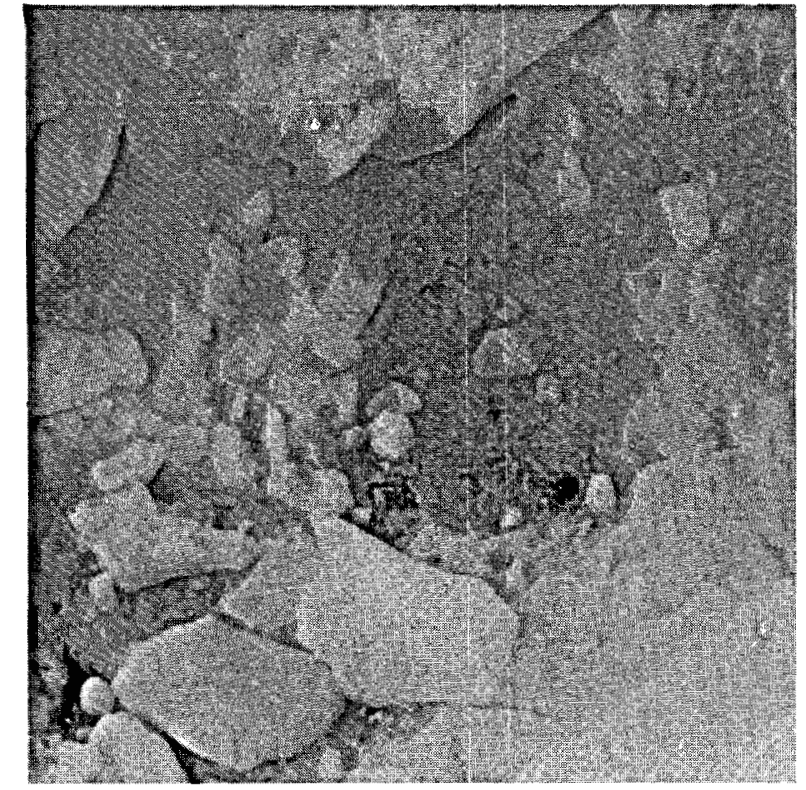

FIG. 95. ML-27(2).

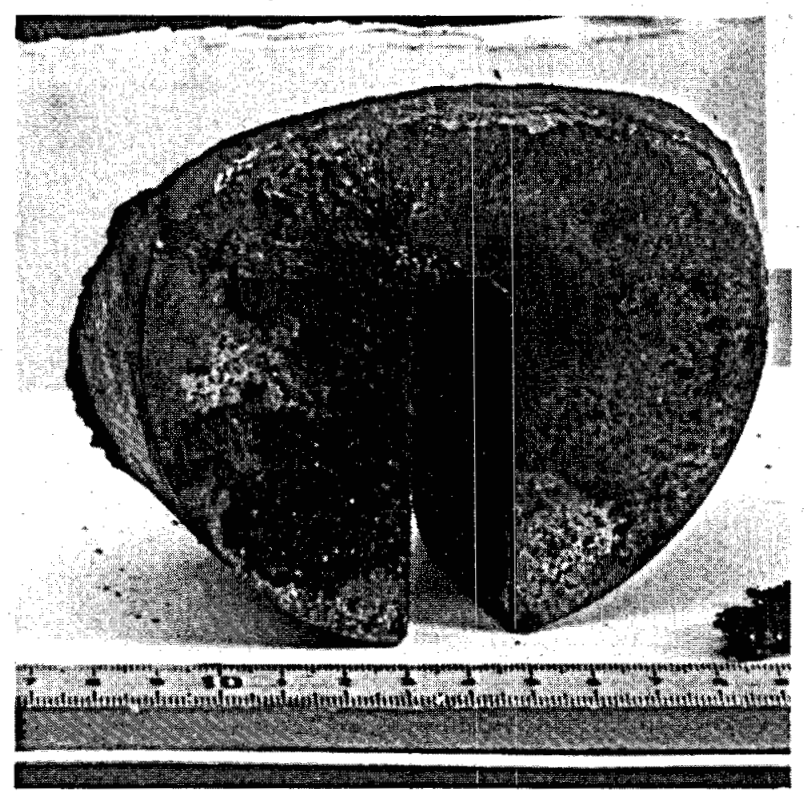

FIG. 96. ML-27(2).

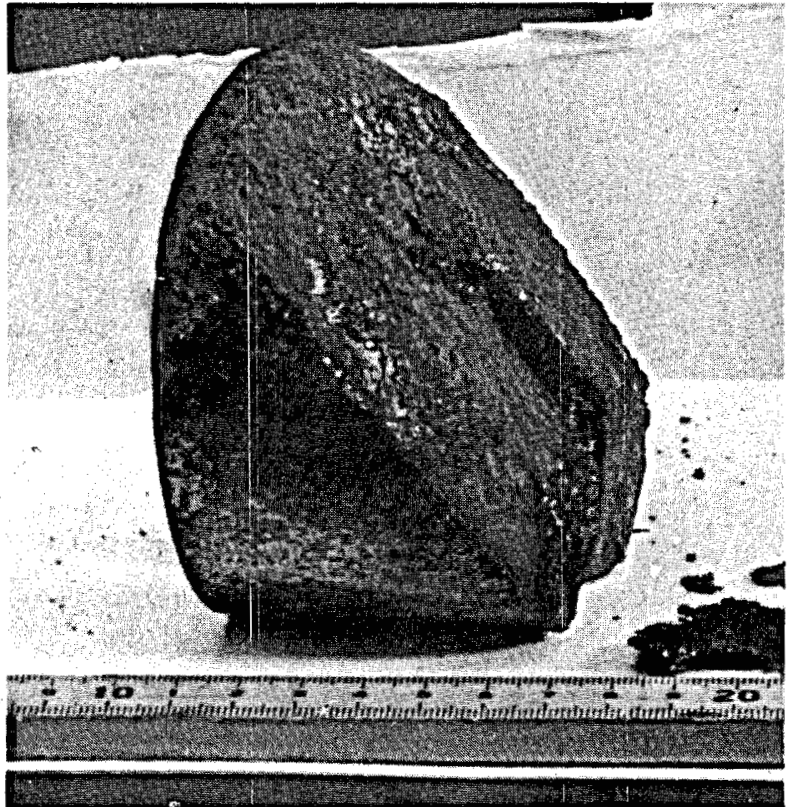

FIG. 97. ML-27(2).

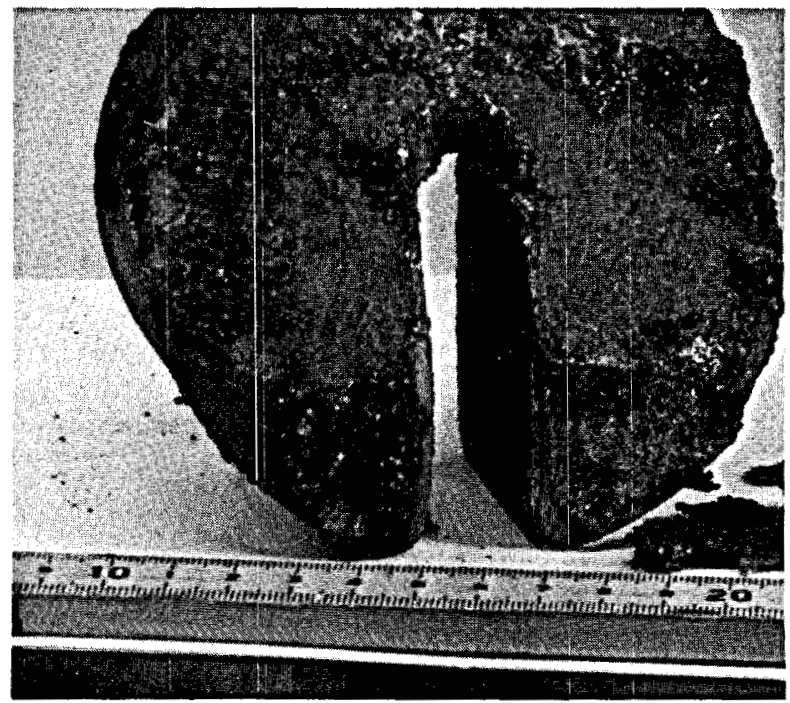

FIG. 98. ML-27(2).

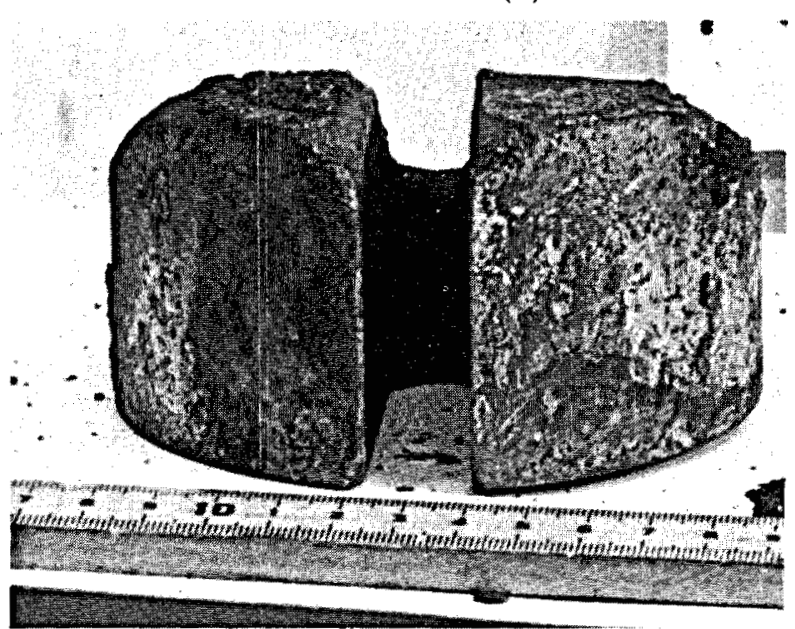

FIG. 99. ML-27(2). 


\title{
Distribution Category
}

UC-25

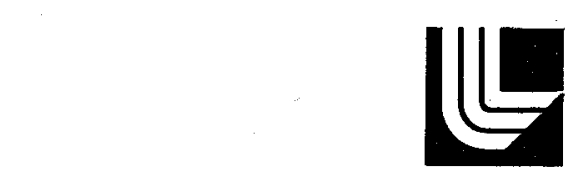

LAWRENCE LIVERMORE LABORATORY

University of Calfornia/Livermore, California/94550

UCRL-52597

\section{ANALYSIS OF BERYLLIUM PARTS FOR COSMOS 954}

\author{
J. E. Hanafee
}

MS. date: October 25, 1978

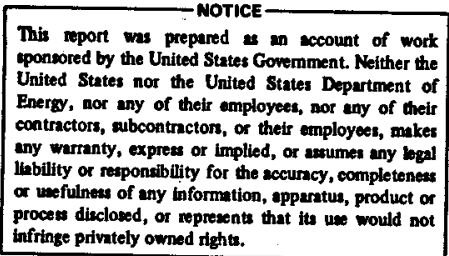

This report was prepared as an cccount of work

uponsored by the United Staces Covernment. Neither the

Energy, nor any of their amployees, not any of their

contractors, ar

or unefulneter 


\title{
APPENDIX A WNRE REPORT ON BERYLLIUM ROD ML-5(1)*
}

\author{
OPERATION MORNING LIGHT
}

\author{
Metallographic Report Sample ML-5(1)1W3
}

Origin:

Transverse cross-section of sample ML-5(1)-1 identified as $\mathrm{Be}$ (with some $\mathrm{BeO}$ ).

Macroscopic Examination:

The cross-sectional shape was tending to tear drop or pear shaping (Figure 1). Approximately onethird of the circumference was circular and relatively smooth; the balance was relatively rough.

Assuming that the cross-section was initially circular, reconstruction indicates that the diameter would have been about $20 \mathrm{~mm}$.

Autoradiography:

A $B Y$ autoradiograph showed extremely little or no activity over the entire sample except for a small portion of the circumference shown by Figure 1A.

Microscopic Examination:

The microstructure present in the majority of the cross-sectional view was of small equiaxed grains of $\alpha$-phase beryllium (Figures 2 and 2A) with particles of BeO evident at the higher magnification. This structure extended from the center out to the circular periphery but was replaced by a columnar structure before reaching the periphery on the non-circular portions. The average grain size in the equiaxed region was $50 \mu \mathrm{m}$.

Close to the non-circular surface the structure consisted of columnar grains of $\alpha$-Be (Figures 3 and 3A). Figure 4 shows where the columnar grain region ended as the surface changed from non-circular to circular. Frequently there was a further layer outside the columnar grain growth (Figure 5). This tended to be intermittent and probably is another layer of $\alpha-B e$ nucleated separately from the columnar grains (probably at the outer surface) and represents material at one time $\beta-B e$ which had transformed to $\alpha-B e$ on cooling.

The outermost layer frequently had an appearance of porosity and the inclusion of material foreign to the basic beryllium structure. This is apparent in Figure 3A and in the unpolarized photographs 6 and 6A.

Interpretation:

The basic microstructure is indicative of the vacuum hot pressed route of manufacture. The modification of this basic structure on the non-circular portions indicates that this part of the surface was the leading surface during re-entry resulting in frictional heating. Due to $\mathrm{BeO}$ particles dispersed in the matrix grain growth is strongly inhibited and only occurs at very high temperatures. The apparent formation of $\beta-\mathrm{Be}$ on the surface indicates that the temperature reached at least $1260^{\circ} \mathrm{C}$ and the intermittent occurrence of this phase indicates probable loss by melting and ablation (melting point $1277^{\circ} \mathrm{C}$ ).

*This is an exact copy of a WNRE report. 


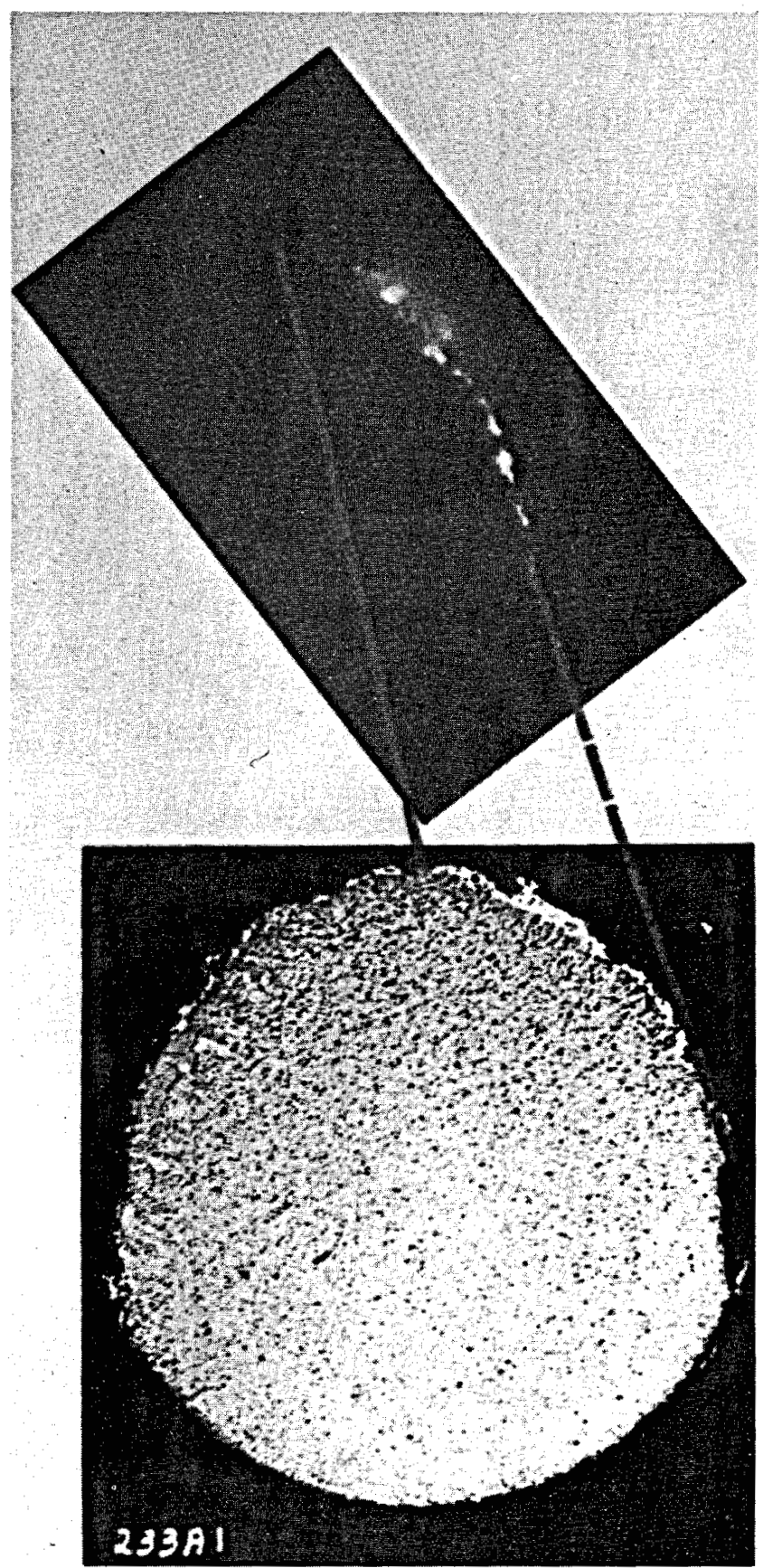

FIG. 1A. Autoradiograph magnification $5 \times$.

FIG. 1. Magnification 5X.

Definite identification of the materials at the surface was impossible since the sample was too radioactive to place in a microprobe. Gamma spectrometry showed the presence of fission products, and mass spectrometry detected ${ }^{235} \mathrm{U}$ on the surface of the unsectioned sample ML-5(1)-1.

Summary:

Sample ML-5(1)-1 was a portion of a $20 \mathrm{~mm}$ diameter Be rod presumably used for reactor control purposes. 


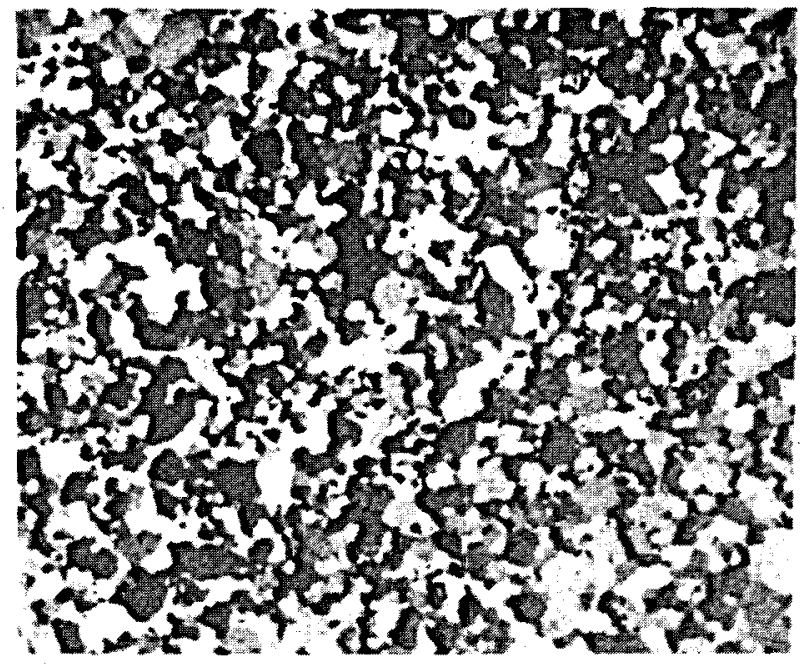

FIG. 2. Magnification 50x. Polarized light.

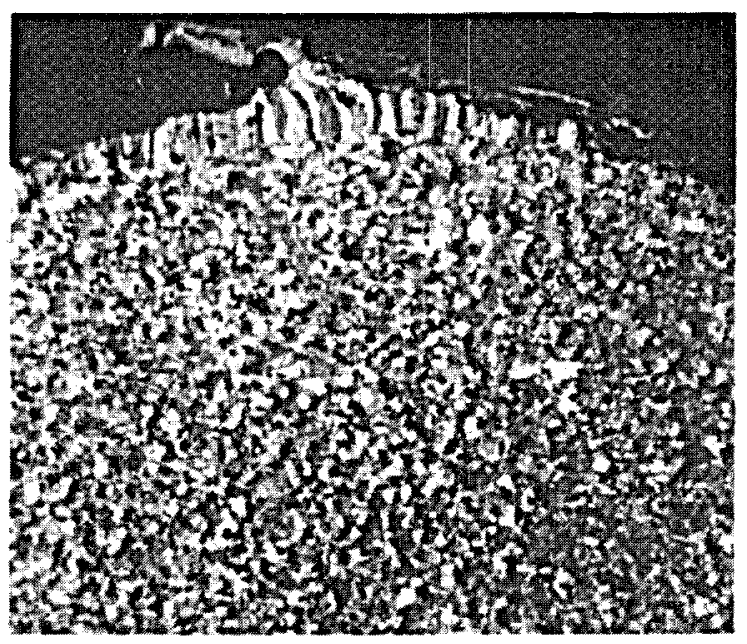

FIG. 3. Magnification 20×. Polarized light.

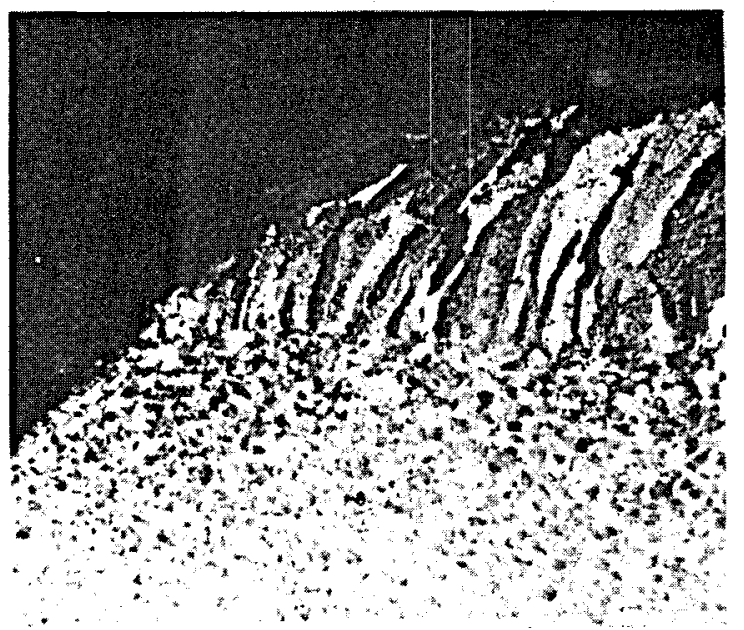

FIG. 4. Magnification 20X. Polarized light.

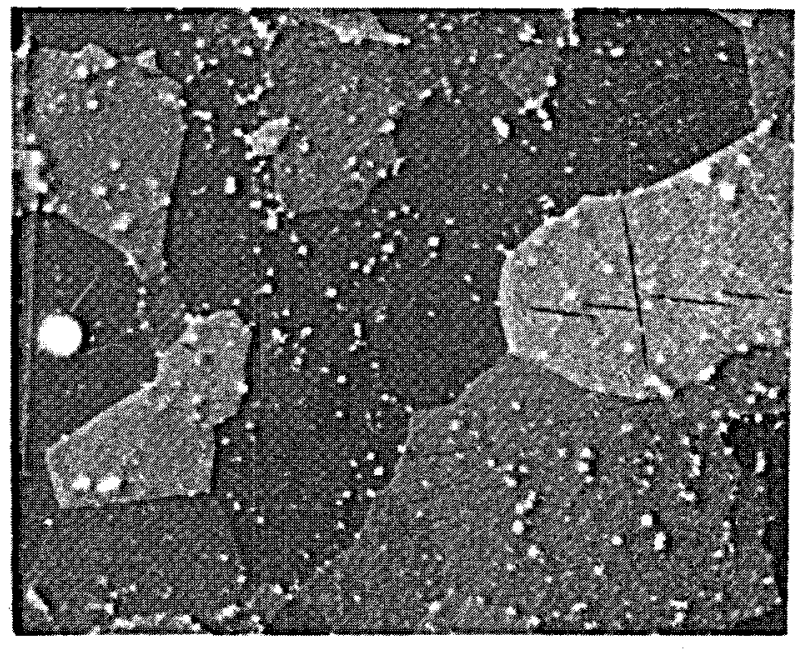

FIG. 2A. Magnification 500x. Polarized light.

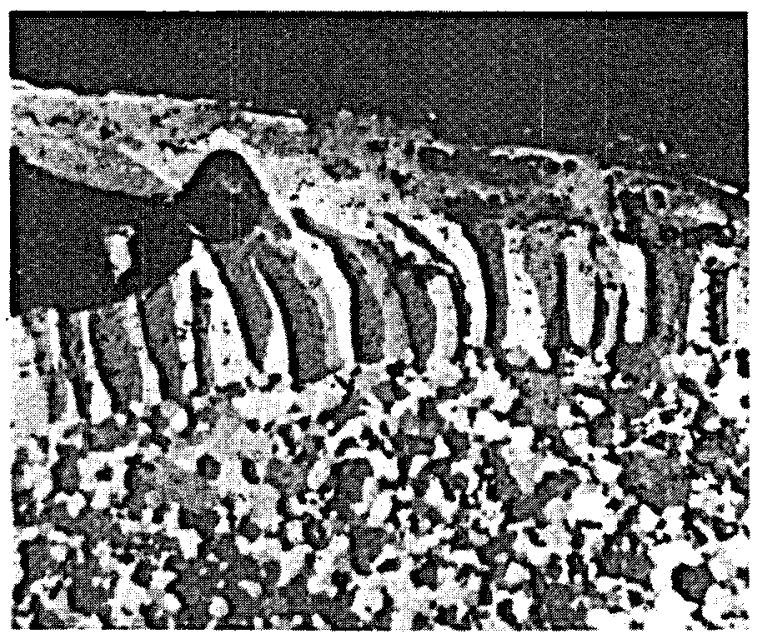

FIG. 3A. Magnification 50X. Polarized light.

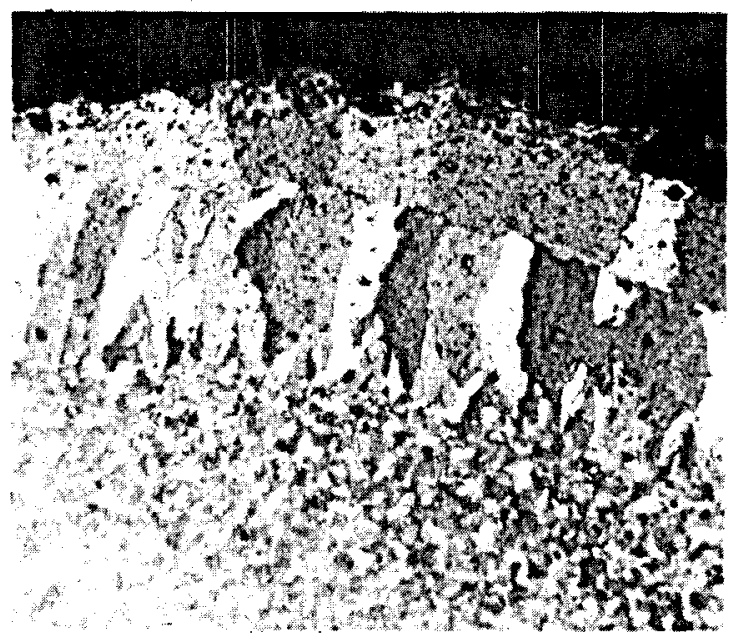

FIG. 5. Magnification 20X. Polarized light. 


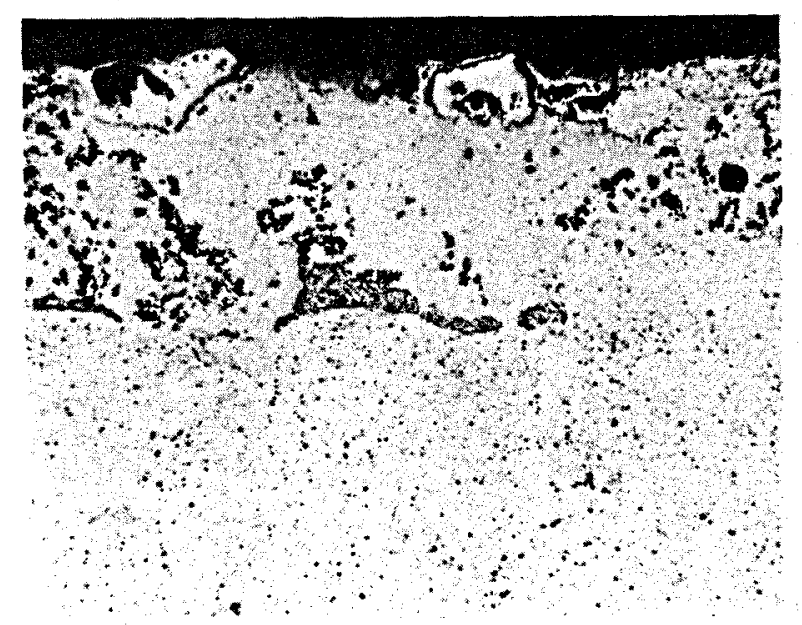

FIG. 6. Magnification 100X. Bright field.

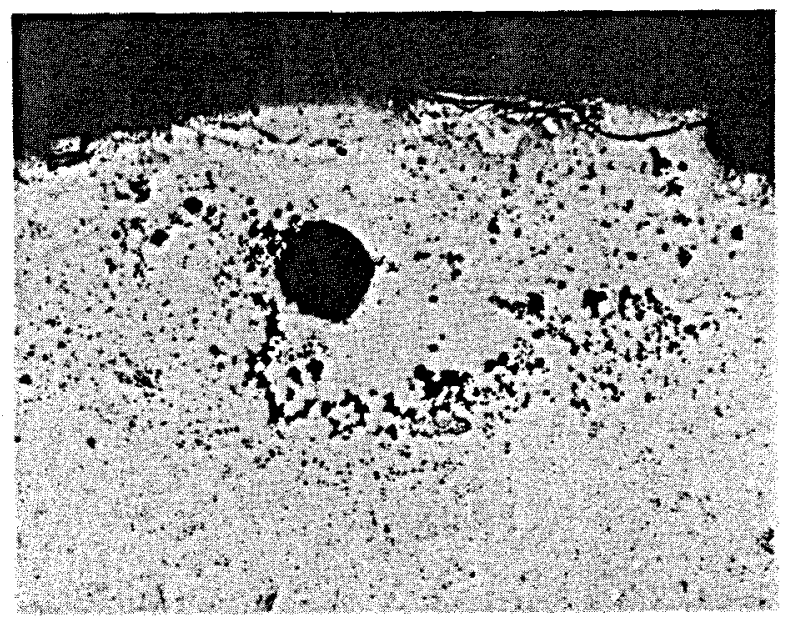

FIG. 6A. Magnification 100X. Bright field.

Since one side of the rod was not heat affected we must assume that it was partially protected during re-entry-there was no sign of protective material or,-in a fixed orientation during re-entry (not tumbling).

The implication of high activity on the leading surface would appear to indicate that the core was ahead of this component in the re-entry train.

M. G. Wright 78-02-20

$\mathrm{k}$

Materials and Component Development Branch

Whiteshell Nuclear Research Establishment 


\section{APPENDIX B \\ WNRE DATA ON NIOBIUM SHEATH* \\ ML-12(1)}

COSMOS SPECIMEN ML-12-(1)-1-W2

SCANNING ELECTRON MICROSCOPY AND X-RAY MICROANALYSIS

ANALYSIS REPORT

Sample Description: Cosmos Specimen ML-12-(1)-1-W2

Corrugated Niobium Sheath with attached scale.

Submitted by: R. B. Stewart

Results: X-ray microanalysis of cross-sectional area shown in Figure 2.

\begin{tabular}{|c|c|c|c|}
\hline X-Ray Energy & $\begin{array}{c}\text { Relative } \\
\text { Intensity } \\
\text { (counts/100 s) } \\
\end{array}$ & Interpretation & \\
\hline $\begin{array}{l}1.62 \mathrm{keV} \\
2.13 \mathrm{keV}\end{array}$ & $\begin{array}{r}122 \\
2678\end{array}$ & $\begin{array}{l}\mathrm{AlK}_{\alpha} \\
\mathrm{NbL}_{\alpha}\end{array}$ & $\begin{array}{l}\text { possible artifact from } \\
\text { stub }\end{array}$ \\
\hline $\begin{array}{l}3.20 \mathrm{keV} \\
5.37 \mathrm{keV}\end{array}$ & $\begin{array}{r}229 \\
65\end{array}$ & $\begin{array}{l}\mathrm{UM}_{\alpha} \\
\mathrm{CrK}_{\alpha}\end{array}$ & \\
\hline $\begin{array}{l}6.35 \mathrm{keV} \\
7.01 \mathrm{keV}\end{array}$ & $\begin{array}{r}752 \\
94\end{array}$ & $\begin{array}{l}\mathrm{FeK}_{\alpha} \\
\mathrm{FeK}_{\beta}\end{array}$ & \\
\hline $\begin{array}{l}9.65 \mathrm{keV} \\
11.45 \mathrm{keV}\end{array}$ & $\begin{array}{r}199 \\
77\end{array}$ & $\begin{array}{l}\operatorname{AuL}_{\alpha} \\
\operatorname{AuL}_{\beta}\end{array}$ & artifact from coating. \\
\hline $\begin{array}{ll}16.51 \mathrm{keV} \\
18.56 \mathrm{keV}\end{array}$ & $\begin{array}{r}129 \\
28\end{array}$ & $\begin{array}{l}\mathrm{NbK}_{\alpha} \\
\mathrm{NbK}_{\beta}\end{array}$ & \\
\hline
\end{tabular}

Remarks: 1. Polished metallographic section was mounted on aluminum stub and coated with a thin layer of gold.

2. Background $\mathrm{x}$-ray intensities (with electron beam off) are negligible.

3. X-ray intensities quoted above are not directly related to elemental concentrations because of matrix effects.

4. Electronbeam accelerating voltage $=20 \mathrm{kV}$.

5. The technique is sensitive only to elements with atomic number $>10$

6. Excitation depth $<1 \mu \mathrm{m}$.

*This is an exact copy of WNRE data. 


\section{ANALYSIS REPORT}

Sample Description: Cosmos Specimen ML-12-(1)-1-W2

Corrugated Niobium Sheath with attached scale.

Submitted by: R. B. Stewart

Results: X-ray microanalysis of cross-sectional area shown in Figure 3

\begin{tabular}{|c|c|c|c|}
\hline X-Ray Energy & $\begin{array}{c}\begin{array}{c}\text { Relative } \\
\text { Intensity } \\
\text { (counts } / 100 \mathrm{~s} \text { ) } \\
\end{array} \\
\end{array}$ & Interpretation & \\
\hline $\begin{array}{l}1.60 \mathrm{keV} \\
2.16 \mathrm{keV}\end{array}$ & $\begin{array}{r}70 \\
3958\end{array}$ & $\begin{array}{l}\mathrm{AlK}_{\alpha} \\
\mathrm{NbL}_{\alpha}\end{array}$ & \\
\hline $\begin{array}{l}3.20 \mathrm{keV} \\
4.20 \mathrm{keV}\end{array}$ & $\begin{array}{r}1079 \\
24\end{array}$ & $\begin{array}{l}\mathrm{UM}_{\alpha} \\
?\end{array}$ & \\
\hline $\begin{array}{l}5.39 \mathrm{keV} \\
5.95 \mathrm{keV}\end{array}$ & $\begin{array}{r}345 \\
26\end{array}$ & $\begin{array}{l}\mathrm{CrK}_{\alpha} \\
\mathrm{CrK}_{\beta}\end{array}$ & \\
\hline $\begin{array}{l}6.38 \mathrm{keV} \\
7.02 \mathrm{keV}\end{array}$ & $\begin{array}{r}3127 \\
387\end{array}$ & $\begin{array}{l}\mathrm{FeK}_{\alpha} \\
\operatorname{FeK}_{\beta}\end{array}$ & \\
\hline $\begin{array}{l}7.47 \mathrm{keV} \\
9.68 \mathrm{keV}\end{array}$ & $\begin{array}{l}191 \\
158\end{array}$ & $\begin{array}{l}\mathrm{NiK}_{\alpha} \\
\operatorname{AuL}_{\alpha}\end{array}$ & due to coating \\
\hline $\begin{array}{l}11.48 \mathrm{keV} \\
13.57 \mathrm{keV}\end{array}$ & $\begin{array}{l}54 \\
24\end{array}$ & $\begin{array}{l}\mathrm{AuL}_{\beta} \\
\mathrm{UL}_{\alpha}\end{array}$ & \\
\hline $\begin{array}{l}16.54 \mathrm{keV} \\
18.59 \mathrm{keV}\end{array}$ & $\begin{array}{r}149 \\
35\end{array}$ & $\begin{array}{l}\mathrm{NbL}_{\alpha} \\
\mathrm{NbL}_{\beta}\end{array}$ & \\
\hline
\end{tabular}

Remarks: Same comments as for $\mathrm{x}$-ray microanalysis of area of Figure 2. 


\section{ANALYSIS REPORT}

Sample Description: ML-12-(1)-1-W5-B

thin-walled, corrugated tubing

Submitted by:- R. B. Stewart

Results: SEM/EDX Analysis (micrographs attached)

Remarks: 1. Major concentrations of $\mathrm{Nb}$ and $\mathrm{Ca}$, with trace amounts of $\mathrm{Fe}$.

2. The $\mathrm{Ca}$ appears as a deposit on the $\mathrm{Nb}$ sheath, but it is not known whether this is the exterior or interior surface.

3. Corrugated nature of tube visible from stereo-pair. 


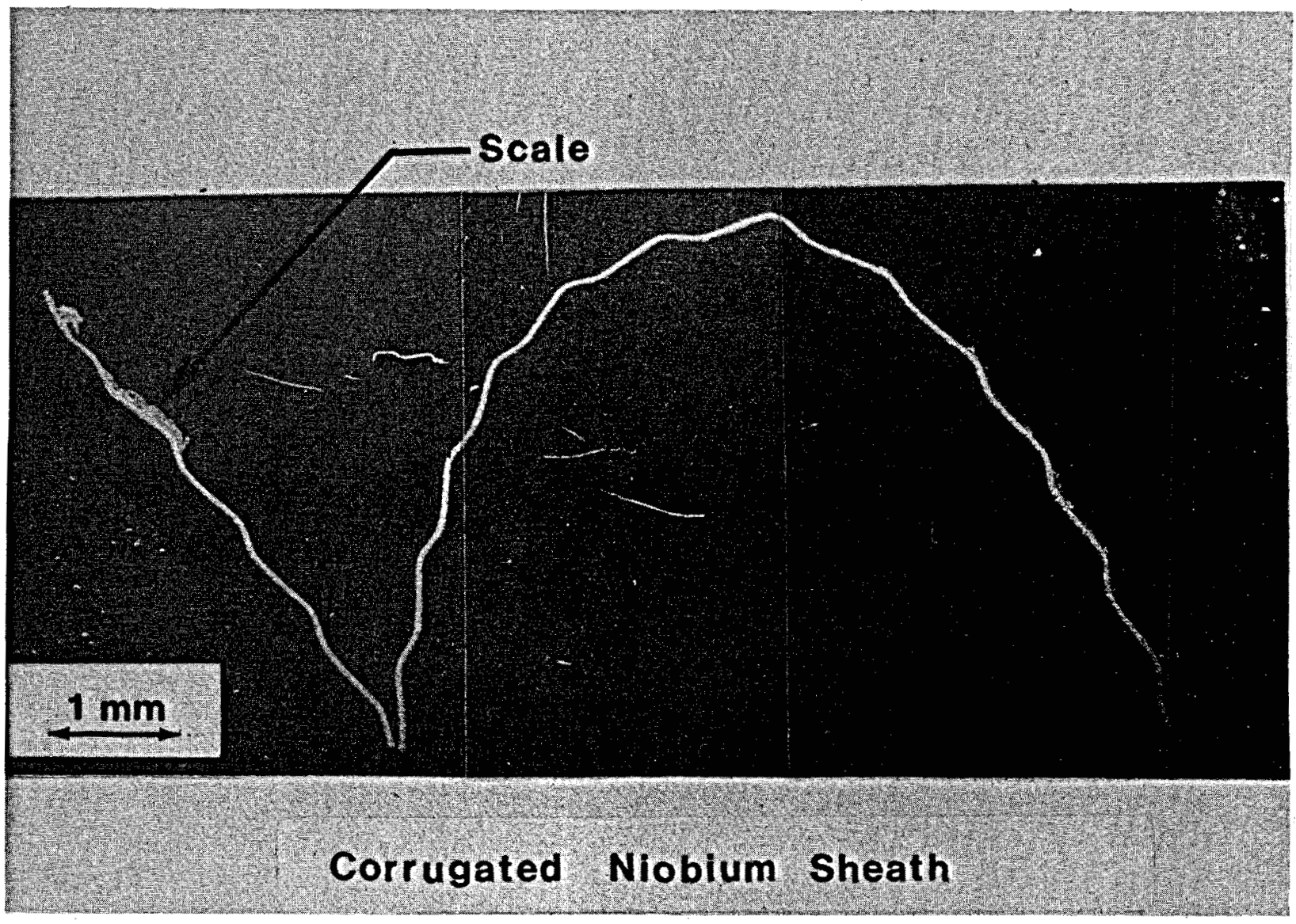

Figure 1: Scanning electron micrograph of a polished section of the corrugated sheath from a beryllium rod. The sheath, originally circular in cross-section, is broken and bent back at the left of the photograph. Prior to viewing, the specimen was embedded in a resin, sectioned, polished, and coated with a thin layer $(\sim 200 \AA)$ of gold to render the surface conductive. Some surface scale material is indicated by the arrow; it is radioactive and believed to be on the external surface. 


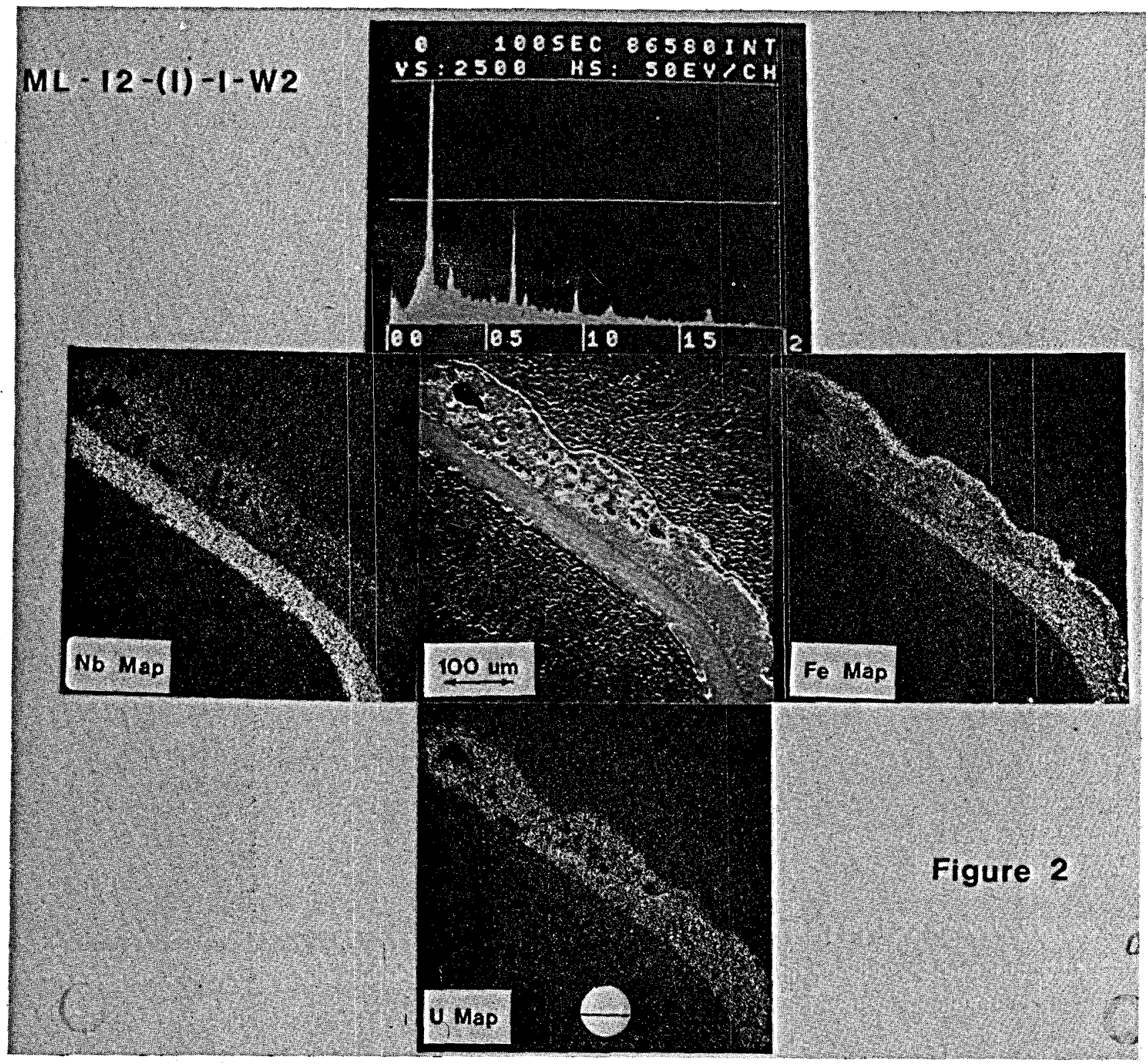

Figure 2: Scanning electron micrograph (and corresponding $\mathrm{x}$-ray spectrum and $\mathrm{x}$-ray distribution maps) showing the section of sheath and scale at somewhat higher magnification. The $x$-ray spectrum (intensity vs energy in $\mathrm{keV}$ ) indicates components of stainless steel ( $\mathrm{Fe}, \mathrm{Cr}, \mathrm{Ni}$ ), fuel (U), and sheath (Nb); see attached report for spectral details. The $x$-ray maps show the elemental distributions of $\mathrm{Fe}, \mathrm{U}$, and $\mathrm{Nb}$ and indicate that $\mathrm{Fe}$ and $\mathrm{U}$ are concentrated preferentially in the scale and $\mathrm{Nb}$ in the sheath. (The density of white dots in the X-ray maps is proportional to the concentration of the given element.) The micrograph shows that part of the scale is quite porous. Also, laminar cracks are seen at the inner boundary of sheath, resulting in spalling of material from this surface. 


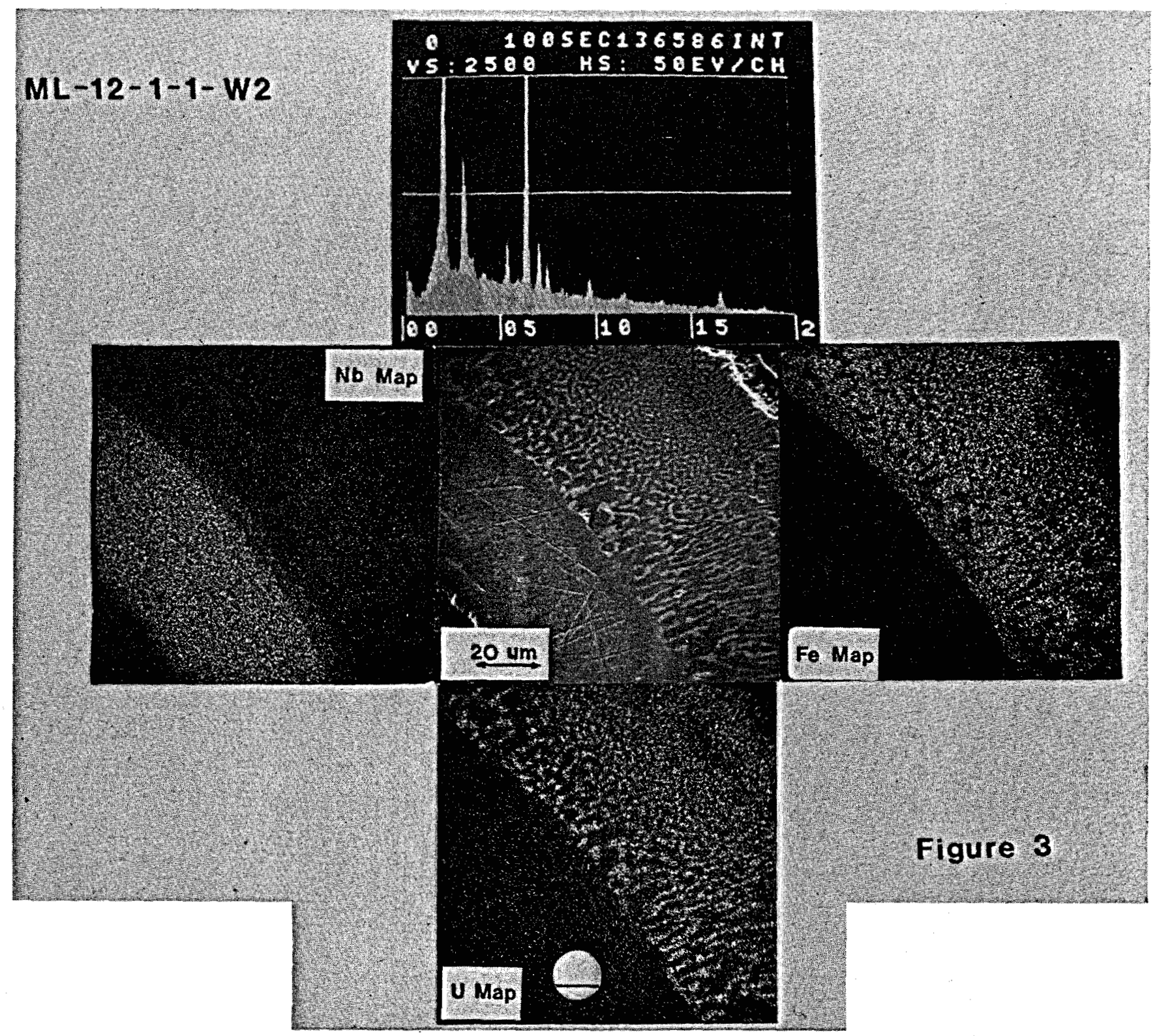

Figure 3: Scanning electron micrograph and $x$-ray maps at high magnification showing the niobium sheath, approximately $40 \mu \mathrm{m}$ thick, and the dendritic grain structure of the scale. See the attached report for a tabulation of $x$-ray intensities and energies derived from the spectrum at the top of the figure. $\mathrm{X}$-ray microanalysis indicates that the scale is composed of elements associated with stainless steel $(\mathrm{Fe}, \mathrm{Cr}, \mathrm{Ni})$ and nuclear fuel (U). Atomic number contrast in the electron optical image reveals microheterogeneities in the Fe- and $\mathrm{U}$-rich scale. Light areas indicate higher atomic number and correspond to U-rich microdomains. Darker areas indicate lower atomic number and correspond to Fe-rich regions. The dendritic texture suggests growth from the melt. Also note that there is an $\mathrm{Fe}$-rich boundary layer between the $\mathrm{Nb}$ sheath and the stainless steel-uranium alloy of the scale. 


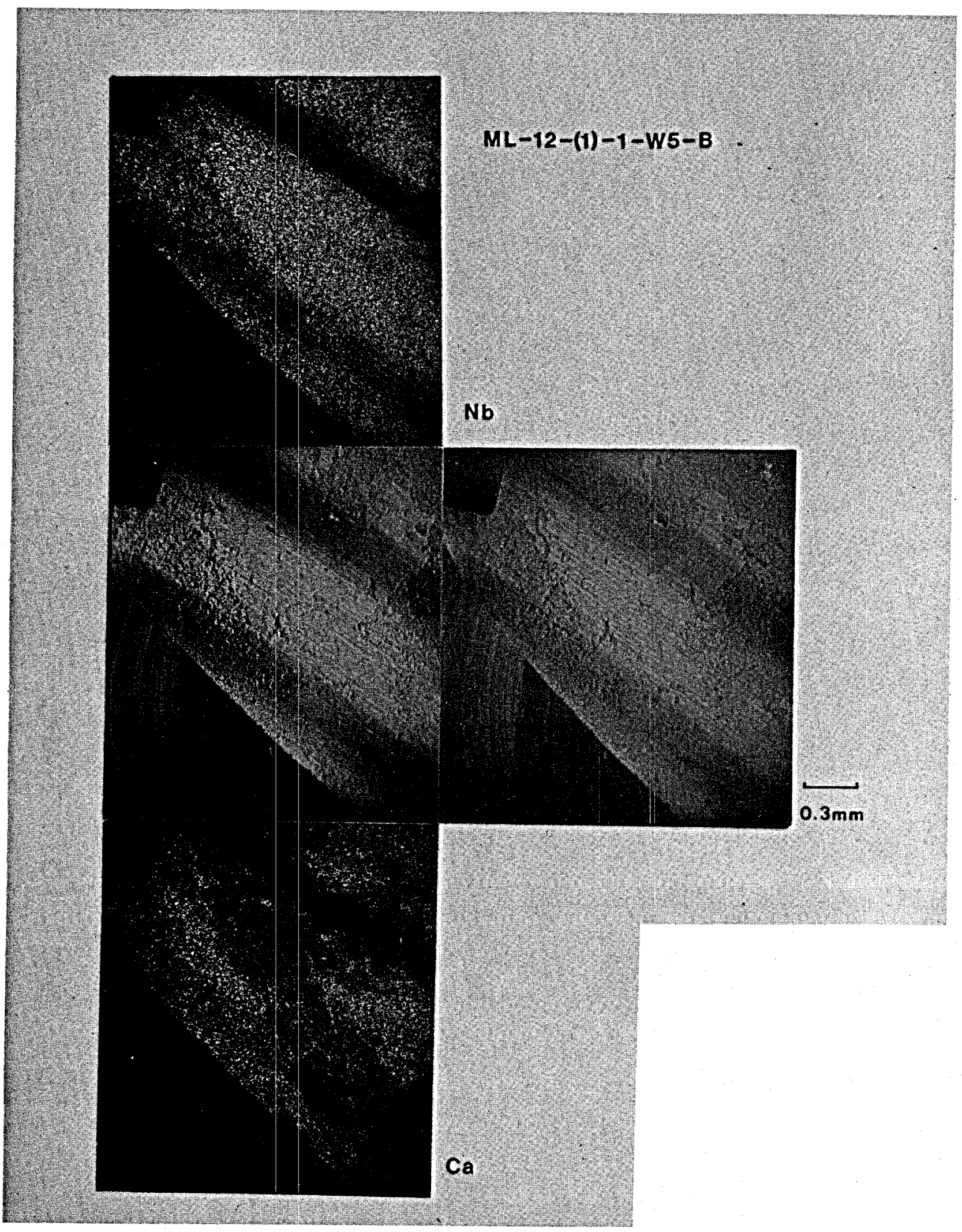




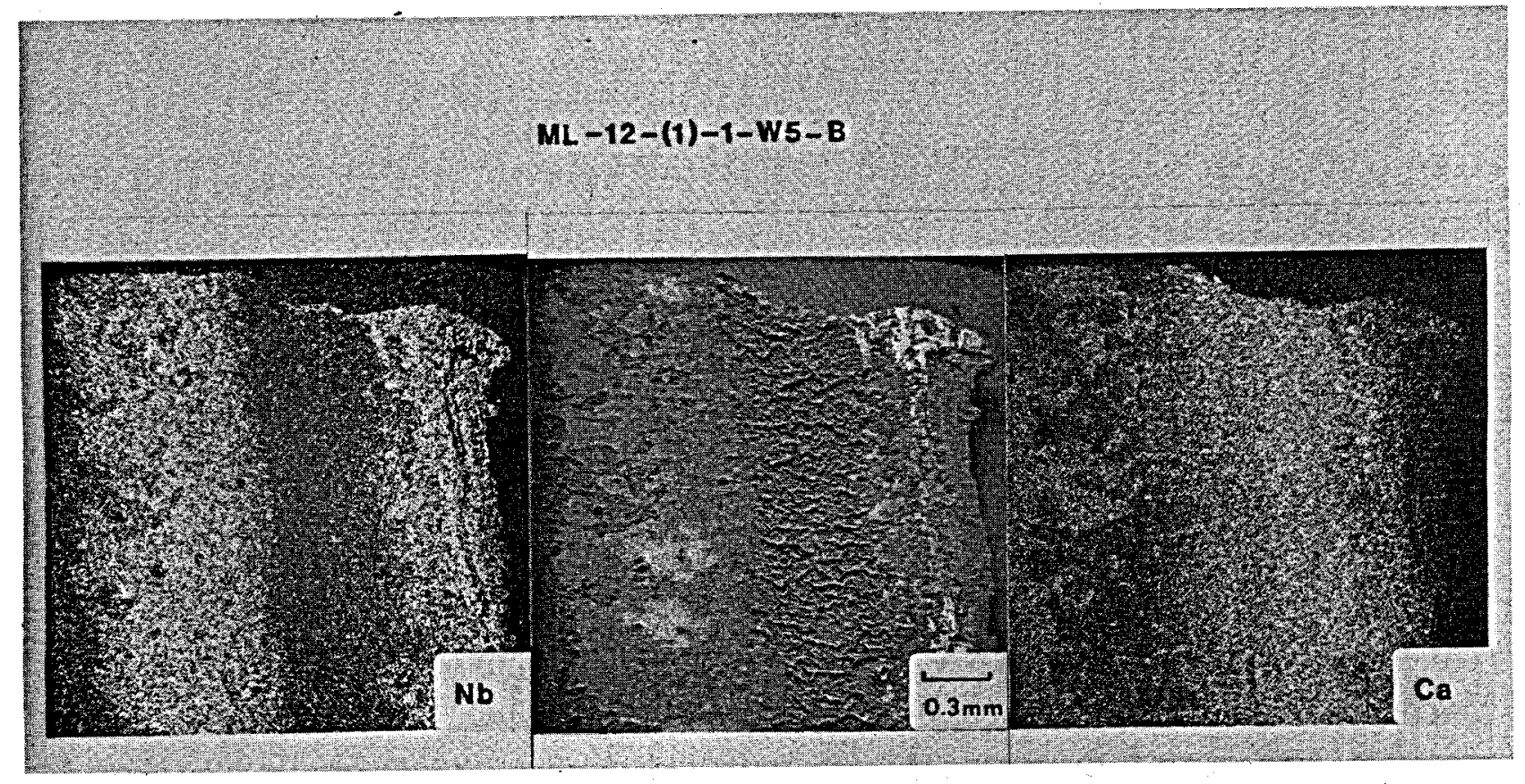

